\title{
Substituent effects on transient, carbodiimide-induced geometry changes in diphenic acids
}

\section{Supporting Information}

Isuru M. Jayalath, Madelyn M. Gerken, Georgia Mantel, and C. Scott Hartley*

Department of Chemistry \& Biochemistry, Miami University, Oxford, OH 45056, United States

scott.hartley@miamioh.edu

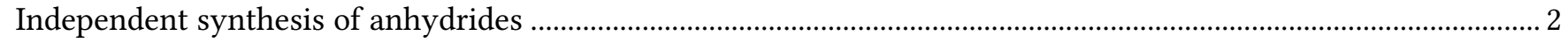

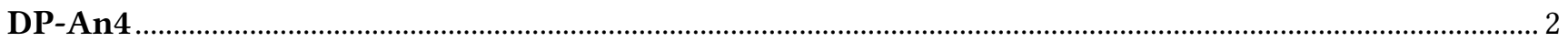

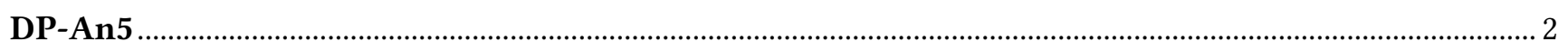

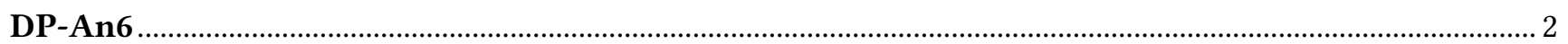

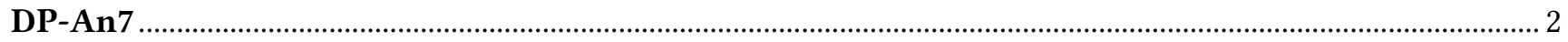

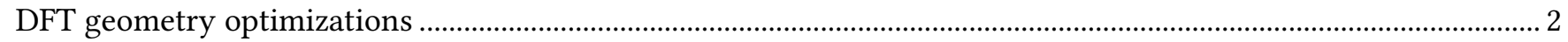

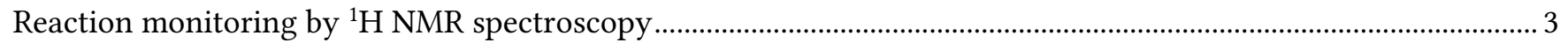

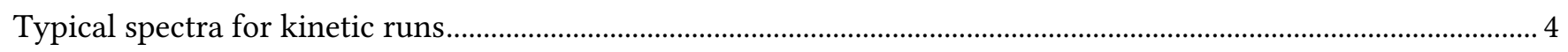

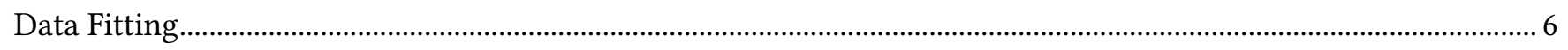

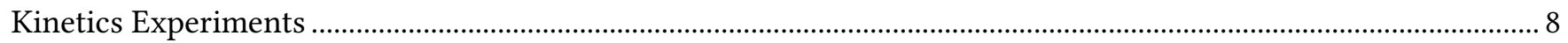

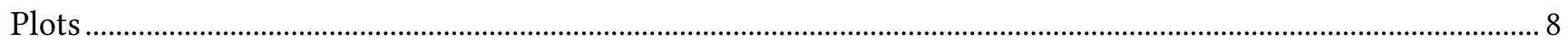

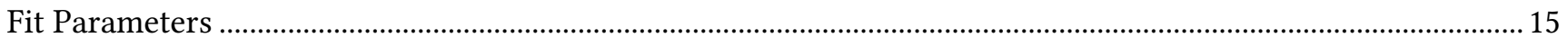

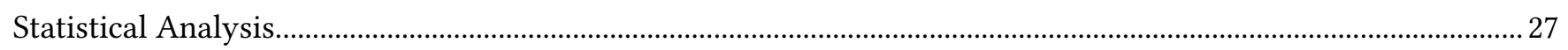

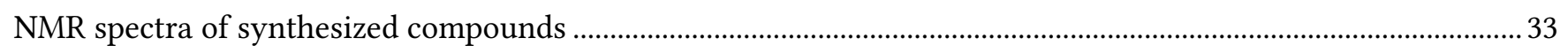

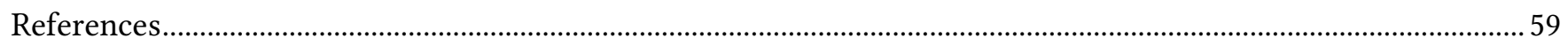




\section{Independent synthesis of anhydrides}

\section{DP-An4}

DP-Ac4 (200 mg, $0.236 \mathrm{mmol})$ was dissolved in dry DCM $(2 \mathrm{~mL})$. The solution was treated with $N, N$ diisopropylcarbodiimide $(74 \mu \mathrm{L}, 0.472 \mathrm{mmol})$ and stirred at room temperature for $2 \mathrm{~h}$. The resulting mixture was filtered and concentrated at reduced pressure. The crude was purified by preparative GPC (toluene as eluent, 5 $\mathrm{mL} / \mathrm{min}$ ) to afford DP-An4 (98 mg) as a yellow oil as the major component of a mixture of compounds: ${ }^{1} \mathrm{H}$ NMR $\left(500 \mathrm{MHz}, \mathrm{CDCl}_{3}\right.$ ) (Figure S78) and ${ }^{13} \mathrm{C}\left\{{ }^{1} \mathrm{H}\right\} \mathrm{NMR}$ spectroscopy (126 $\mathrm{MHz}, \mathrm{CDCl}_{3}$ ) (Figure S79) support the formation of the title compound. HRMS (APCI-MS) calcd for $\mathrm{C}_{41} \mathrm{H}_{62} \mathrm{O}_{17} \mathrm{Na}\left([\mathrm{M}+\mathrm{Na}]^{+}\right) 849.3879$, found 849.3871.

\section{DP-An5}

DP-Ac5 (50 mg, $0.058 \mathrm{mmol})$ was dissolved in dry DCM $(2 \mathrm{~mL})$. The solution was treated with dicyclohexylcarbodiimide $(18 \mathrm{mg}, 0.087 \mathrm{mmol})$ and stirred at room temperature for $8 \mathrm{~h}$. The resulting solution was filtered and concentrated at reduced pressure. The crude was purified by preparative GPC (toluene as eluent, $5 \mathrm{~mL} / \mathrm{min})$ to afford DP-An5 $(24 \mathrm{mg})$ as a yellow oil as the major component of a mixture of compounds: ${ }^{1} \mathrm{H}$ NMR $\left(500 \mathrm{MHz}, \mathrm{CDCl}_{3}\right.$ ) (Figure S80) and ${ }^{13} \mathrm{C}\left\{{ }^{1} \mathrm{H}\right\} \mathrm{NMR}$ spectroscopy (126 $\mathrm{MHz}, \mathrm{CDCl}_{3}$ ) (Figure S81) support the formation of the title compound. HRMS (APCI-MS) calcd for $\mathrm{C}_{41} \mathrm{H}_{62} \mathrm{O}_{18} \mathrm{Na}\left([\mathrm{M}+\mathrm{Na}]^{+}\right)$865.3828, found 865.3830.

\section{DP-An6}

The procedure for DP-An5 was followed using DP-Ac6 (86 mg, $0.095 \mathrm{mmol}$ ) to afford DP-An6 (32 mg) as a colorless oil as the major component of a mixture of compounds: ${ }^{1} \mathrm{H}$ NMR $\left(500 \mathrm{MHz}, \mathrm{CDCl}_{3}\right)$ (Figure S82) and ${ }^{13} \mathrm{C}\left\{{ }^{1} \mathrm{H}\right\} \mathrm{NMR}$ spectroscopy $\left(126 \mathrm{MHz}, \mathrm{CDCl}_{3}\right.$ ) (Figure S83) support the formation of the title compound. HRMS (APCI-MS) calcd for $\mathrm{C}_{46} \mathrm{H}_{64} \mathrm{O}_{17} \mathrm{Na}\left([\mathrm{M}+\mathrm{Na}]^{+}\right)$911.4036, found 911.4038.

\section{DP-An7}

The procedure for DP-An5 was followed using DP-Ac7 (70 mg, $0.08 \mathrm{mmol}$ ) to afford DP-An7 (31 mg) as a colorless oil as the major component of a mixture of compounds: ${ }^{1} \mathrm{H}$ NMR $\left(500 \mathrm{MHz}, \mathrm{CDCl}_{3}\right.$ ) (Figure S84) and ${ }^{13} \mathrm{C}\left\{{ }^{1} \mathrm{H}\right\} \mathrm{NMR}$ spectroscopy $\left(126 \mathrm{MHz}, \mathrm{CDCl}_{3}\right.$ ) (Figure S85) support the formation of the title compound. HRMS (APCI-MS) calcd for $\mathrm{C}_{41} \mathrm{H}_{59} \mathrm{NO}_{17} \mathrm{Na}\left([\mathrm{M}+\mathrm{Na}]^{+}\right)$860.3675, found 860.3676 .

\section{DFT geometry optimizations}

For simplicity, the hexaglyme groups replaced with $\mathrm{H}$ for the geometry optimizations. Terms such as DP-Ac4', DP-An4' refer to these simplified structures.

All optimized geometries were confirmed to be minima by vibrational frequency analysis. Energies and Cartesian coordinates are provided in a separate plain text file. The carboxylic acid groups were oriented according to the analysis previously reported. ${ }^{1}$
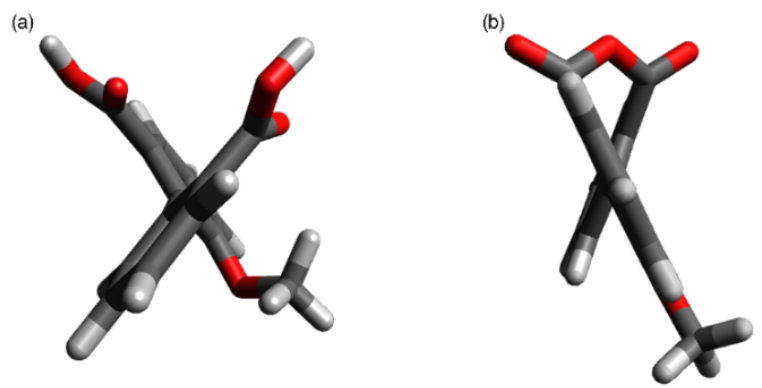

Figure S1. Optimized geometries of (a) DP-Ac5' and (b) DP-An5' at the B97-D3(BJ)/TZV(2d,2p) level and viewed down the biaryl axis. 
(a)

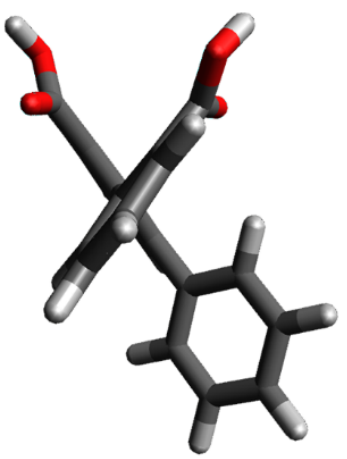

(b)

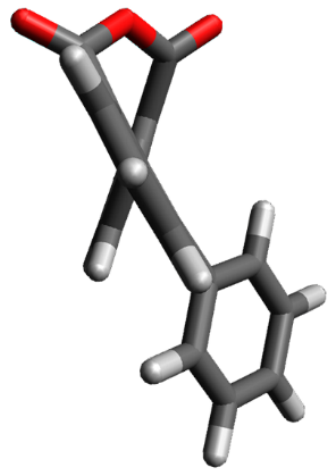

Figure S2. Optimized geometries of (a) DP-Ac6' and (b) DP-An6' at the B97-D3(BJ)/TZV(2d,2p) level and viewed down the biaryl axis.

(a)

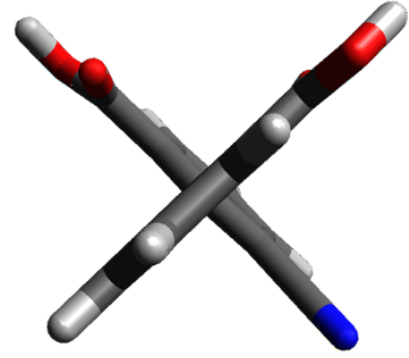

(b)

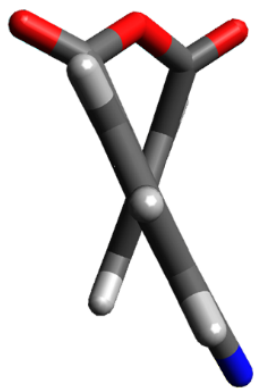

Figure S3. Optimized geometries of (a) DP-Ac7' and (b) DP-An7' at the B97-D3(BJ)/TZV(2d,2p) level and viewed down the biaryl axis.

\section{Reaction monitoring by ${ }^{1 H}$ NMR spectroscopy}

The reactions were monitored by ${ }^{1} \mathrm{H}$ NMR spectroscopy $(500 \mathrm{MHz})$. All concentrations were determined relative to the methylene peak of ethylene carbonate, which was included as an internal standard (this peak was also used to calibrate the chemical shift scale). Stock solutions $\left(5.00 \mathrm{~mL}\right.$ in $1: 1$ mixture of $\mathrm{D}_{2} \mathrm{O}$ : acetone- $\left.d_{6}\right)$ were prepared of the appropriate carboxylic acid $(15 \mathrm{mM})$ and ethylene carbonate $(15 \mathrm{mM})$. The $\mathrm{pD}$ of the $\mathrm{D}_{2} \mathrm{O}$ was adjusted to $\mathrm{pD}=2$ before adding acetone- $d_{6}$. A small amount $(2 \mathrm{mM})$ of pyridine- $d_{5}$ was added to the aqueous solution before adjusting the $\mathrm{pD}$. A separate solution of EDC in $\mathrm{D}_{2} \mathrm{O}$ : acetone- $d_{6}(1: 1)$ was also prepared at such a concentration that $200 \mu \mathrm{L}$ would deliver the target concentrations. For all NMR experiments, all solutions were cooled in an ice bath until immediately before beginning a run. The NMR spectrometer was locked and shimmed on a $600 \mu \mathrm{L}$ sample of the stock solution (10 mM, after being equilibrated at the appropriate temperature). For each run, a standard NMR tube was charged with $400 \mu \mathrm{L}$ of the acid-containing solution, then treated with $200 \mu \mathrm{L}$ of the EDC solution. The reaction mixture was quickly mixed, inserted into the spectrometer, and acquisition started. The time of first mixing was taken as $t=0$. Each time point constitutes a single scan, with the time taken as the midpoint of acquisition. 


\section{Typical spectra for kinetic runs}

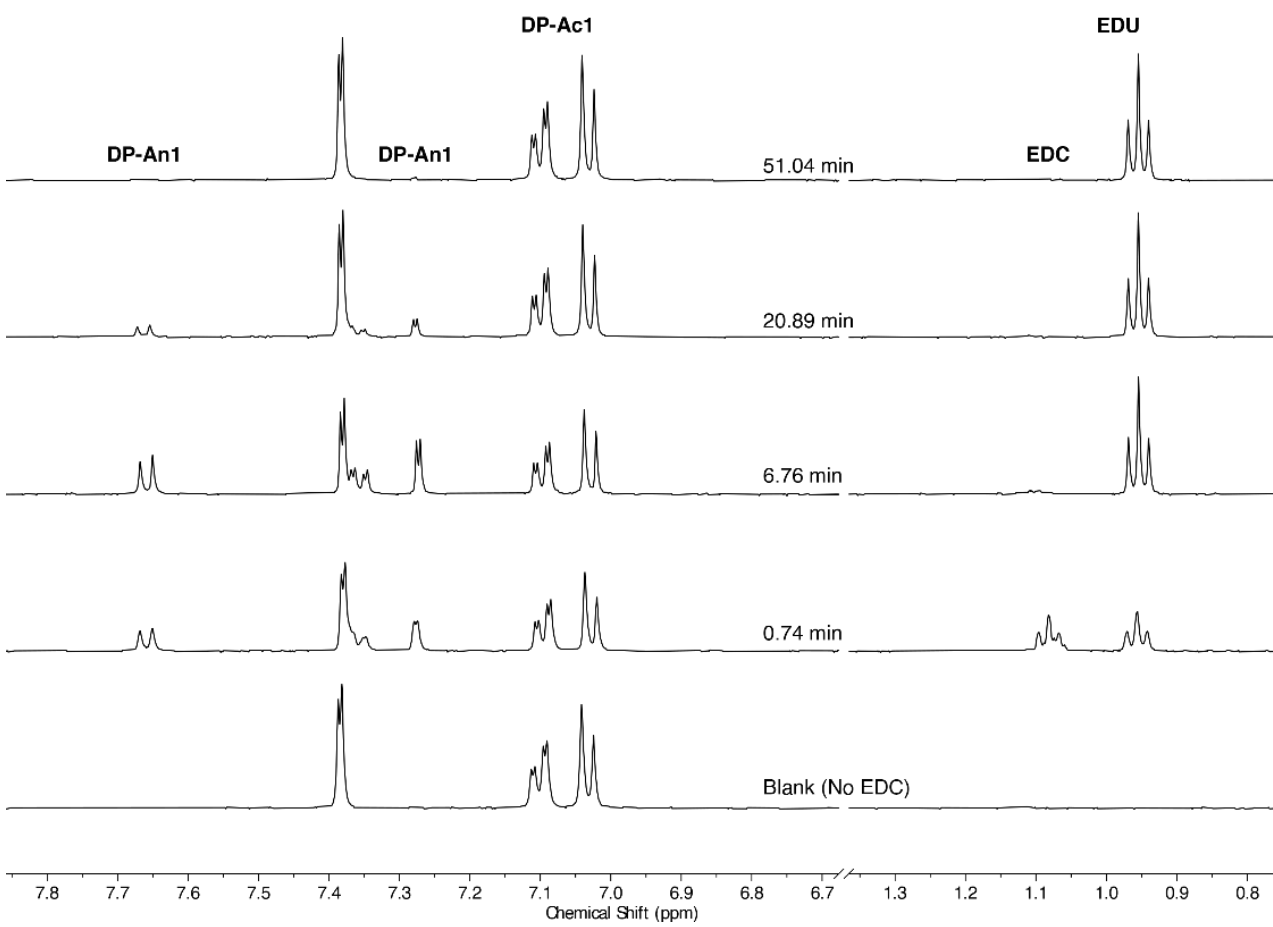

Figure S4. ${ }^{1} \mathrm{H}$ NMR spectra of DP-An1 formation from DP-Ac1 $(10 \mathrm{mM})$ treated with 1 eq. of EDC in $\mathrm{D}_{2} \mathrm{O}$ :acetone- $d_{6}$ in the presence of pyridine- $d_{5}(2 \mathrm{mM})$ at $276 \mathrm{~K}\left(\mathrm{pD}\right.$ of $\mathrm{D}_{2} \mathrm{O}$ adjusted to $\left.\mathrm{pD}=2\right)$.

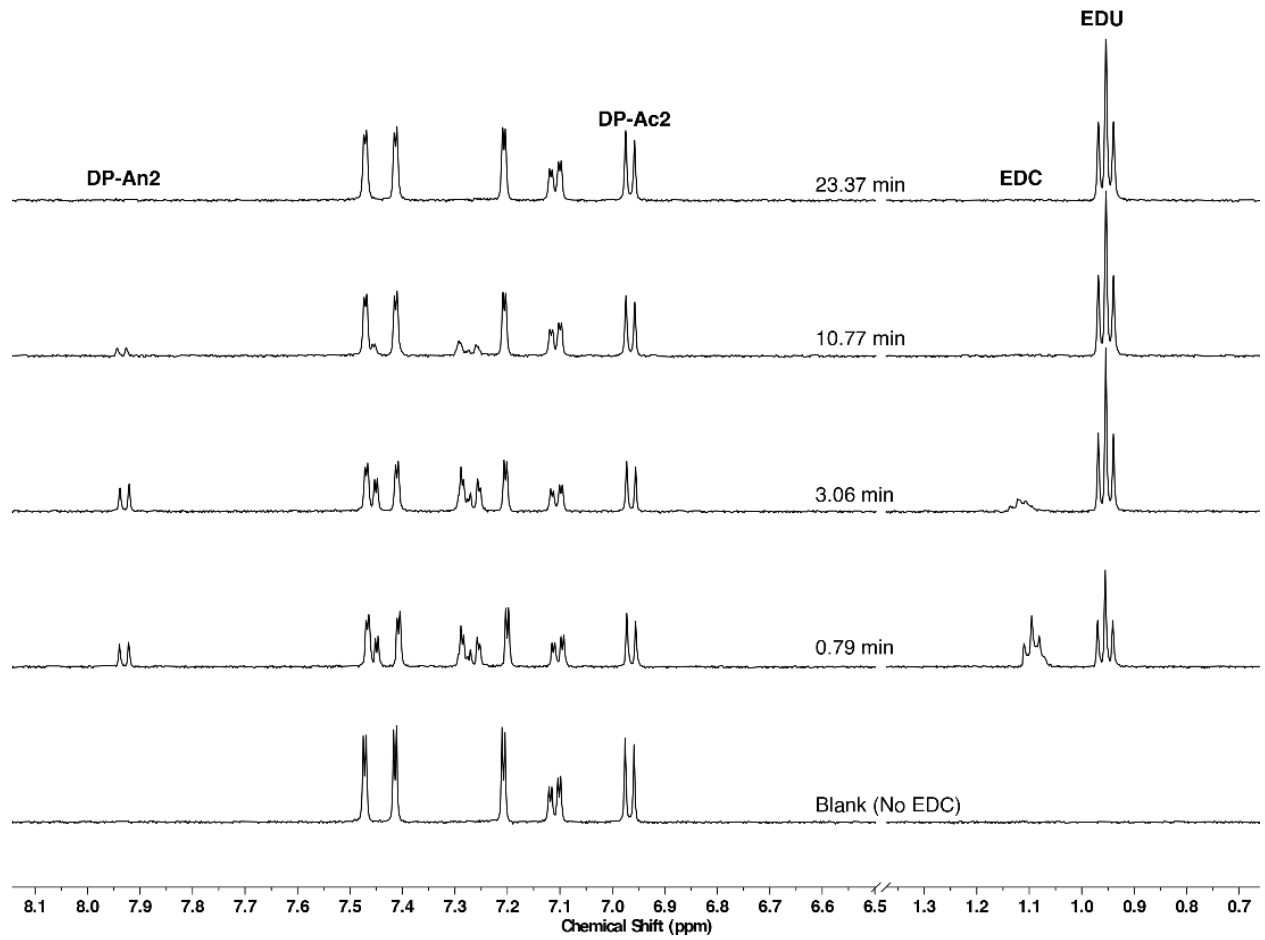

Figure S5. ${ }^{1} \mathrm{H}$ NMR spectra of DP-An2 formation from DP-Ac2 $(10 \mathrm{mM})$ treated with 1 eq. of EDC in $\mathrm{D}_{2} \mathrm{O}$ :acetone- $d_{6}$ in the presence of pyridine- $d_{5}(2 \mathrm{mM})$ at $276 \mathrm{~K}\left(\mathrm{pD}\right.$ of $\mathrm{D}_{2} \mathrm{O}$ adjusted to $\left.\mathrm{pD}=2\right)$. 

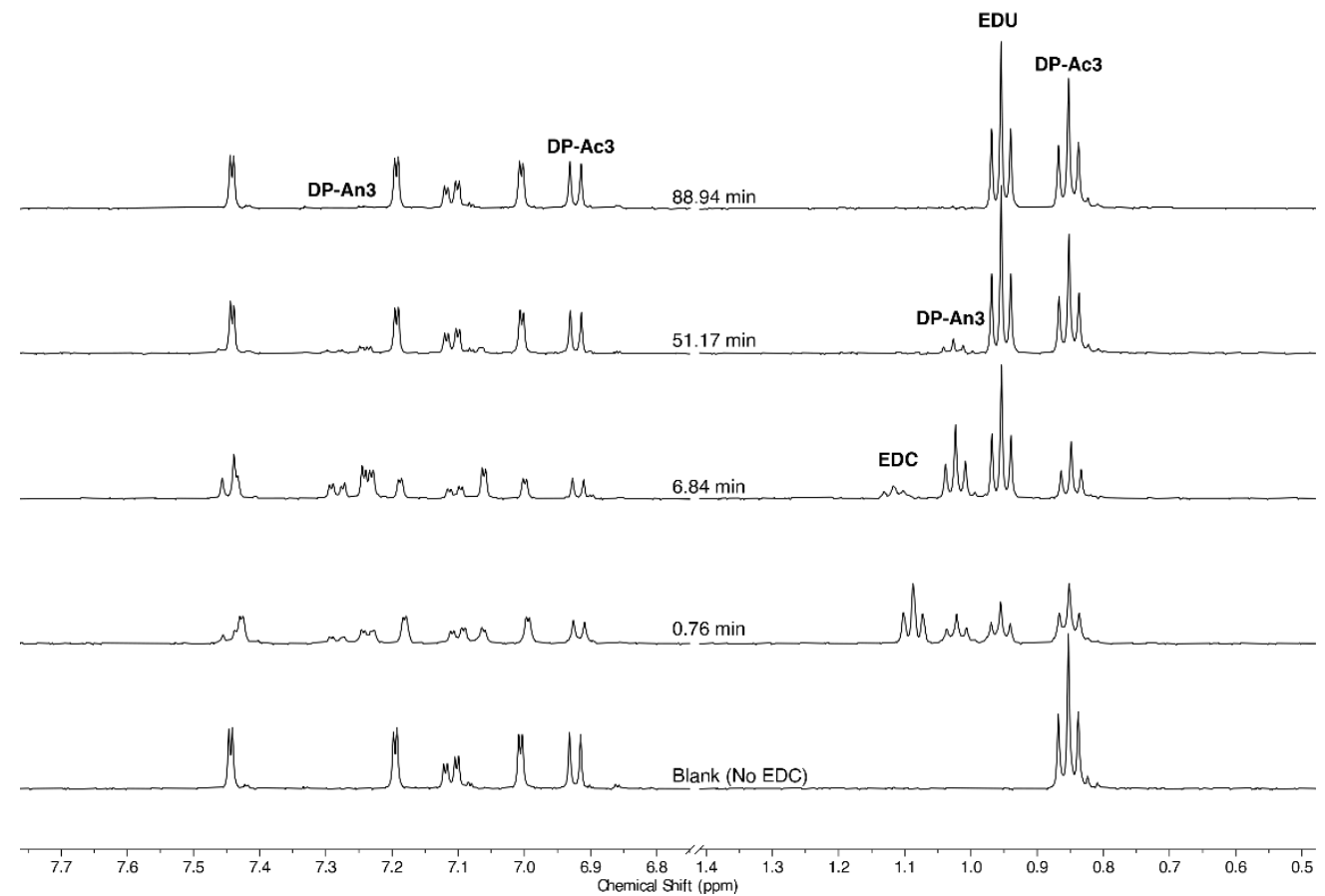

Figure S6. ${ }^{1} \mathrm{H}$ NMR spectra of DP-An3 formation from DP-Ac3 $(10 \mathrm{mM})$ treated with 1 eq. of EDC in $\mathrm{D}_{2} \mathrm{O}$ :acetone- $d_{6}$ in the presence of pyridine- $d_{5}(2 \mathrm{mM})$ at $276 \mathrm{~K}\left(\mathrm{pD}\right.$ of $\mathrm{D}_{2} \mathrm{O}$ adjusted to $\left.\mathrm{pD}=2\right)$.
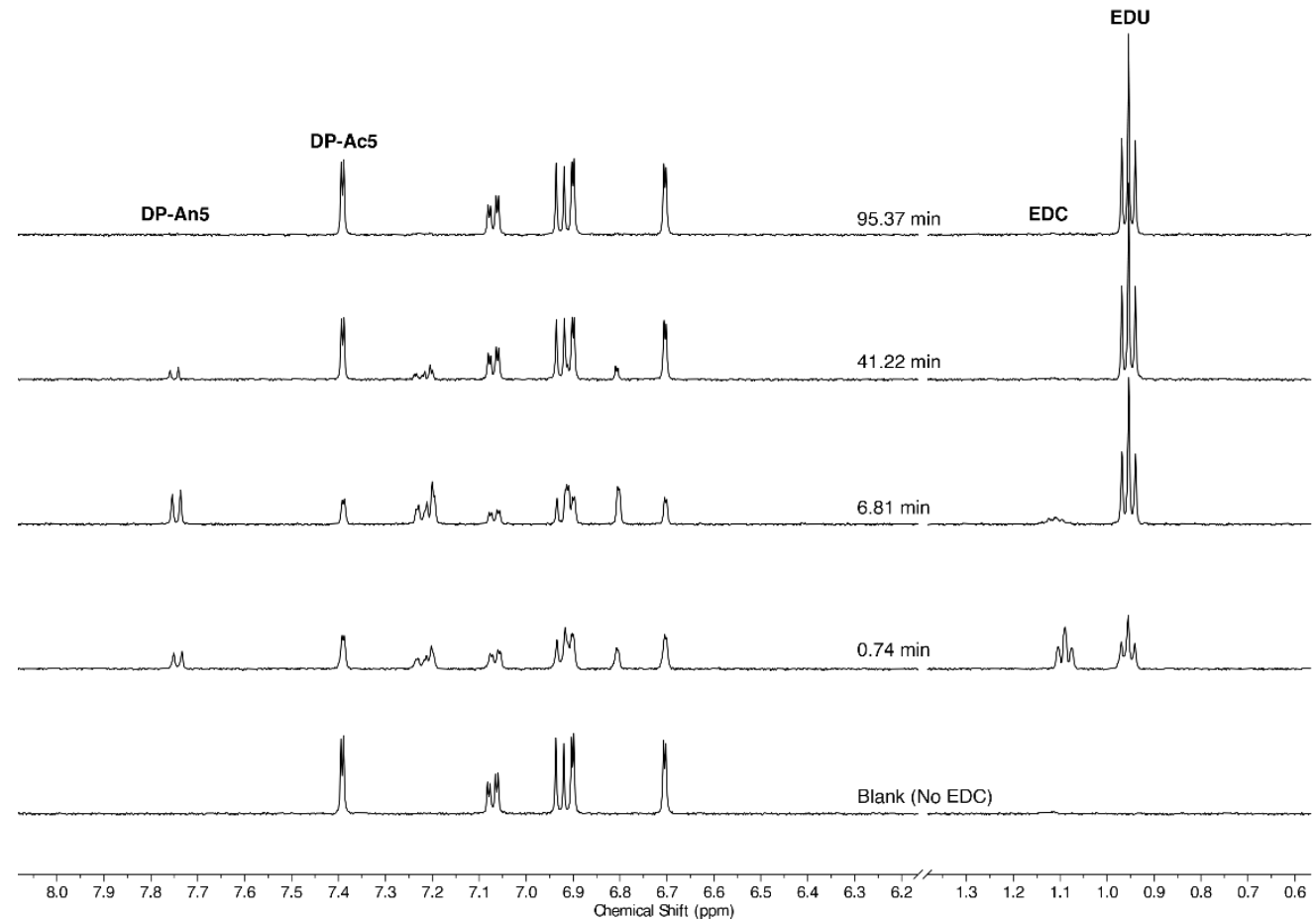

Figure S7. ${ }^{1} \mathrm{H}$ NMR spectra of DP-An5 formation from DP-Ac5 $(10 \mathrm{mM})$ treated with 1 eq. of EDC in $\mathrm{D}_{2} \mathrm{O}$ :acetone- $d_{6}$ in the presence of pyridine- $d_{5}(2 \mathrm{mM})$ at $276 \mathrm{~K}\left(\mathrm{pD}\right.$ of $\mathrm{D}_{2} \mathrm{O}$ adjusted to $\left.\mathrm{pD}=2\right)$. 


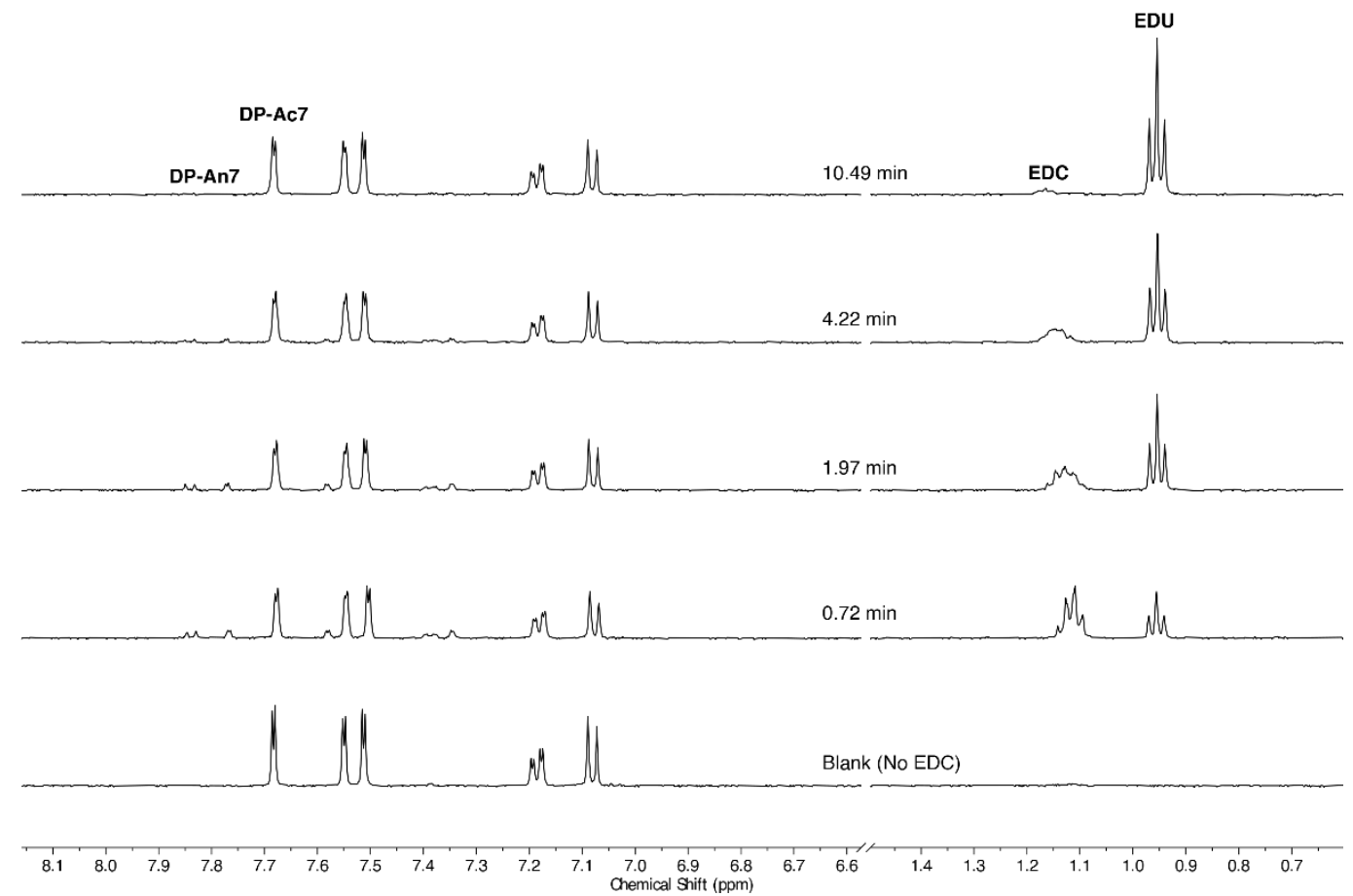

Figure S8. ${ }^{1} \mathrm{H}$ NMR spectra of DP-An7 formation from DP-Ac7 (10 mM) treated with 1 eq. of EDC in $\mathrm{D}_{2} \mathrm{O}$ :acetone- $d_{6}$ in the presence of pyridine- $d_{5}(2 \mathrm{mM})$ at $276 \mathrm{~K}\left(\mathrm{pD}\right.$ of $\mathrm{D}_{2} \mathrm{O}$ adjusted to $\left.\mathrm{pD}=2\right)$.

\section{Data Fitting}

As stated in the manuscript, the kinetic data were fit to the following mechanism:

$$
\begin{gathered}
\mathrm{DA}+\mathrm{E} \stackrel{k_{1}}{\rightarrow} \mathrm{I}+\mathrm{U} \\
\mathrm{I} \stackrel{k_{i}^{A n}}{\rightleftharpoons} \mathrm{An} \\
k_{2} \\
\mathrm{I} \stackrel{k_{i}^{D A}}{\longrightarrow} \mathrm{DA}
\end{gathered}
$$

Where DA is the acid, An is the anhydride, and I is the acylpyridinium intermediate, E is EDC and U is urea. The system is therefore described by the following set of differential equations:

$$
\begin{gathered}
\frac{d[D A]}{d t}=-k_{1}[D A][E]+k_{i}^{D A}[I] \\
\frac{d[A n]}{d t}=+k_{i}^{A n}[I]-k_{2}[A n] \\
\frac{d[I]}{d t}=+k_{1}[D A][E]+k_{2}[A n]-k_{i}^{A n}[I]-k_{i}^{D A}[I] \\
\frac{d[E]}{d t}=-k_{1}[D A][E] \\
\frac{d[U]}{d t}=+k_{1}[D A][E]
\end{gathered}
$$


Assuming a steady-state in [I], we can derive:

$$
\begin{gathered}
\frac{d[D A]}{d t}=+\frac{[D A][E]\left(k_{1} \alpha-k_{1}-\alpha\right)}{1+\alpha}+\frac{k_{2} \alpha[A n]}{1+\alpha} \\
\frac{d[A n]}{d t}=+\frac{k_{1}[A n][E]}{1+\alpha}-\frac{k_{2} \alpha[A n]}{1+\alpha}
\end{gathered}
$$

Here $\alpha=k_{i}^{D A} / k_{i}^{A n}$.

The above data fitting was done using a custom program written in Python 3 (kinmodel). The features of this program and the resulting data simulations are discussed in detail in our previous publication. ${ }^{1}$ A copy of the version used for the current work is included separately. The code continues to be developed by our group, with the most recent version available on Github (https://github.com/scotthartley/kinmodel). 


\section{Kinetics Experiments}

Plots

(a)

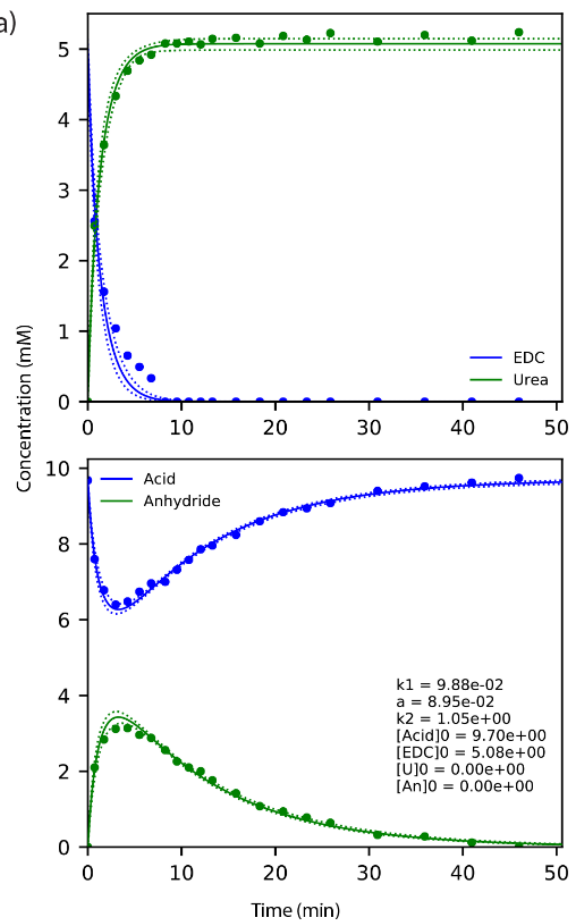

(c)

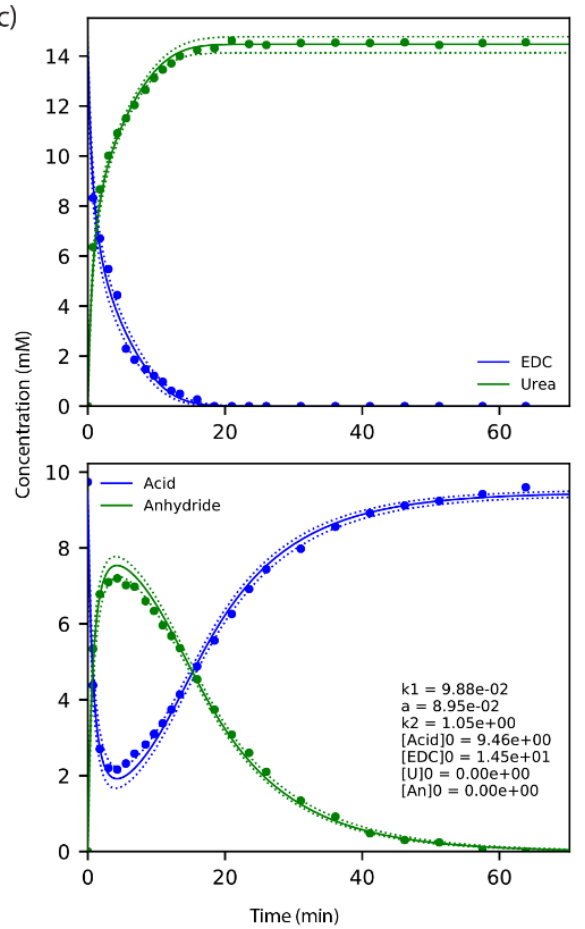

(b)
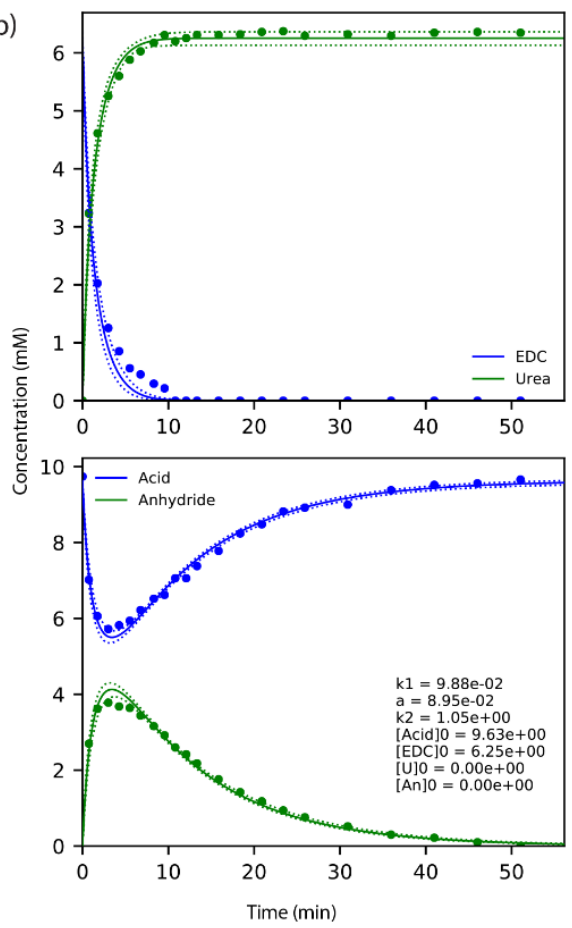

(d)

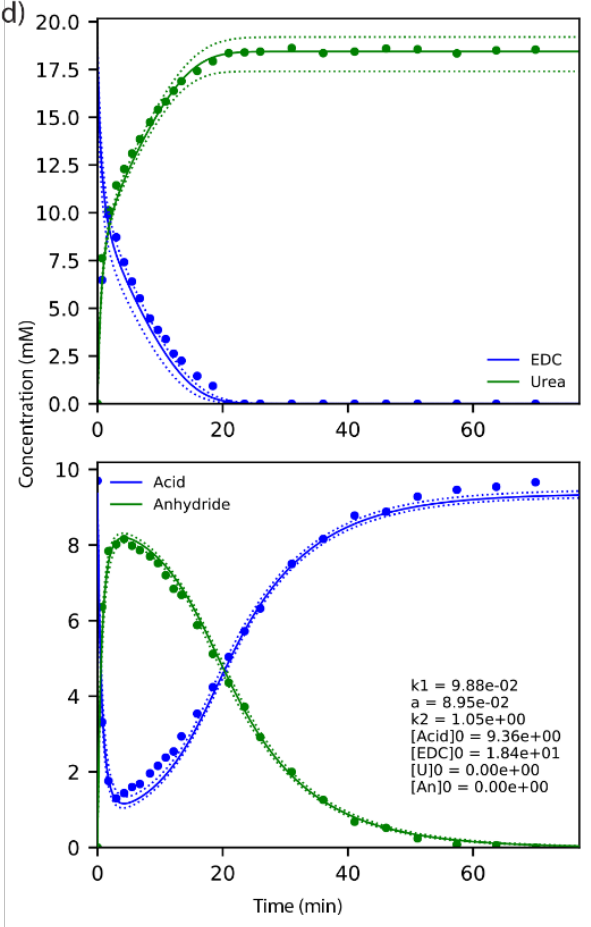

Figure S9. ${ }^{1} \mathrm{H}$ NMR spectroscopy monitoring of the treatment of $10 \mathrm{mM}$ DP-Ac1 with (a) $5 \mathrm{mM}$, (b) $6 \mathrm{mM}$, (c) $14 \mathrm{mM}$, (d) $18 \mathrm{mM}$ EDC in $\mathrm{D}_{2} \mathrm{O}$ :acetone- $d_{6}$ in the presence of pyridine- $d_{5}(2 \mathrm{mM})$ at $276 \mathrm{~K}\left(\mathrm{pD}\right.$ of $\mathrm{D}_{2} \mathrm{O}$ adjusted to $\mathrm{pD}=2$ ). The dashed lines represent $95 \%$ confidence intervals for the fits. 
(a)

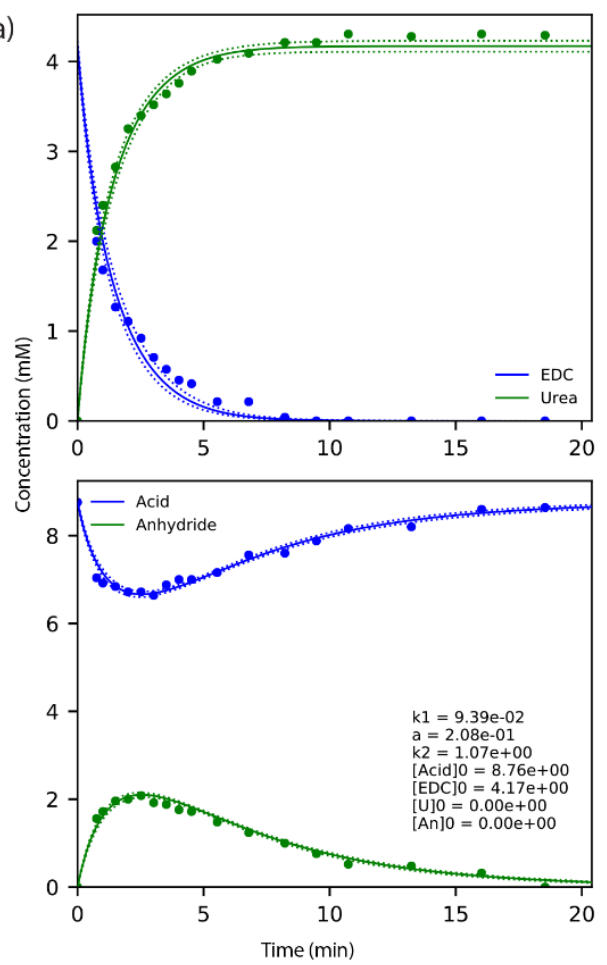

(c)

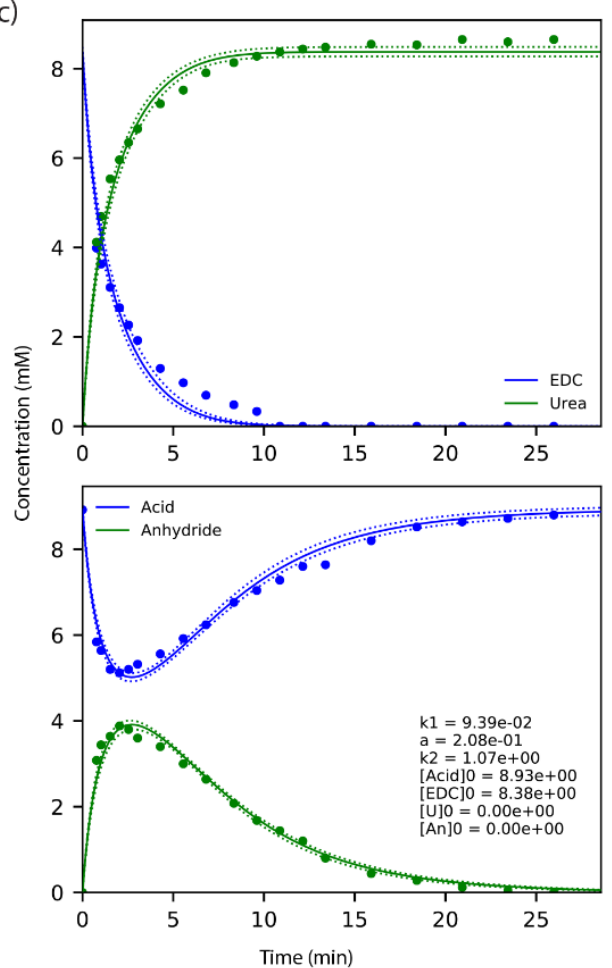

(b)

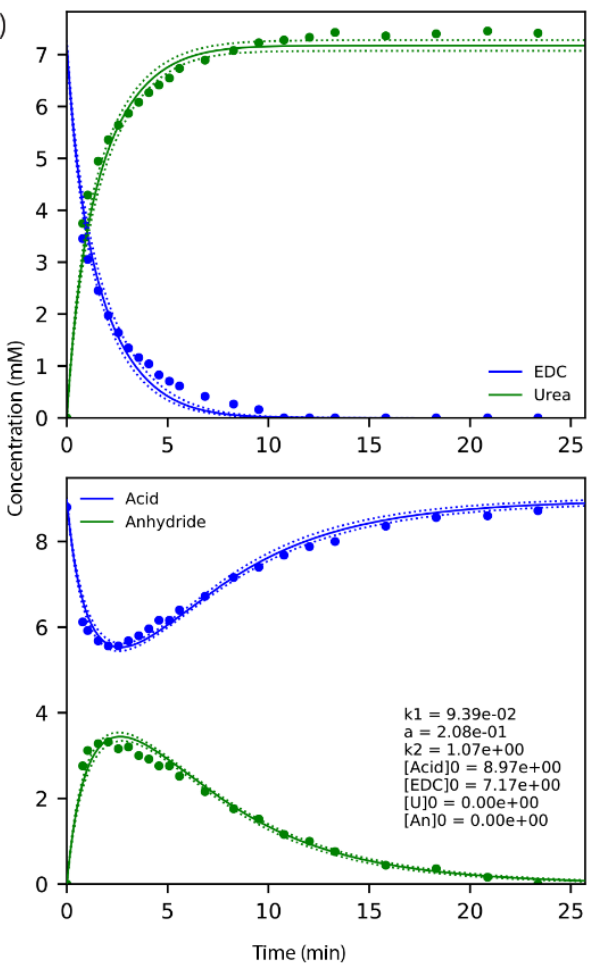

(d)

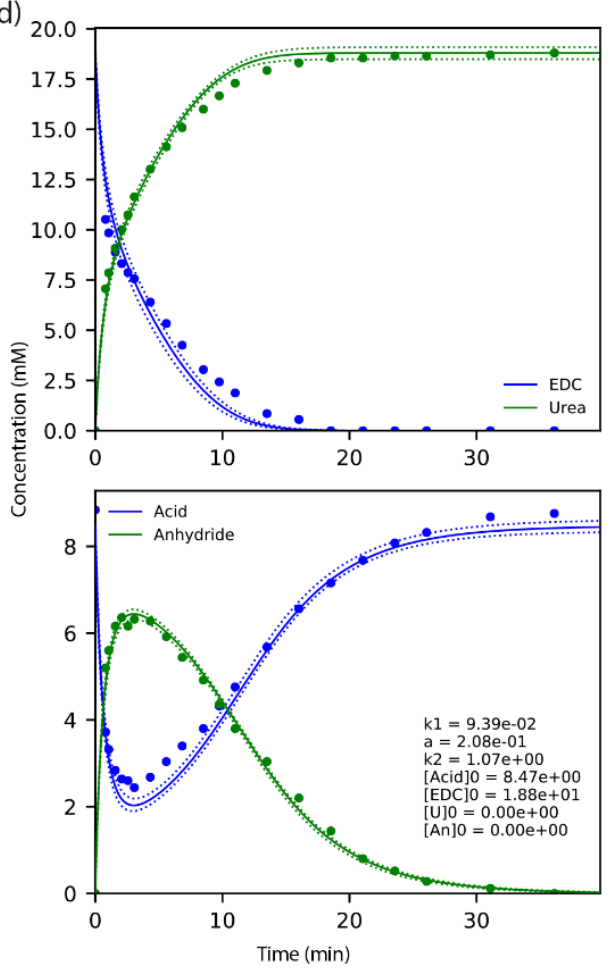

Figure S10. ${ }^{1} \mathrm{H}$ NMR spectroscopy monitoring of the treatment of $10 \mathrm{mM}$ DP-Ac2 with (a) $4 \mathrm{mM}$, (b) 7 $\mathrm{mM}$, (c) $8 \mathrm{mM}$, (d) $18 \mathrm{mM}$ EDC in $\mathrm{D}_{2} \mathrm{O}$ :acetone- $d_{6}$ in the presence of pyridine- $d_{5}(2 \mathrm{mM})$ at $276 \mathrm{~K}$ (pD of $\mathrm{D}_{2} \mathrm{O}$ adjusted to $\mathrm{pD}=2$ ). The dashed lines represent $95 \%$ confidence intervals for the fits. 

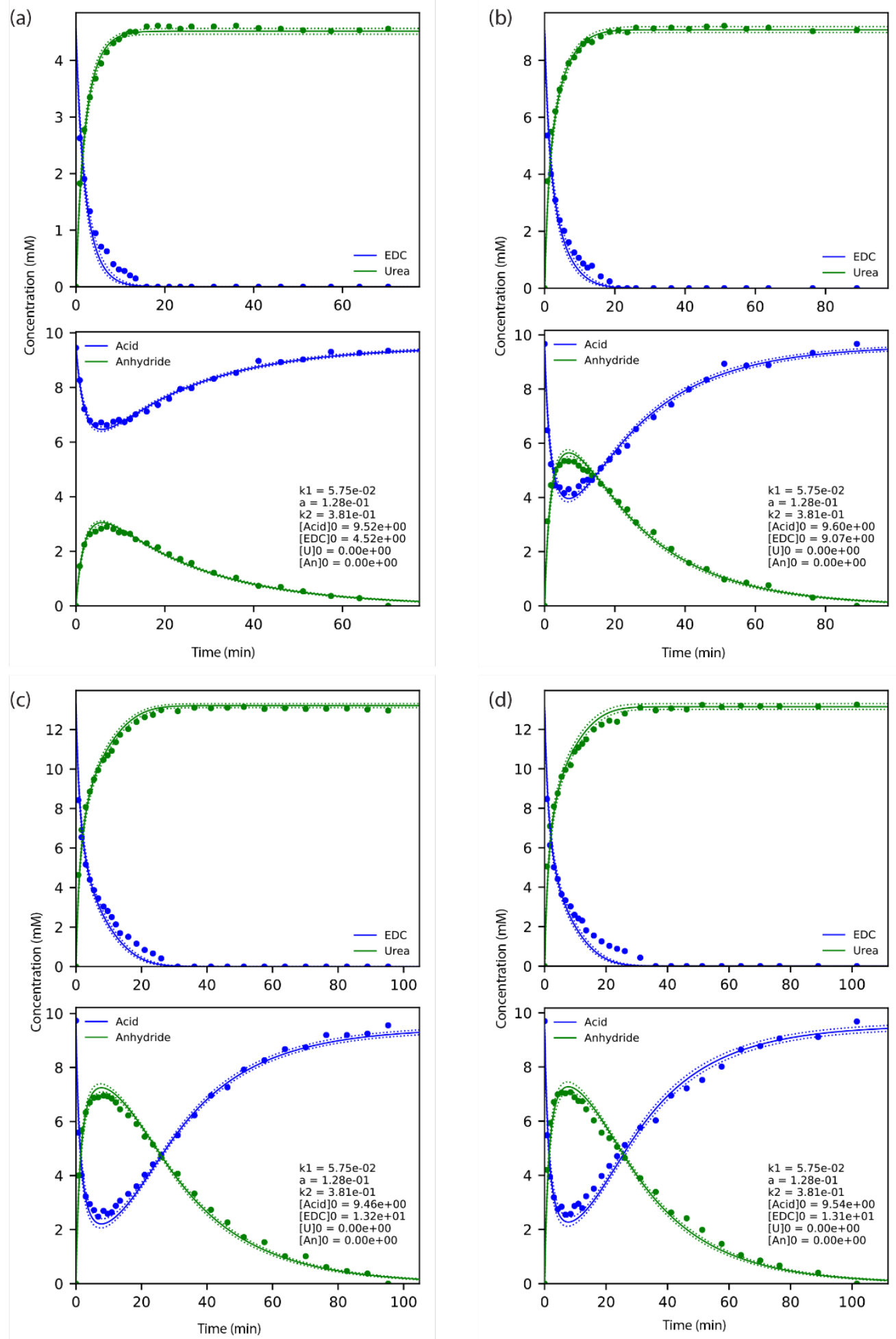

Figure S11. ${ }^{1} \mathrm{H}$ NMR spectroscopy monitoring of the treatment of $10 \mathrm{mM}$ DP-Ac3 with (a) $5 \mathrm{mM}$, (b) 9 $\mathrm{mM}$, (c) $12 \mathrm{mM}$, (d) $13 \mathrm{mM}$ EDC in $\mathrm{D}_{2} \mathrm{O}$ :acetone- $d_{6}$ in the presence of pyridine- $d_{5}(2 \mathrm{mM})$ at $276 \mathrm{~K}$ (pD of $\mathrm{D}_{2} \mathrm{O}$ adjusted to $\mathrm{pD}=2$ ). The dashed lines represent $95 \%$ confidence intervals for the fits. 
(a)

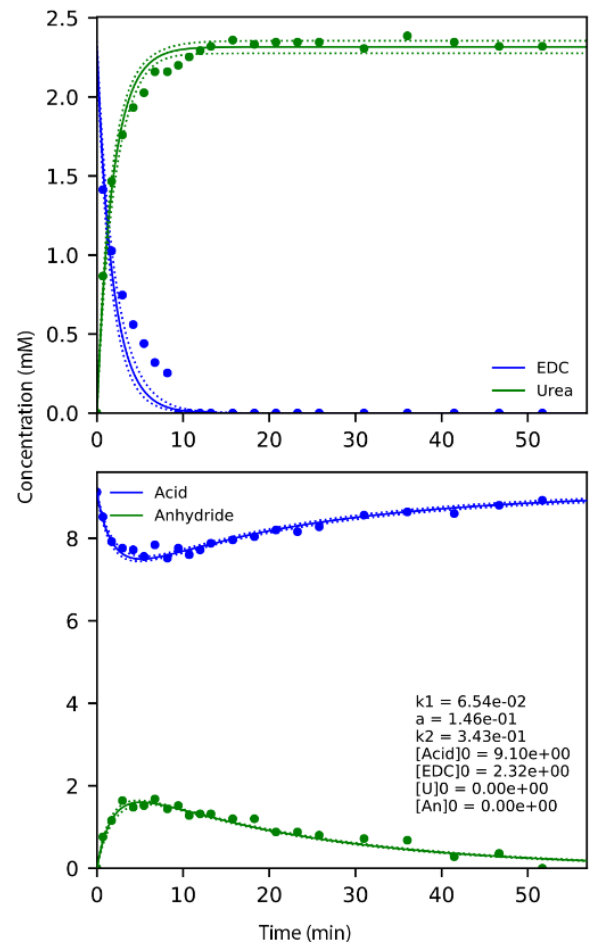

(c)

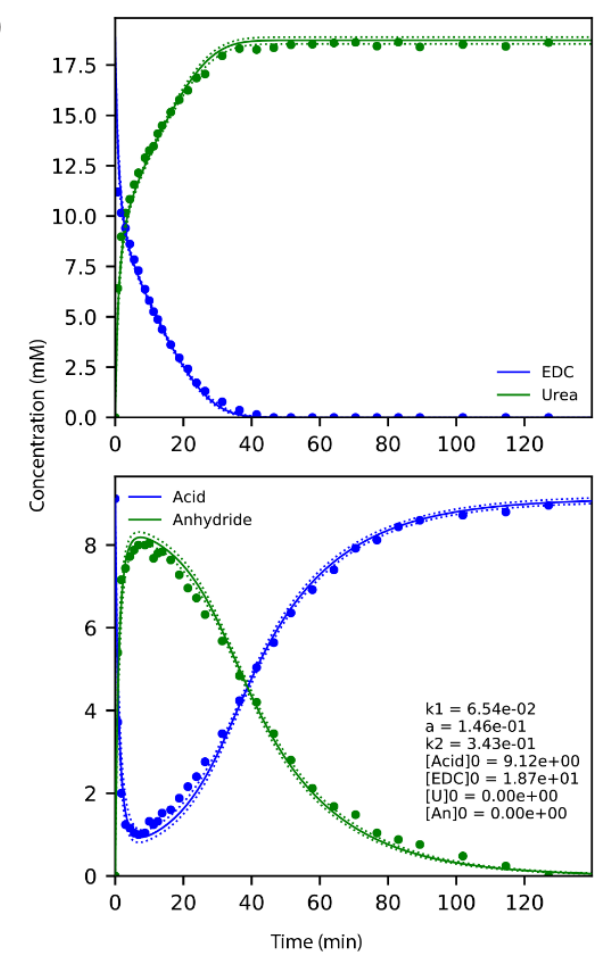

(b)

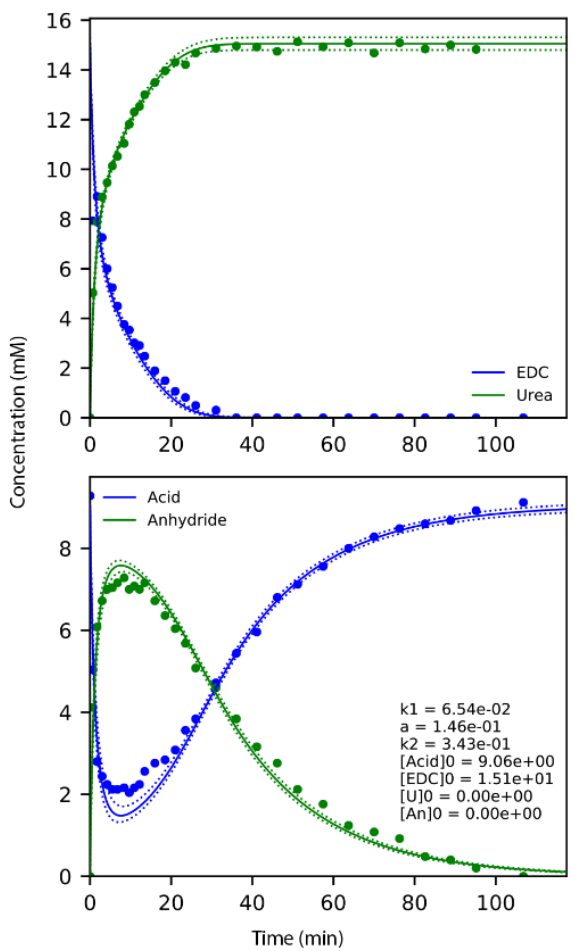

Figure S12. ${ }^{1} \mathrm{H}$ NMR spectroscopy monitoring of the treatment of $10 \mathrm{mM}$ DP-Ac4 with (a) $2.5 \mathrm{mM}$, (b) 15 $\mathrm{mM}$, (c) $18 \mathrm{mM}$ EDC in $\mathrm{D}_{2} \mathrm{O}$ :acetone- $d_{6}$ in the presence of pyridine- $d_{5}(2 \mathrm{mM})$ at $276 \mathrm{~K}\left(\mathrm{pD}\right.$ of $\mathrm{D}_{2} \mathrm{O}$ adjusted to $\mathrm{pD}=2$ ). The dashed lines represent $95 \%$ confidence intervals for the fits. 
(a)

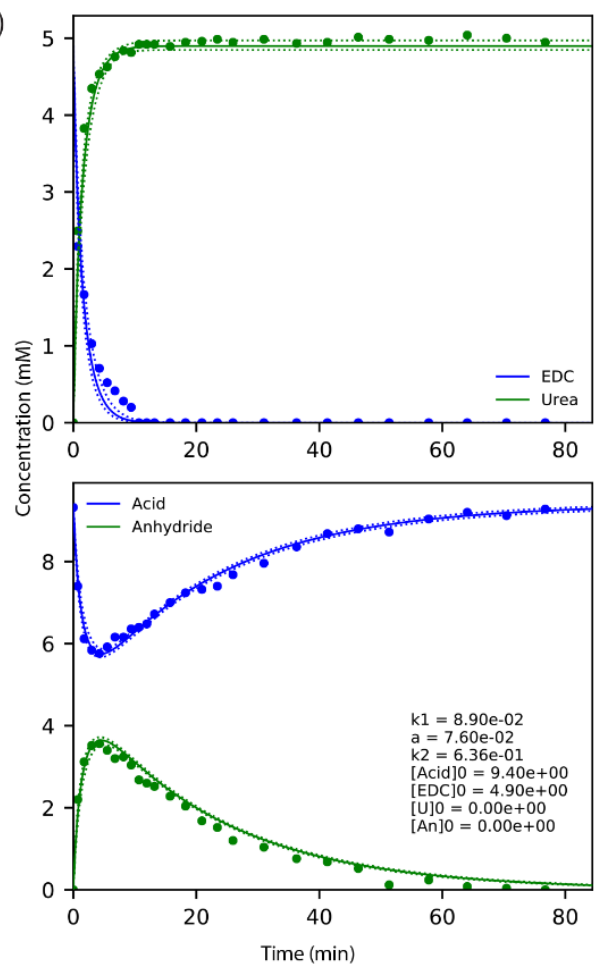

(c)

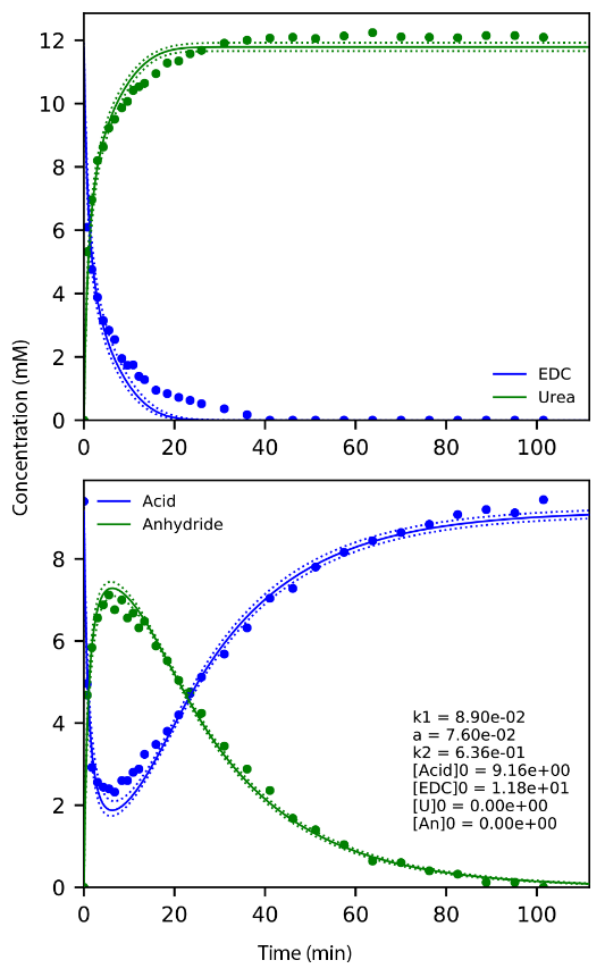

(b)

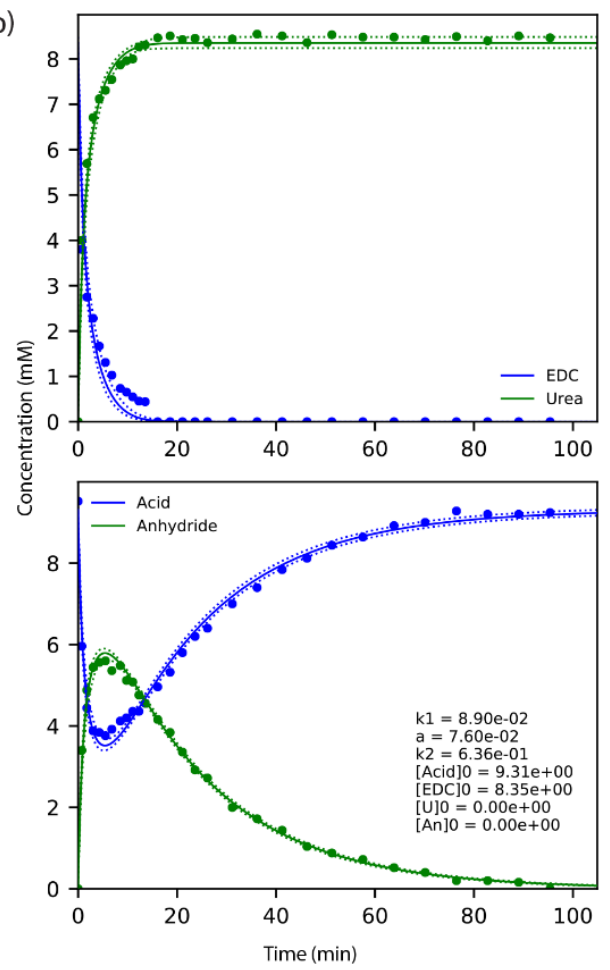

(d)
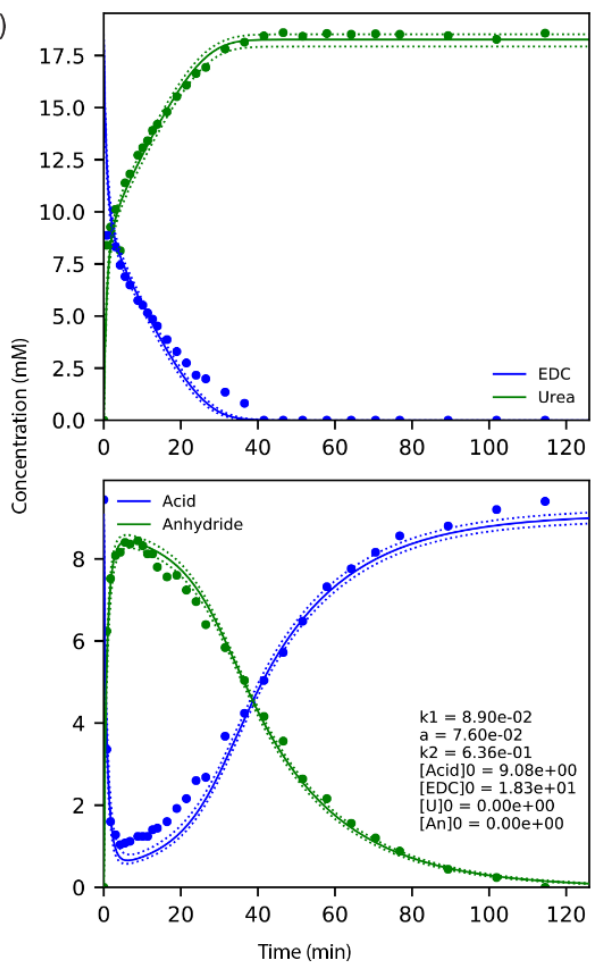

Figure S13. ${ }^{1} \mathrm{H}$ NMR spectroscopy monitoring of the treatment of $10 \mathrm{mM}$ DP-Ac5 with (a) $5 \mathrm{mM}$, (b) 9 $\mathrm{mM}$, (c) $12 \mathrm{mM}$, (d) $18 \mathrm{mM}$ EDC in $\mathrm{D}_{2} \mathrm{O}$ :acetone- $d_{6}$ in the presence of pyridine- $d_{5}(2 \mathrm{mM})$ at $276 \mathrm{~K}$ (pD of $\mathrm{D}_{2} \mathrm{O}$ adjusted to $\mathrm{pD}=2$ ). The dashed lines represent $95 \%$ confidence intervals for the fits. 
(a)
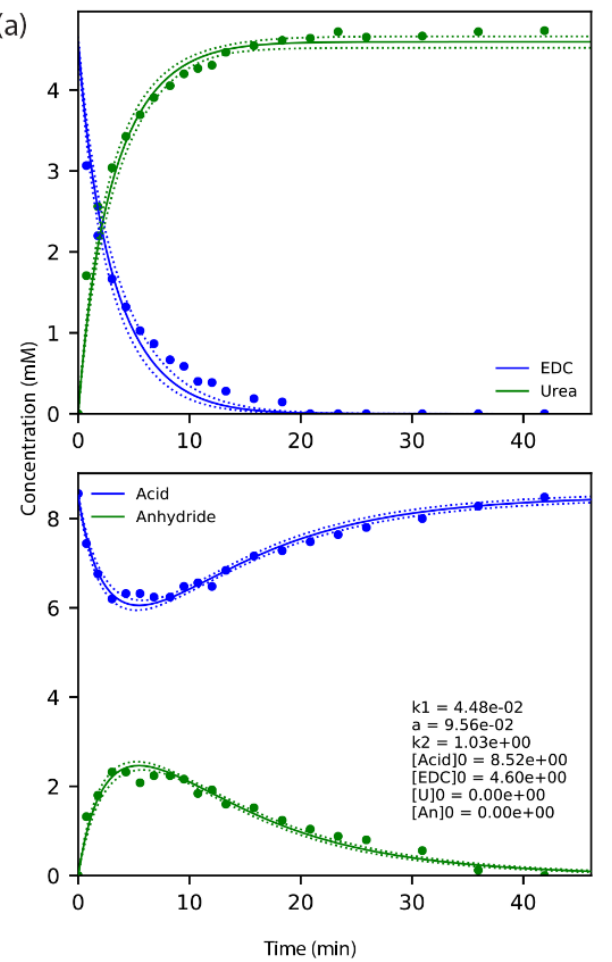

(c)

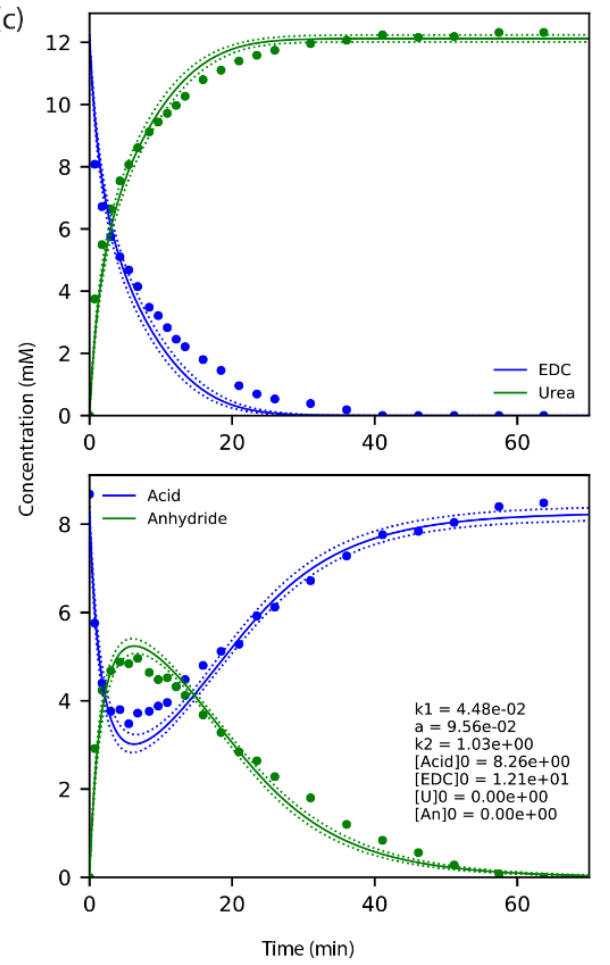

(b)
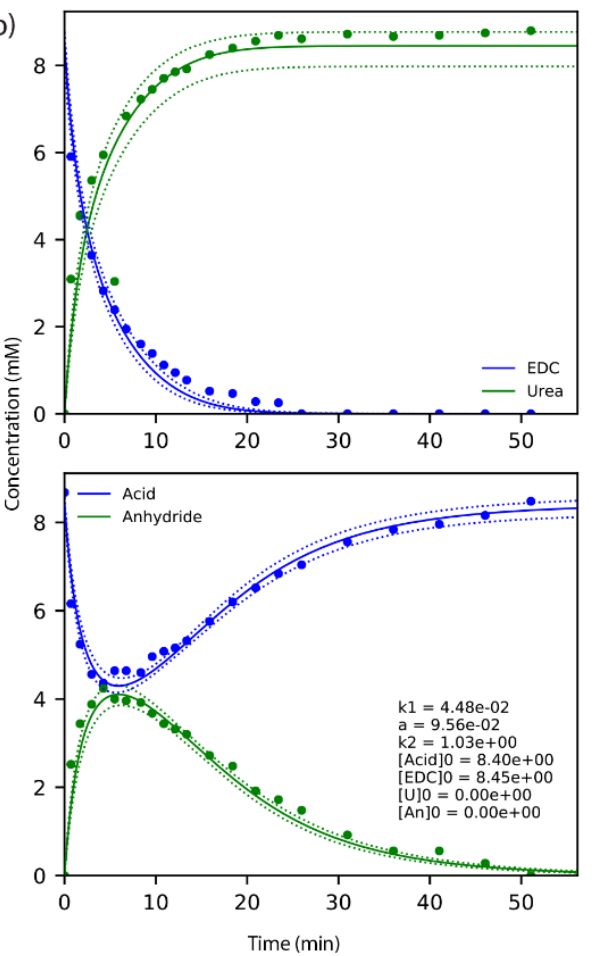

(d)

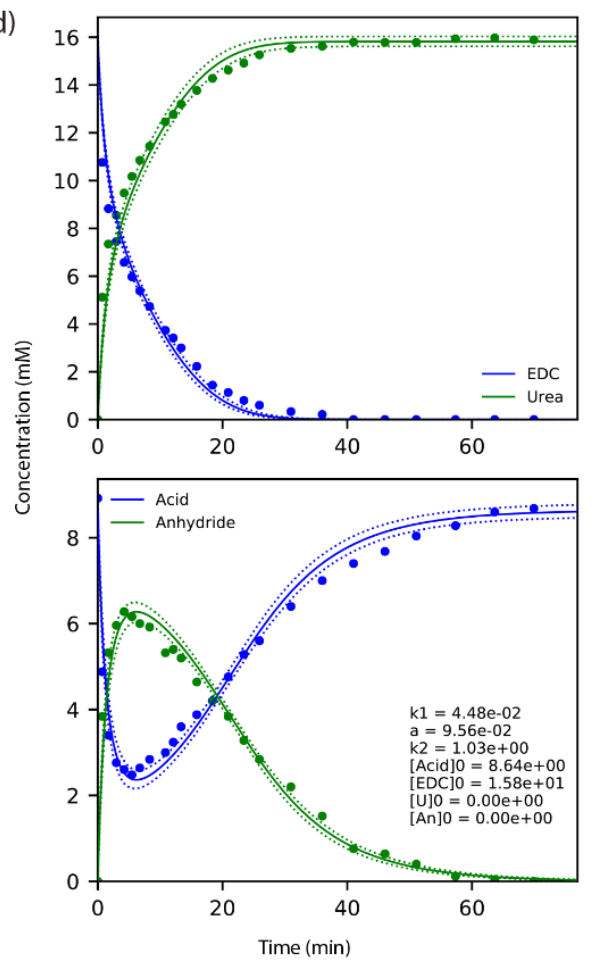

Figure S14. ${ }^{1} \mathrm{H}$ NMR spectroscopy monitoring of the treatment of $10 \mathrm{mM}$ DP-Ac6 with (a) $5 \mathrm{mM}$, (b) 8 $\mathrm{mM}$, (c) $12 \mathrm{mM}$, (d) $16 \mathrm{mM}$ EDC in $\mathrm{D}_{2} \mathrm{O}$ :acetone- $d_{6}$ in the presence of pyridine- $d_{5}(2 \mathrm{mM})$ at $276 \mathrm{~K}(\mathrm{pD}$ of $\mathrm{D}_{2} \mathrm{O}$ adjusted to $\mathrm{pD}=2$ ). The dashed lines represent $95 \%$ confidence intervals for the fits. 
(a)

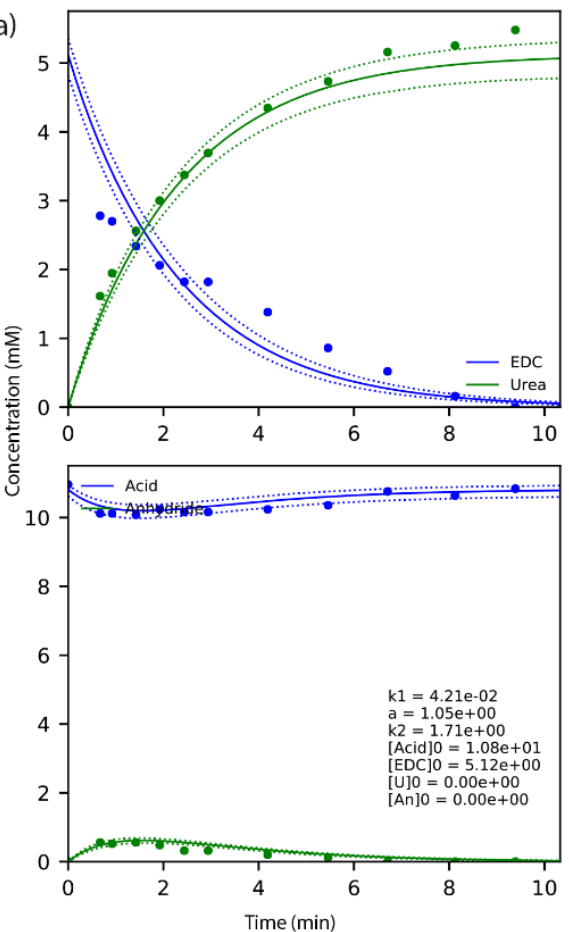

(c)

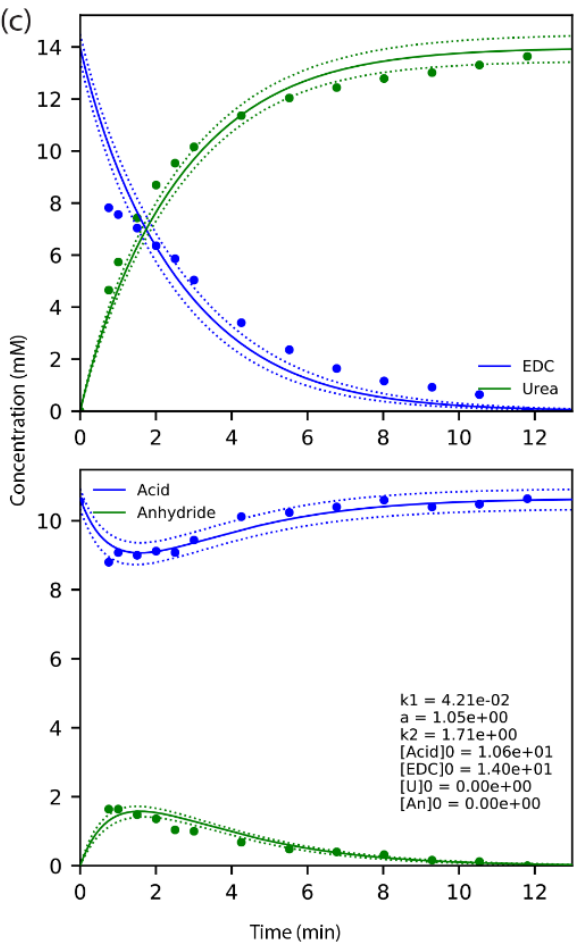

(b)

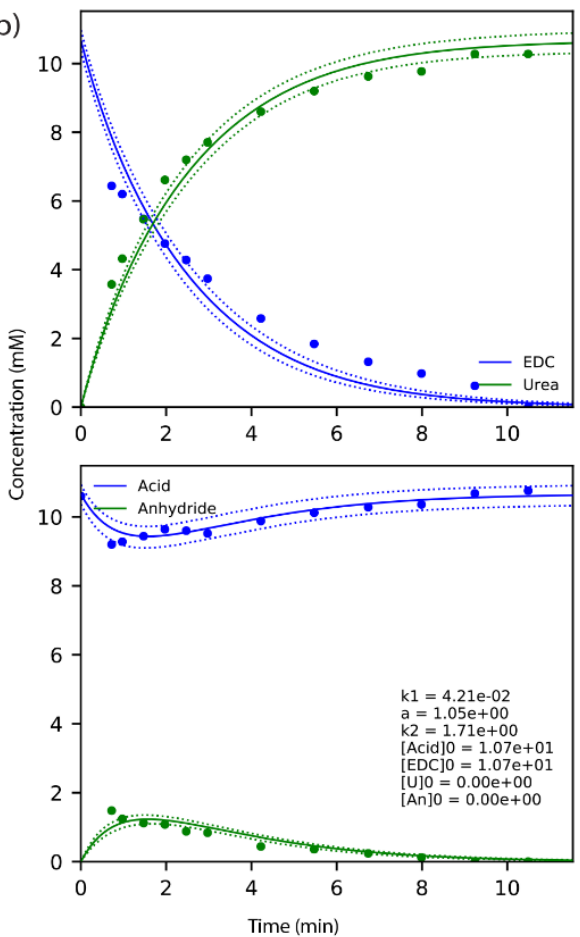

(d)

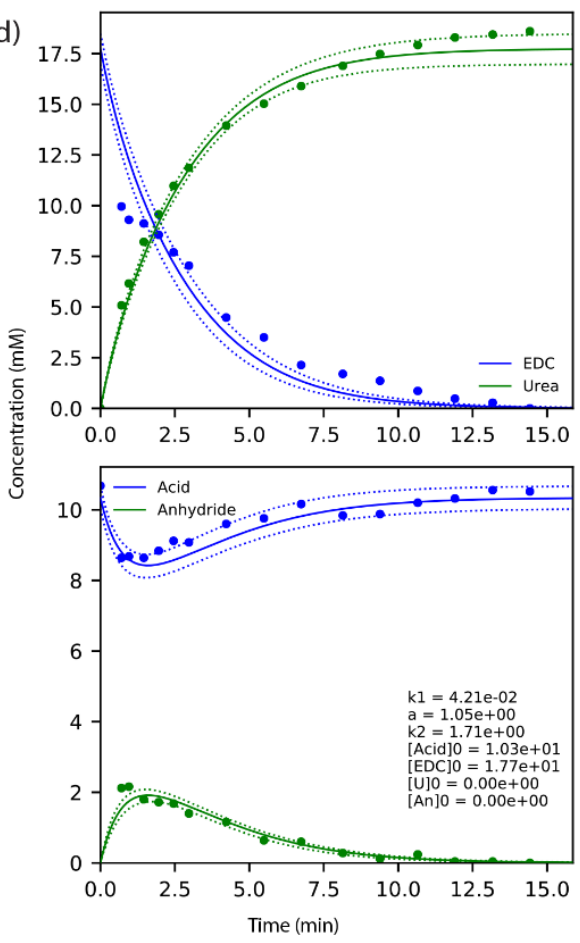

Figure S15. ${ }^{1} \mathrm{H}$ NMR spectroscopy monitoring of the treatment of $10 \mathrm{mM}$ DP-Ac7 with (a) $5 \mathrm{mM}$, (b) 10 $\mathrm{mM}$, (c) $14 \mathrm{mM}$, (d) $18 \mathrm{mM}$ EDC in $\mathrm{D}_{2} \mathrm{O}$ :acetone- $d_{6}$ in the presence of pyridine- $d_{5}(2 \mathrm{mM})$ at $276 \mathrm{~K}$ (pD of $\mathrm{D}_{2} \mathrm{O}$ adjusted to $\mathrm{pD}=2$ ). The dashed lines represent $95 \%$ confidence intervals for the fits. 


\section{Fit Parameters}

Parameters extracted from the fits to the kinetic model for the diphenic acid systems are summarized in Table S1. The 95\% confidence intervals were determined using a nonparametric bootstrapping method with 10,000 iterations, which has been discussed previously. ${ }^{2}$ In brief, new datasets are randomly generated from the experimental data (by choosing randomly from the experimental data points) and the fitting is rerun multiple times. ${ }^{3}$

Table S1. Fit parameters for the diphenic acid systems for anhydride formation and hydrolysis. The parameters are determined from fitting simultaneously to four datasets with different EDC concentrations (Conditions: $\mathrm{D}_{2} \mathrm{O}$ : acetone- $d_{6} 1: 1$, pyridine- $d_{5} 2 \mathrm{mM}, \mathrm{D}_{2} \mathrm{O}$ pD adjusted to $\mathrm{pD}=2$, initial acid conc. $=10 \mathrm{mM}$ at $276 \mathrm{~K})$.

\begin{tabular}{cccc}
\hline Diphenic acid & $\begin{array}{c}\mathrm{k}_{1} \\
\left(\mathrm{mM}^{-1} \mathrm{~min}^{-1}\right)\end{array}$ & $\begin{array}{c}\mathrm{k}_{2} \\
\left(\mathrm{~min}^{-1}\right)\end{array}$ & $\alpha$ \\
\hline DP-Ac4 & $6.54_{-0.90}^{+0.85} \times 10^{-2}$ & $3.43_{-0.49}^{+0.50} \times 10^{-1}$ & $1.46_{-0.19}^{+0.24} \times 10^{-1}$ \\
DP-Ac3 & $5.75_{-0.61}^{+0.61} \times 10^{-2}$ & $3.81_{-0.49}^{+0.71} \times 10^{-1}$ & $1.28_{-0.17}^{+0.18} \times 10^{-1}$ \\
DP-Ac1 & $9.88_{-1.49}^{+1.88} \times 10^{-2}$ & $1.05_{-0.28}^{+0.36}$ & $8.95_{-2.43}^{+3.45} \times 10^{-2}$ \\
DP-Ac6 & $4.48_{-0.50}^{+0.56} \times 10^{-2}$ & $1.03_{-0.37}^{+1.54}$ & $9.56_{-5.66}^{+5.17} \times 10^{-2}$ \\
DP-Ac5 & $8.90_{-1.44}^{+1.26} \times 10^{-2}$ & $6.36_{-1.37}^{+2.48} \times 10^{-1}$ & $7.60_{-2.12}^{+2.04} \times 10^{-2}$ \\
DP-Ac2 & $9.39_{-0.80}^{+0.74} \times 10^{-2}$ & $1.07_{-0.19}^{+0.33}$ & $2.08_{-0.45}^{+0.40} \times 10^{-1}$ \\
DP-Ac7 & $4.21_{-0.30}^{+0.37} \times 10^{-2}$ & $1.71_{-0.44}^{+0.90}$ & $1.05_{-0.34}^{+0.40}$ \\
\hline
\end{tabular}

The interdependence of the parameters was further tested by calculating confidence contour plots, in which the sum square error of the regression is calculated as a function of each possible pair of kinetic parameters. ${ }^{4}$ In the plots below, the inverse error function is plotted. If the parameters are well-constrained by the data, the plots will show distinct maxima (distinct dark red regions) that correspond to the optimum parameter values. If they are not-that is, a change in one can compensate for a change in another, such that the fit quality is unchanged-this will be represented by a poorly defined maximum over a wide range of values. Their use in similar systems is discussed further in our previous work. ${ }^{2}$

These plots, plus the bootstrapping analysis discussed above, ensure that the parameters are well-constrained by the data. 

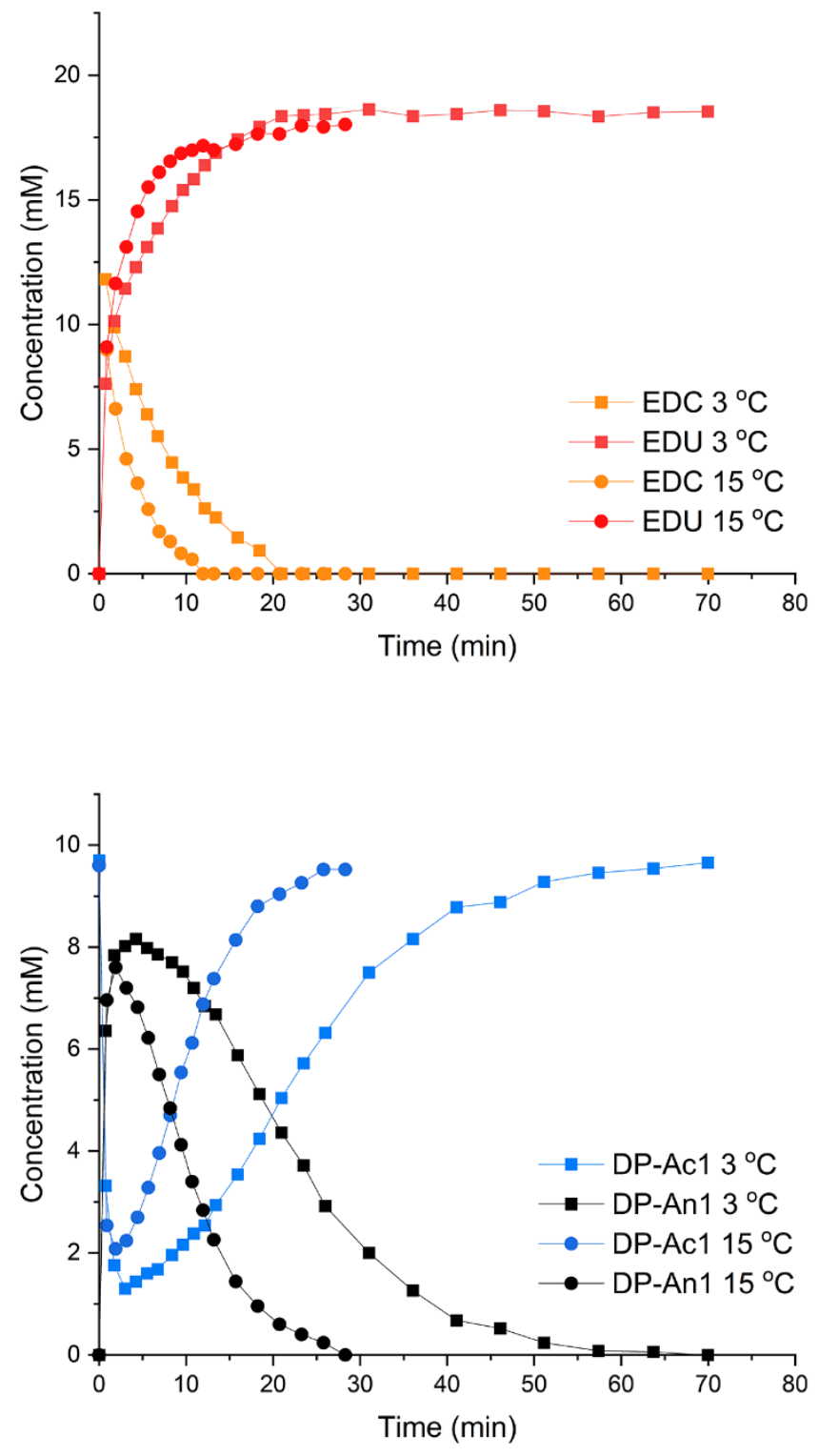

Figure S16. Temperature dependence of the kinetics of anhydride formation and hydrolysis, ${ }^{1} \mathrm{H}$ NMR spectroscopy monitoring of the treatment of $10 \mathrm{mM}$ DP-Ac1 with $18 \mathrm{mM}$ EDC in $\mathrm{D}_{2} \mathrm{O}$ acetone- $d_{6}$ in the presence of pyridine- $d_{5}(2 \mathrm{mM})$ at $276 \mathrm{~K}$ and $288 \mathrm{~K}\left(\mathrm{pD}\right.$ of $\mathrm{D}_{2} \mathrm{O}$ adjusted to $\left.\mathrm{pD}=2\right)$. 


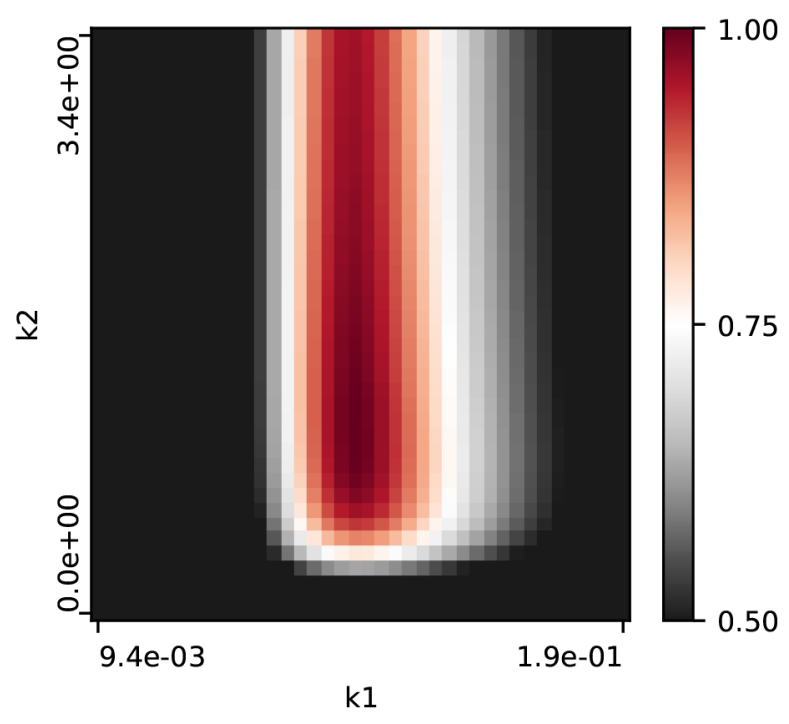

Figure S17. Heat map of the response of the regression error function to variation of $k_{2}$ and $k_{1}$ for the DPAc1/DP-An1 system. The inverse error function is plotted, normalized against the value for the optimized system.

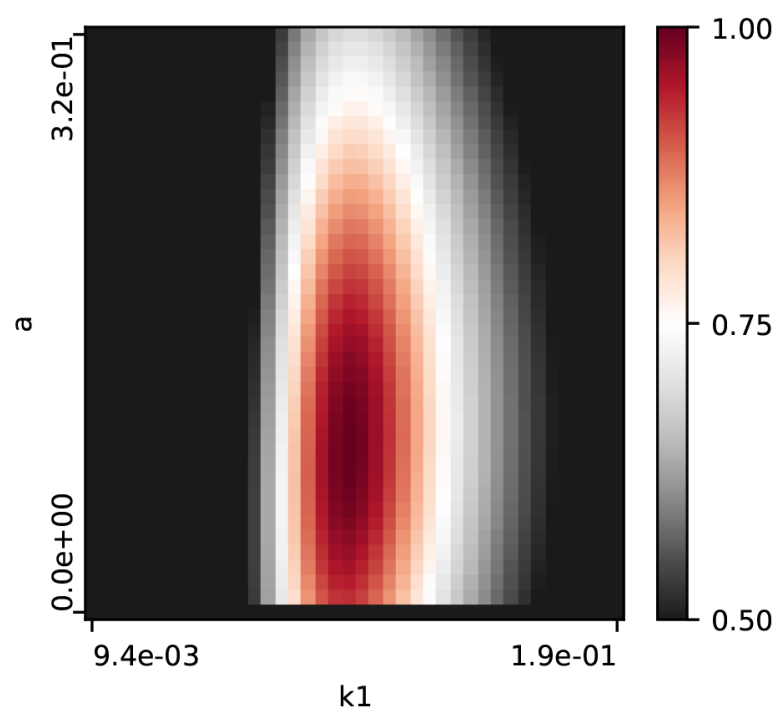

Figure S18. Heat map of the response of the regression error function to variation of $\alpha$ and $k_{1}$ for the DPAc1/DP-An1 system. The inverse error function is plotted, normalized against the value for the optimized system. 


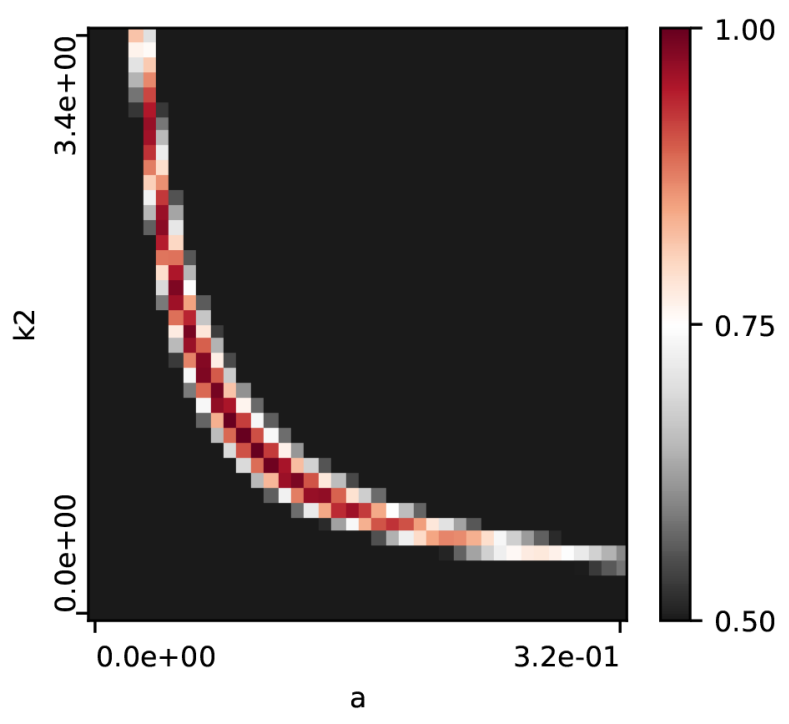

Figure S19. Heat map of the response of the regression error function to variation of $k_{2}$ and $\alpha$ for the DPAc1/DP-An1 system. The inverse error function is plotted, normalized against the value for the optimized system.

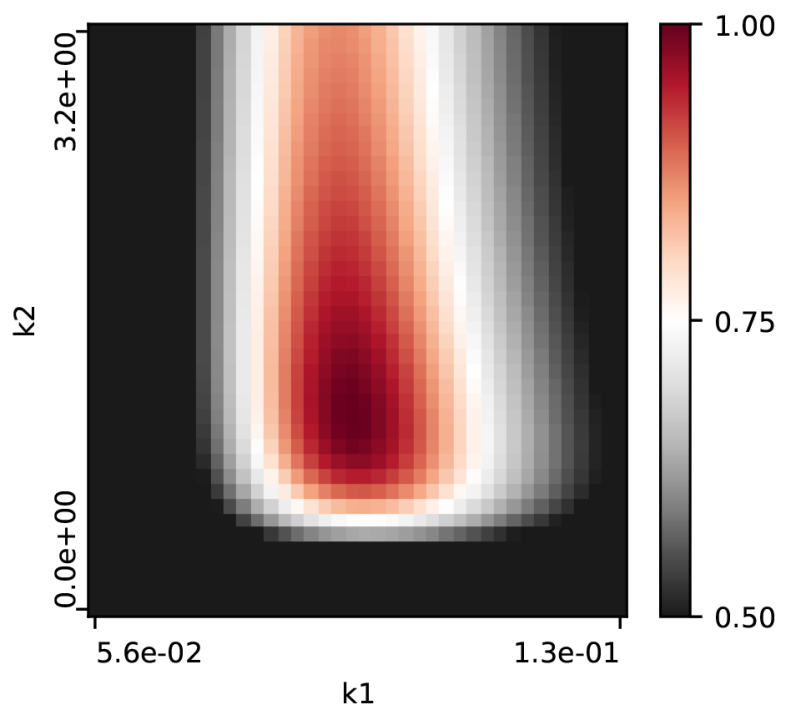

Figure S20. Heat map of the response of the regression error function to variation of $k_{2}$ and $k_{1}$ for the DPAc2/DP-An2 system. The inverse error function is plotted, normalized against the value for the optimized system. 


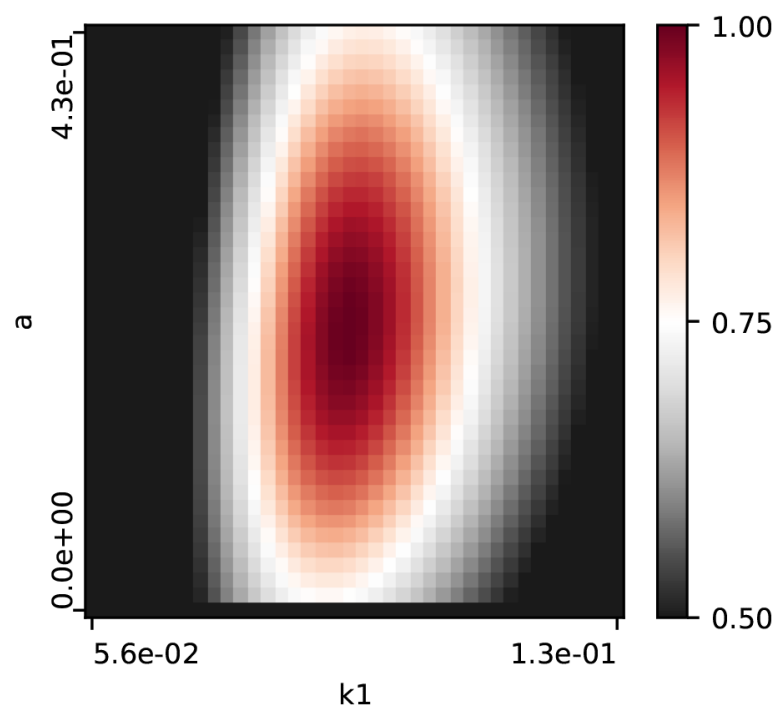

Figure S21. Heat map of the response of the regression error function to variation of $\alpha$ and $k_{1}$ for the DPAc2/DP-An2 system. The inverse error function is plotted, normalized against the value for the optimized system.

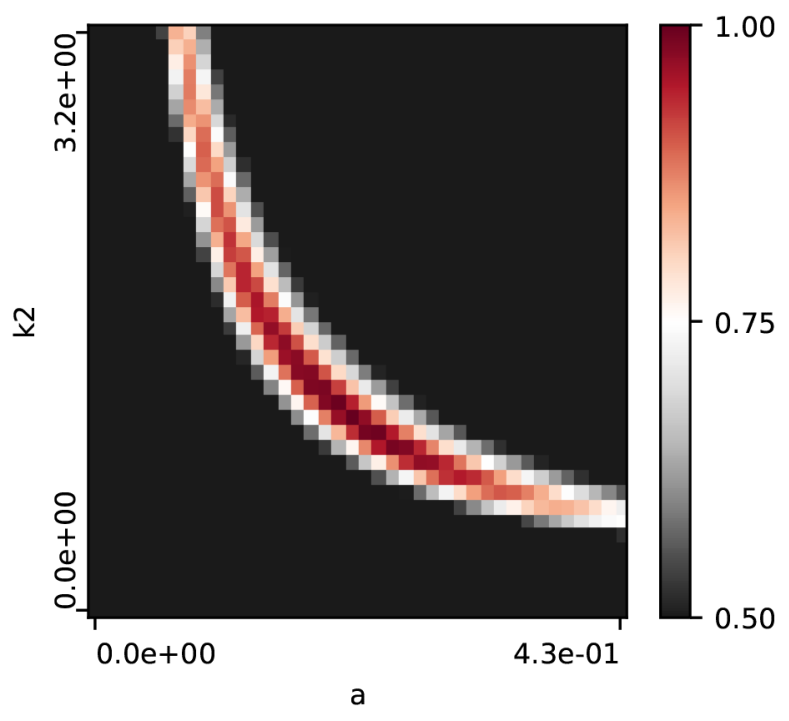

Figure S22. Heat map of the response of the regression error function to variation of $k_{2}$ and $\alpha$ for the DPAc2/DP-An2 system. The inverse error function is plotted, normalized against the value for the optimized system. 


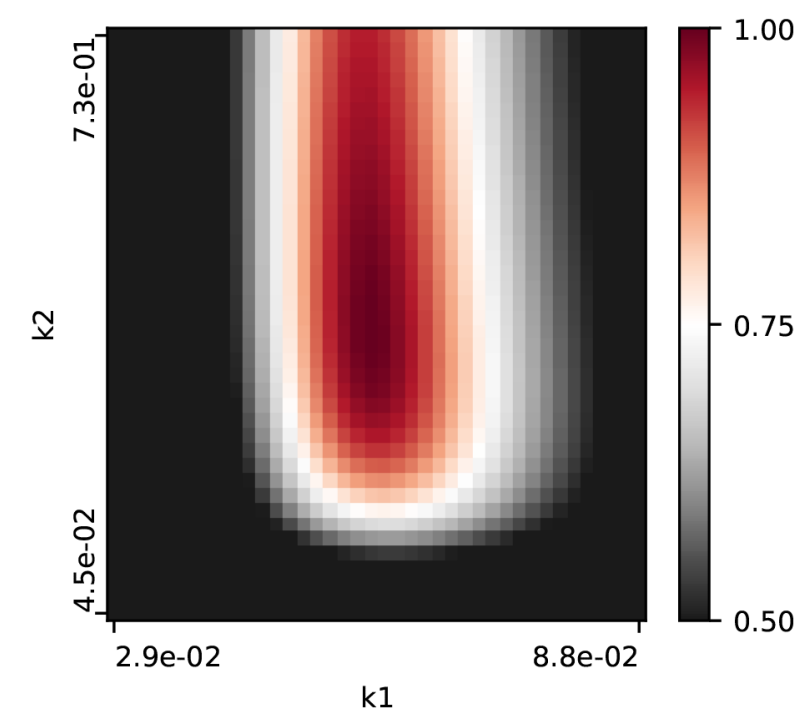

Figure S23. Heat map of the response of the regression error function to variation of $k_{2}$ and $k_{1}$ for the DPAc3/DP-An3 system. The inverse error function is plotted, normalized against the value for the optimized system.

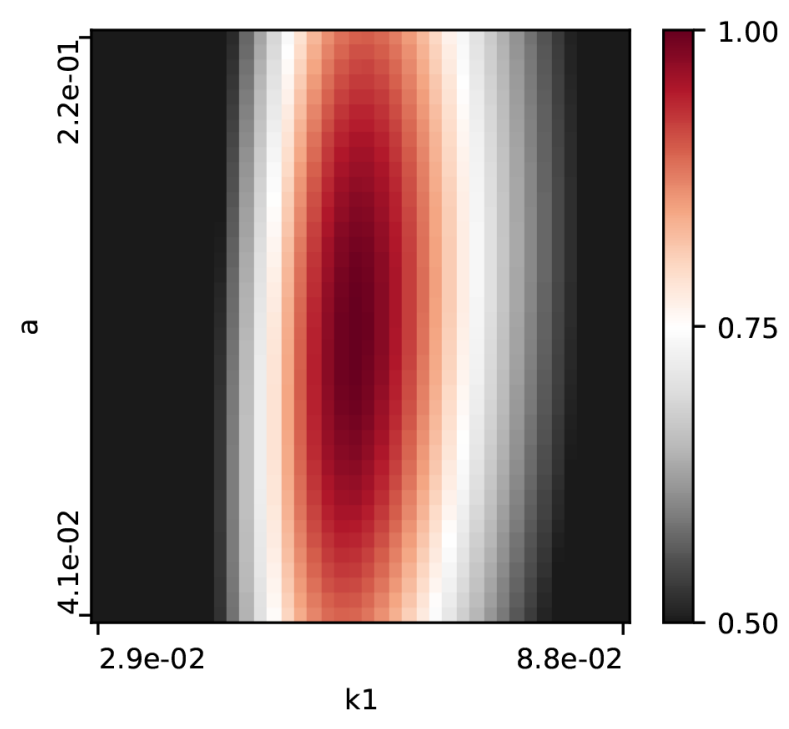

Figure S24. Heat map of the response of the regression error function to variation of $\alpha$ and $k_{1}$ for the DPAc3/DP-An3 system. The inverse error function is plotted, normalized against the value for the optimized system. 


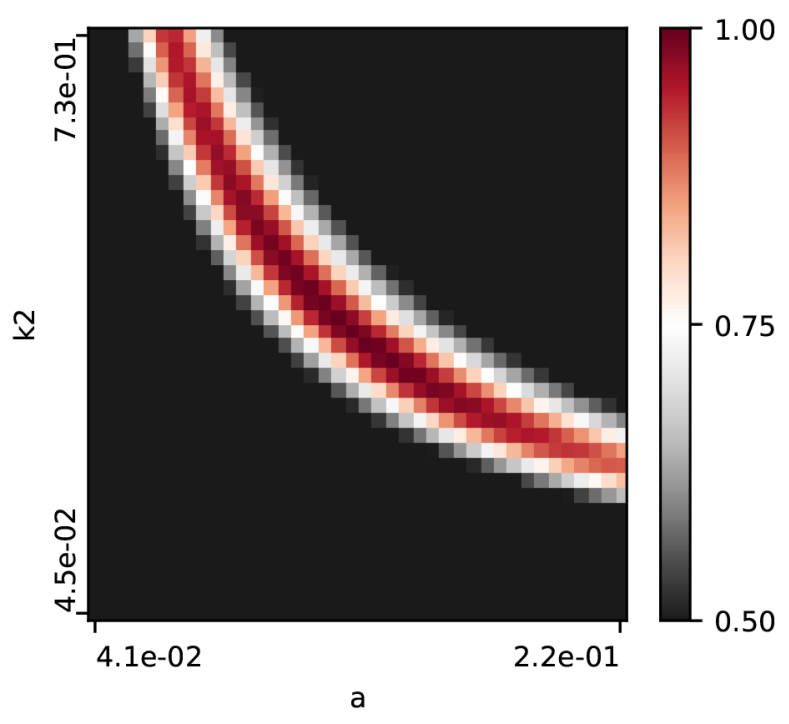

Figure S25. Heat map of the response of the regression error function to variation of $k_{2}$ and $\alpha$ for the DPAc3/DP-An3 system. The inverse error function is plotted, normalized against the value for the optimized system.

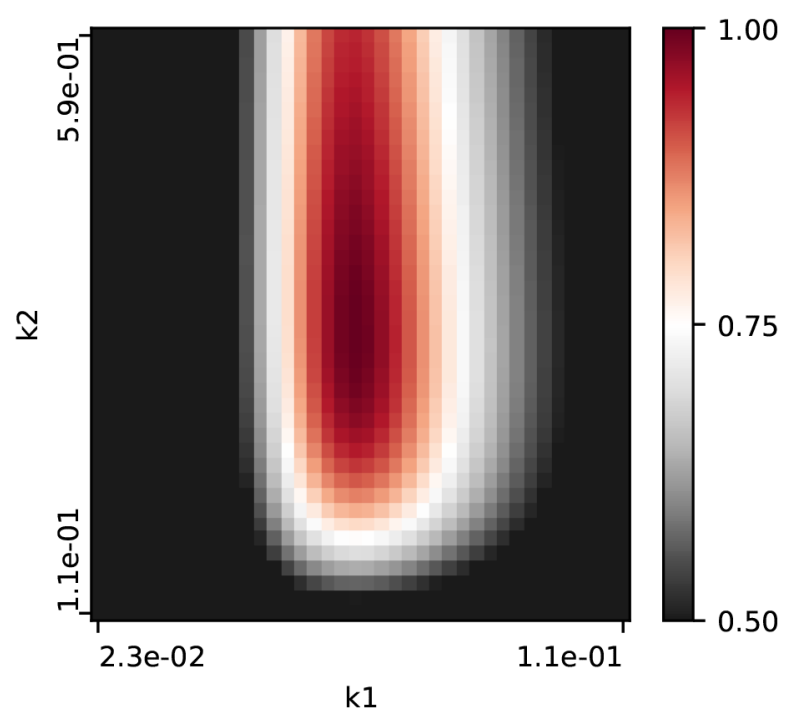

Figure S26. Heat map of the response of the regression error function to variation of $k_{2}$ and $k_{1}$ for the DPAc4/DP-An4 system. The inverse error function is plotted, normalized against the value for the optimized system. 


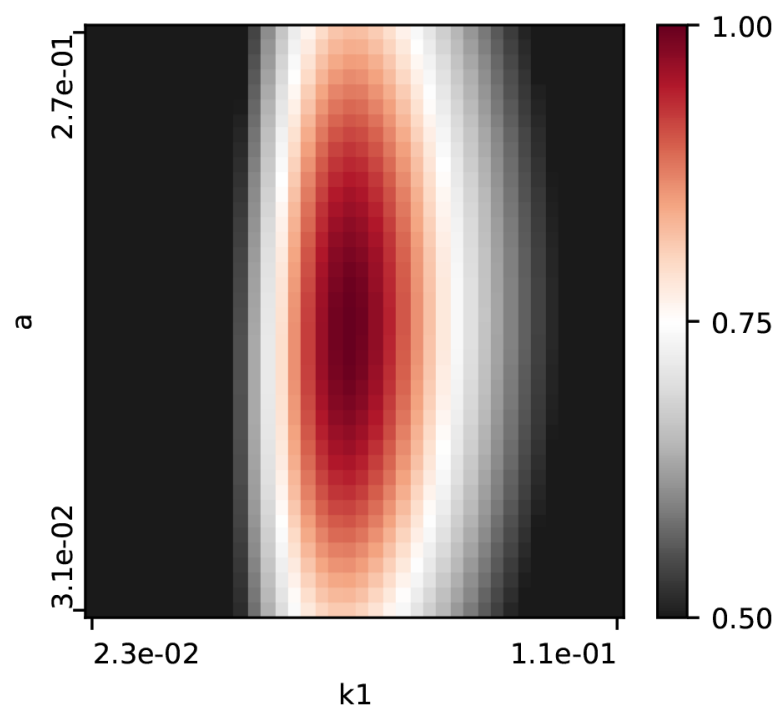

Figure S27. Heat map of the response of the regression error function to variation of $\alpha$ and $k_{1}$ for the DPAc4/DP-An4 system. The inverse error function is plotted, normalized against the value for the optimized system.

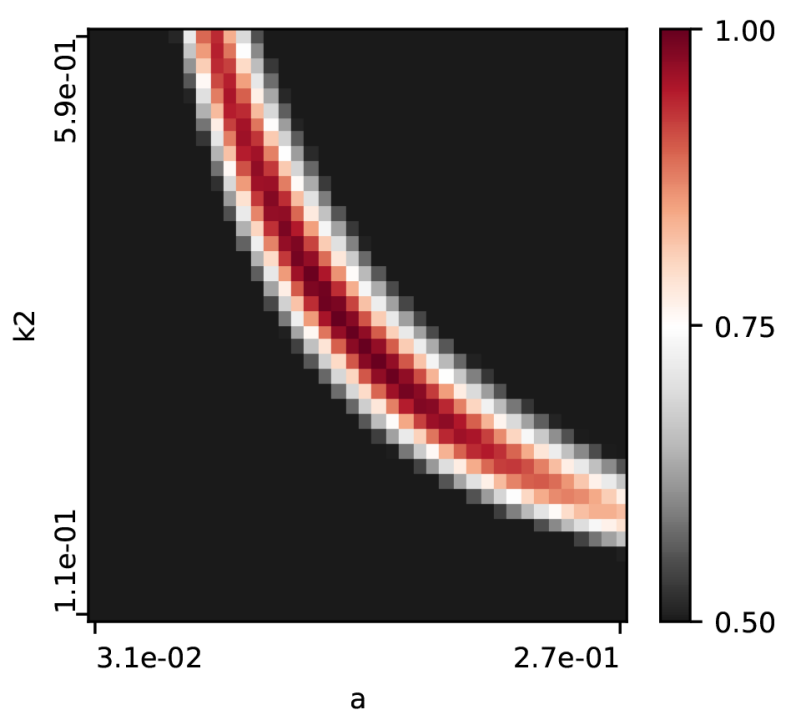

Figure S28. Heat map of the response of the regression error function to variation of $k_{2}$ and $\alpha$ for the DPAc4/DP-An4 system. The inverse error function is plotted, normalized against the value for the optimized system. 


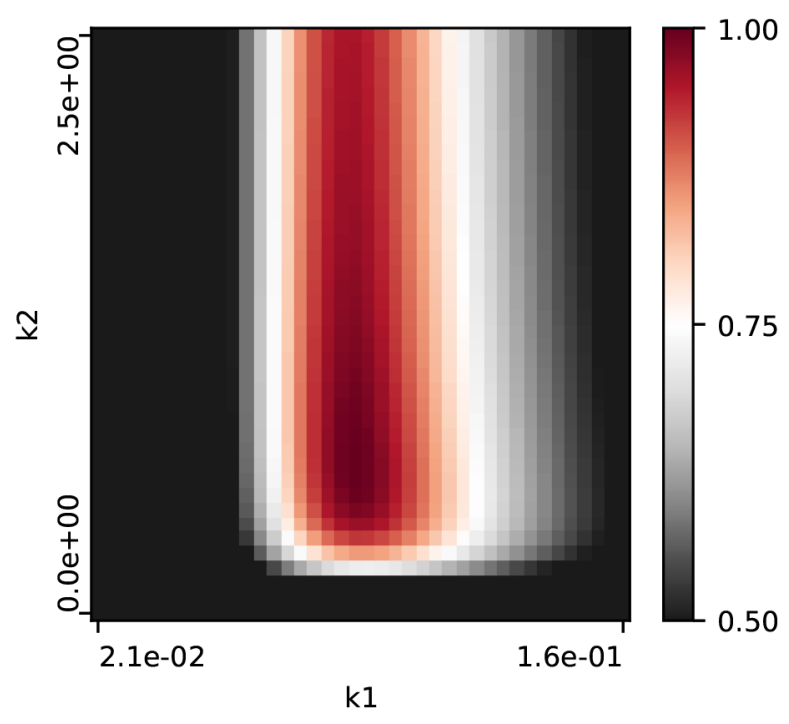

Figure S29. Heat map of the response of the regression error function to variation of $k_{2}$ and $k_{1}$ for the DPAc5/DP-An5 system. The inverse error function is plotted, normalized against the value for the optimized system.

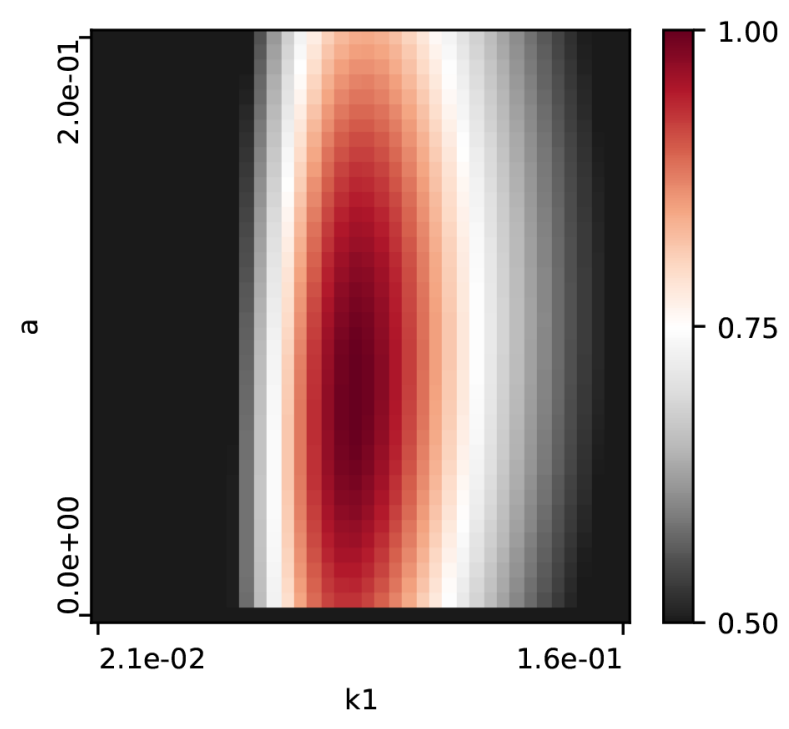

Figure S30. Heat map of the response of the regression error function to variation of $\alpha$ and $k_{1}$ for the DPAc5/DP-An5 system. The inverse error function is plotted, normalized against the value for the optimized system. 


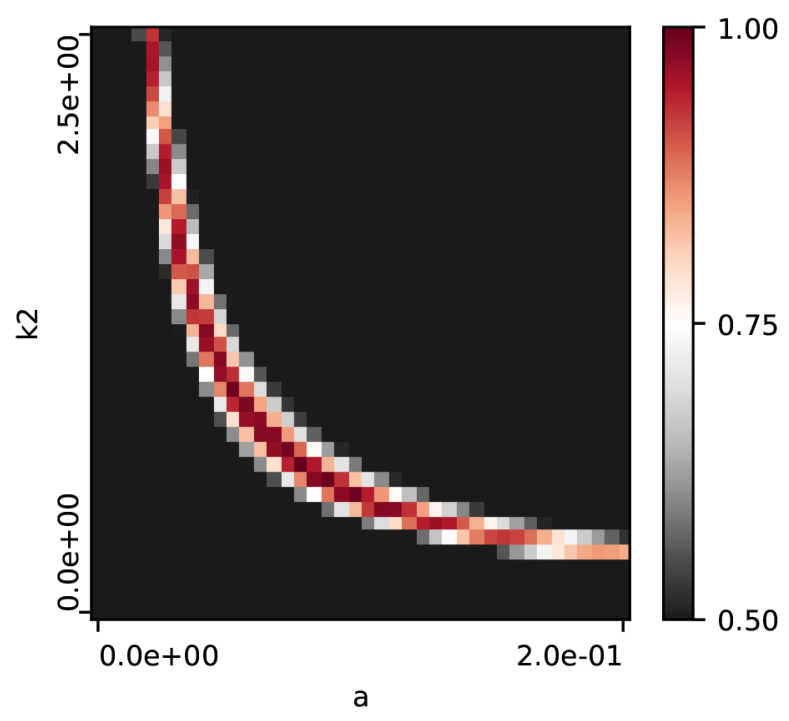

Figure S31. Heat map of the response of the regression error function to variation of $k_{2}$ and $\alpha$ for the DPAc5/DP-An5 system. The inverse error function is plotted, normalized against the value for the optimized system.

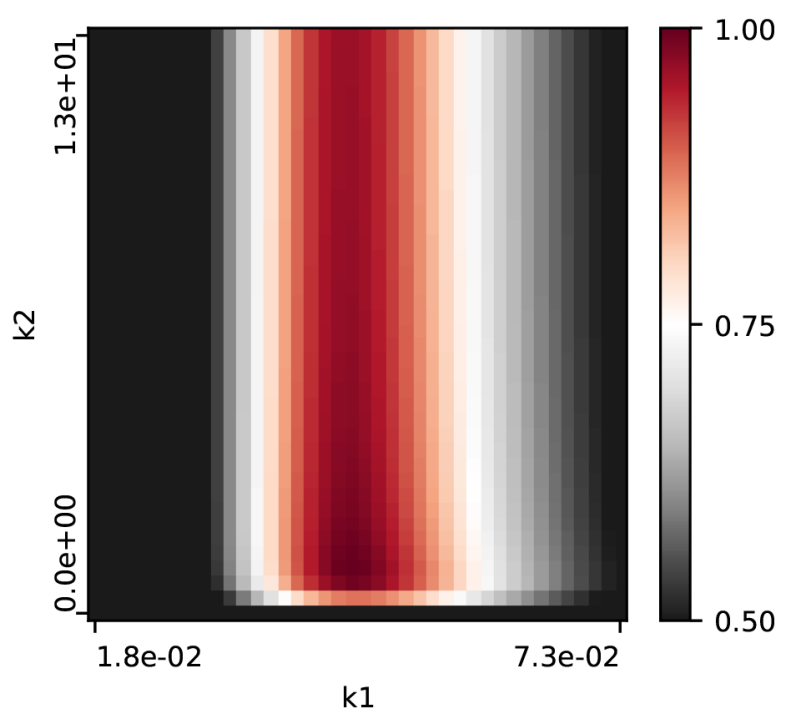

Figure S32. Heat map of the response of the regression error function to variation of $k_{2}$ and $k_{1}$ for the DPAc6/DP-An6 system. The inverse error function is plotted, normalized against the value for the optimized system. 


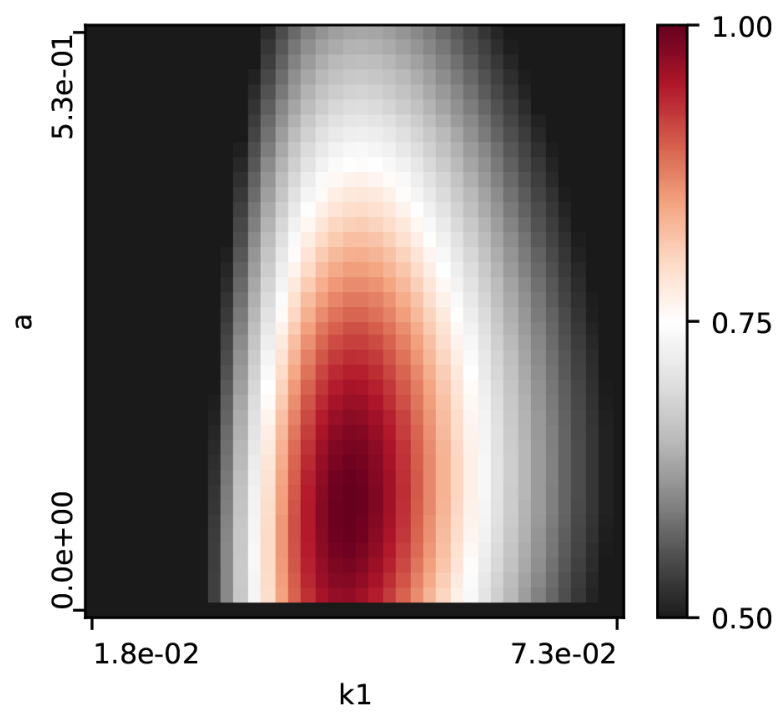

Figure S33. Heat map of the response of the regression error function to variation of $\alpha$ and $k_{1}$ for the DPAc6/DP-An6 system. The inverse error function is plotted, normalized against the value for the optimized system.

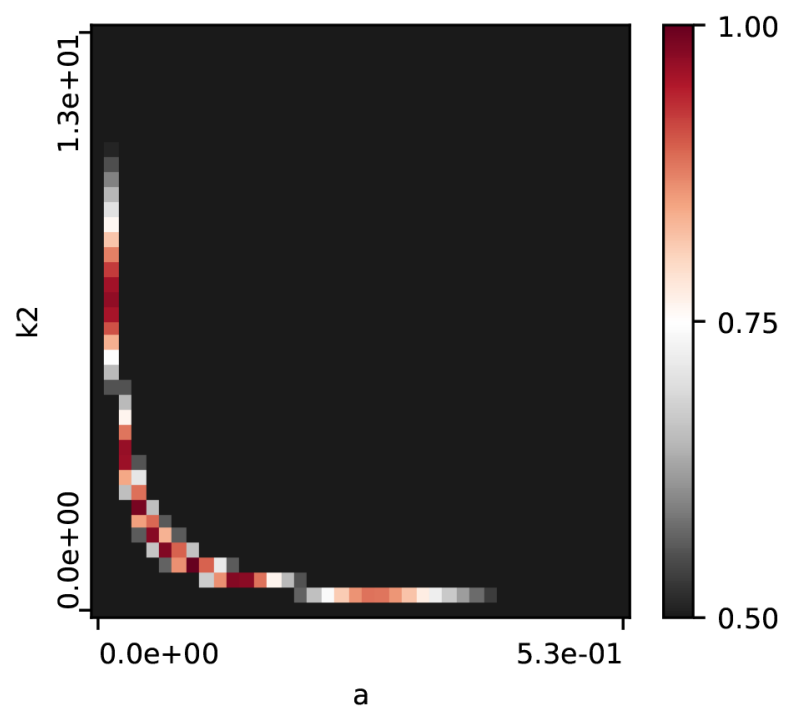

Figure S34. Heat map of the response of the regression error function to variation of $k_{2}$ and $\alpha$ for the DPAc6/DP-An6 system. The inverse error function is plotted, normalized against the value for the optimized system. 


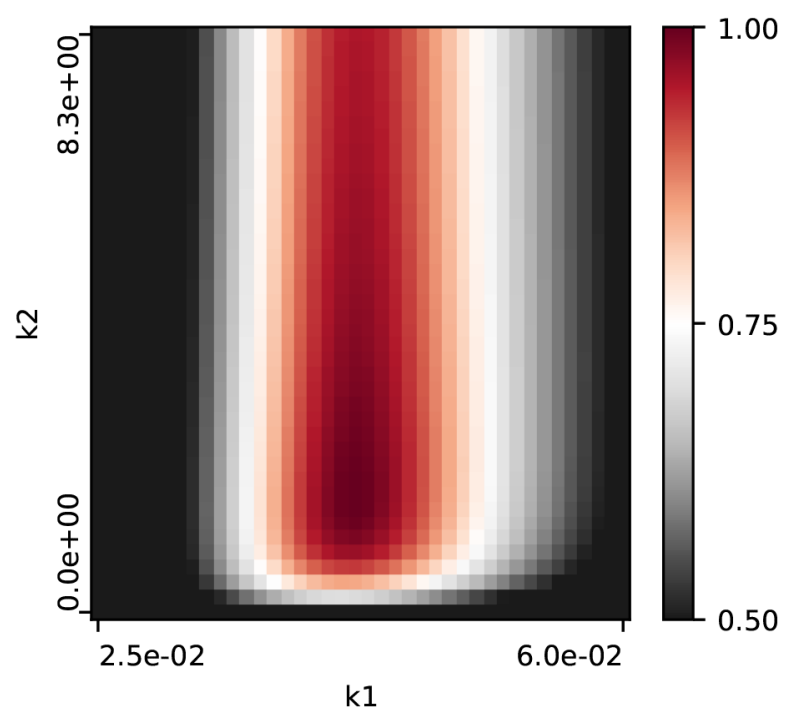

Figure S35. Heat map of the response of the regression error function to variation of $k_{2}$ and $k_{1}$ for the DPAc7/DP-An7 system. The inverse error function is plotted, normalized against the value for the optimized system.

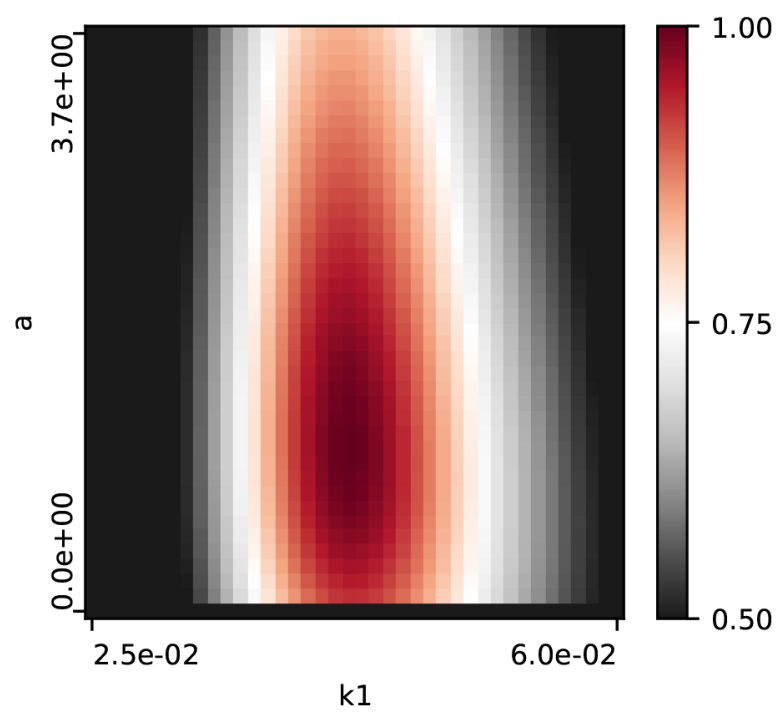

Figure S36. Heat map of the response of the regression error function to variation of $\alpha$ and $k_{1}$ for the DPAc7/DP-An7 system. The inverse error function is plotted, normalized against the value for the optimized system. 


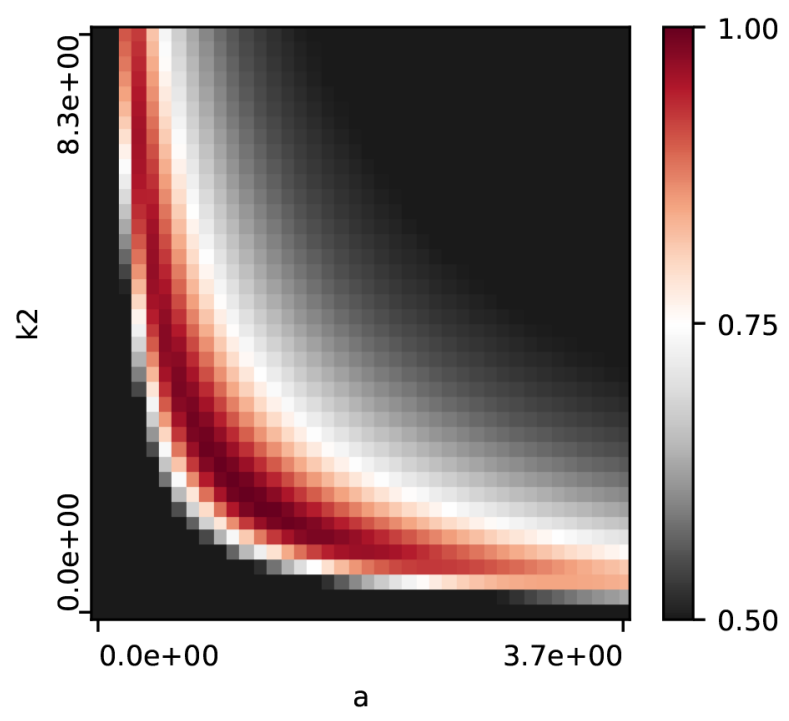

Figure S37. Heat map of the response of the regression error function to variation of $k_{2}$ and $\alpha$ for the DPAc7/DP-An7 system. The inverse error function is plotted, normalized against the value for the optimized system.

\section{Statistical Analysis}

Table S2. Multiple regression analysis for the dependence of $\log k_{1}$ on $\varphi_{\text {acid }}$ and $\sigma_{m}$

\begin{tabular}{|cccc|}
\hline Compound & $\sigma_{\mathrm{m}}$ & $\varphi_{\text {acid }}$ & $\log \mathrm{k}_{1}$ \\
\hline DP-Ac4 & -0.069 & 88.5 & -1.18 \\
DP-Ac3 & -0.07 & 90.9 & -1.24 \\
DP-Ac1 & 0 & 81.8 & -1.01 \\
DP-Ac6 & 0.06 & 69.8 & -1.35 \\
DP-Ac5 & 0.115 & 90.5 & -1.05 \\
DP-Ac2 & 0.21 & 90.7 & -1.03 \\
DP-Ac7 & 0.56 & 89.3 & -1.38 \\
\hline
\end{tabular}

\begin{tabular}{|lr|}
\hline \multicolumn{2}{|c|}{ Regression Statistics } \\
\hline Multiple R & 0.5679 \\
R Square & 0.3225 \\
Adjusted R Square & -0.0162 \\
Standard Error & 0.1543 \\
Observations & 7 \\
\hline
\end{tabular}

\begin{tabular}{|lcc|}
\hline & Coefficients & Standard Error \\
\hline Intercept & -1.86 & 0.66 \\
$\sigma_{\mathrm{m}}$ & -0.30 & 0.29 \\
$\varphi_{\text {acid }}$ & 0.0082 & 0.0076 \\
\hline
\end{tabular}


Table S3. Multiple regression analysis for the dependence of $\log k_{2}$ on $\varphi_{a c i d}$ and $\sigma_{m}$

\begin{tabular}{|cccc|}
\hline Compound & $\sigma_{\mathrm{m}}$ & $\varphi_{\text {acid }}$ & $\log \mathrm{k}_{2}$ \\
\hline DP-Ac4 & -0.069 & 88.5 & -0.46 \\
DP-Ac3 & -0.07 & 90.9 & -0.42 \\
DP-Ac1 & 0 & 81.8 & 0.02 \\
DP-Ac6 & 0.06 & 69.8 & 0.01 \\
DP-Ac5 & 0.115 & 90.5 & -0.20 \\
DP-Ac2 & 0.21 & 90.7 & 0.03 \\
DP-Ac7 & 0.56 & 89.3 & 0.23 \\
\hline
\end{tabular}

\begin{tabular}{|lr|}
\hline \multicolumn{2}{|c|}{ Regression Statistics } \\
\hline Multiple R & 0.8997 \\
R Square & 0.8095 \\
Adjusted R Square & 0.7143 \\
Standard Error & 0.1378 \\
Observations & 7 \\
\hline
\end{tabular}

\begin{tabular}{|lcc|}
\hline & Coefficients & Standard Error \\
\hline Intercept & 0.98 & 0.59 \\
$\sigma_{\mathrm{m}}$ & 1.00 & 0.26 \\
$\varphi_{\text {acid }}$ & -0.014 & 0.007 \\
\hline
\end{tabular}

Table S4. Multiple regression analysis for the dependence of $\log \alpha$ on $\varphi_{a c i d}$ and $\sigma_{m}$

\begin{tabular}{|c|c|c|c|c|}
\hline Compound & $\sigma_{m}$ & $\varphi_{a}$ & & $\log \alpha$ \\
\hline DP-Ac4 & -0.069 & 88 & & -0.84 \\
\hline DP-Ac3 & -0.07 & 90 & & -0.89 \\
\hline DP-Ac1 & 0 & 81 & & -1.05 \\
\hline DP-Ac6 & 0.06 & 69 & & -1.02 \\
\hline DP-Ac5 & 0.115 & 90 & & -1.12 \\
\hline DP-Ac2 & 0.21 & 90 & & -0.68 \\
\hline DP-Ac7 & 0.56 & 89 & & 0.02 \\
\hline \multicolumn{4}{|c|}{ Regression Statistics } & \\
\hline \multicolumn{2}{|l|}{ Multiple R } & & 0.8604 & \\
\hline \multicolumn{2}{|l|}{ R Square } & & 0.7402 & \\
\hline \multicolumn{2}{|c|}{ Adjusted R Square } & & 0.6104 & \\
\hline \multicolumn{2}{|c|}{ Standard Error } & & 0.2435 & \\
\hline \multicolumn{2}{|l|}{ Observations } & & 7 & \\
\hline & \multicolumn{2}{|c|}{ Coefficients } & \multicolumn{2}{|c|}{ Standard Error } \\
\hline Intercept & \multicolumn{2}{|c|}{-1.29} & \multicolumn{2}{|c|}{1.04} \\
\hline$\sigma_{m}$ & \multicolumn{2}{|c|}{1.49} & \multicolumn{2}{|c|}{0.46} \\
\hline$\varphi_{\text {acid }}$ & \multicolumn{2}{|c|}{0.004} & \multicolumn{2}{|c|}{0.012} \\
\hline
\end{tabular}


Table S5. Multiple regression analysis for the dependence of $\log k_{1}$ on $\varphi_{a n h y d r i d e}$ and $\sigma_{m}$

\begin{tabular}{|cccc|}
\hline Compound & $\sigma_{\mathrm{m}}$ & $\varphi_{\text {anhydride }}$ & $\log \mathrm{k}_{1}$ \\
\hline DP-Ac4 & -0.069 & 46.5 & -1.18 \\
DP-Ac3 & -0.07 & 49.9 & -1.24 \\
DP-Ac1 & 0 & 36.8 & -1.01 \\
DP-Ac6 & 0.06 & 43.7 & -1.35 \\
DP-Ac5 & 0.115 & 44.3 & -1.05 \\
DP-Ac2 & 0.21 & 43.7 & -1.03 \\
DP-Ac7 & 0.56 & 42.5 & -1.38 \\
\hline
\end{tabular}

\begin{tabular}{|c|c|c|}
\hline \multicolumn{2}{|c|}{ Regression Statistics } & \\
\hline \multicolumn{2}{|l|}{ Multiple R } & 0.5809 \\
\hline \multicolumn{2}{|l|}{ R Square } & 0.3374 \\
\hline \multicolumn{2}{|c|}{ Adjusted R Square } & 0.0061 \\
\hline \multicolumn{2}{|c|}{ Standard Error } & 0.1526 \\
\hline \multicolumn{2}{|c|}{ Observations } & 7 \\
\hline & Coefficients & Standard Error \\
\hline Intercept & -0.33 & 0.72 \\
\hline$\sigma_{m}$ & -0.33 & 0.29 \\
\hline$\varphi_{\text {anhydride }}$ & -0.018 & 0.016 \\
\hline
\end{tabular}

Table S6. Multiple regression analysis for the dependence of $\log k_{2}$ on $\varphi_{\text {anhydride }}$ and $\sigma_{m}$

\begin{tabular}{|cccc|}
\hline Compound & $\sigma_{\mathrm{m}}$ & $\varphi_{\text {anhydride }}$ & $\log \mathrm{k}_{2}$ \\
\hline DP-Ac4 & -0.069 & 46.5 & -0.46 \\
DP-Ac3 & -0.07 & 49.9 & -0.42 \\
DP-Ac1 & 0 & 36.8 & 0.02 \\
DP-Ac6 & 0.06 & 43.7 & 0.01 \\
DP-Ac5 & 0.115 & 44.3 & -0.20 \\
DP-Ac2 & 0.21 & 43.7 & 0.03 \\
DP-Ac7 & 0.56 & 42.5 & 0.23 \\
\hline
\end{tabular}

\begin{tabular}{|lr|}
\hline \multicolumn{2}{|c|}{ Regression Statistics } \\
\hline Multiple R & 0.9464 \\
R Square & 0.8957 \\
Adjusted R Square & 0.8436 \\
Standard Error & 0.1875 \\
Observations & 7 \\
\hline
\end{tabular}

\begin{tabular}{|lcc|}
\hline & Coefficients & Standard Error \\
\hline Intercept & -0.55 & 0.89 \\
$\sigma_{\mathrm{m}}$ & 1.94 & 0.36 \\
$\varphi_{\text {anhydride }}$ & -0.015 & 0.020 \\
\hline
\end{tabular}


Table S7. Multiple regression analysis for the dependence of $\log \alpha$ on $\varphi_{\text {anhydride }}$ and $\sigma_{m}$

\begin{tabular}{|cccc|}
\hline Compound & $\sigma_{\mathrm{m}}$ & $\varphi_{\text {anhydride }}$ & $\log \alpha$ \\
\hline DP-Ac4 & -0.069 & 46.5 & -0.84 \\
DP-Ac3 & -0.07 & 49.9 & -0.89 \\
DP-Ac1 & 0 & 36.8 & -1.05 \\
DP-Ac6 & 0.06 & 43.7 & -1.02 \\
DP-Ac5 & 0.115 & 44.3 & -1.12 \\
DP-Ac2 & 0.21 & 43.7 & -0.68 \\
DP-Ac7 & 0.56 & 42.5 & 0.02 \\
\hline
\end{tabular}

\begin{tabular}{|lr|}
\hline \multicolumn{2}{|c|}{ Regression Statistics } \\
\hline Multiple R & 0.8845 \\
R Square & 0.7823 \\
Adjusted R Square & 0.6734 \\
Standard Error & 0.2229 \\
Observations & 7 \\
\hline
\end{tabular}

\begin{tabular}{|lcc|}
\hline & Coefficients & Standard Error \\
\hline Intercept & -1.96 & 1.06 \\
$\sigma_{\mathrm{m}}$ & 1.62 & 0.43 \\
$\varphi_{\text {anhydride }}$ & 0.022 & 0.024 \\
\hline
\end{tabular}

Table S8. Multiple regression analysis for the dependence of $\log k_{1}$ on $\mathrm{E}_{\mathrm{s}}$ (Taft) and $\sigma_{m}$

\begin{tabular}{|cccc|}
\hline Compound & $\sigma_{m}$ & $\mathrm{E}_{\mathrm{s}}$ (Taft) & $\log \mathrm{k}_{1}$ \\
\hline DP-Ac4 & -0.069 & 0 & -1.18 \\
DP-Ac3 & -0.07 & 0.07 & -1.24 \\
DP-Ac1 & 0 & -1.24 & -1.01 \\
DP-Ac6 & 0.06 & 2.54 & -1.35 \\
DP-Ac5 & 0.115 & -0.69 & -1.05 \\
DP-Ac7 & 0.56 & -0.73 & -1.38 \\
\hline
\end{tabular}

\begin{tabular}{|lr|}
\hline \multicolumn{2}{|c|}{ Regression Statistics } \\
\hline Multiple R & 0.8580 \\
R Square & 0.7361 \\
Adjusted R Square & 0.5602 \\
Standard Error & 0.1005 \\
Observations & 6 \\
\hline
\end{tabular}

\begin{tabular}{|lcc|}
\hline & Coefficients & Standard Error \\
\hline Intercept & -1.16 & 0.05 \\
$\sigma_{m}$ & -0.41 & 0.19 \\
$E_{s}$ (Taft) & -0.081 & 0.034 \\
\hline
\end{tabular}


Table S9. Multiple regression analysis for the dependence of $\log k_{2}$ on $\mathrm{E}_{\mathrm{s}}(\mathrm{Taft})$ and $\sigma_{m}$

\begin{tabular}{|cccc|}
\hline Compound & $\sigma_{\mathrm{m}}$ & $\mathrm{E}_{\mathrm{s}}$ (Taft) & $\log \mathrm{k}_{2}$ \\
\hline DP-Ac4 & -0.069 & 0 & -0.46 \\
DP-Ac3 & -0.07 & 0.07 & -0.42 \\
DP-Ac1 & 0 & -1.24 & 0.02 \\
DP-Ac6 & 0.06 & 2.54 & 0.01 \\
DP-Ac5 & 0.115 & -0.69 & -0.20 \\
DP-Ac7 & 0.56 & -0.73 & 0.23 \\
\hline
\end{tabular}

\begin{tabular}{|lr|}
\hline \multicolumn{2}{|c|}{ Regression Statistics } \\
\hline Multiple R & 0.9379 \\
R Square & 0.8796 \\
Adjusted R Square & 0.7994 \\
Standard Error & 0.2256 \\
Observations & 6 \\
\hline
\end{tabular}

\begin{tabular}{|lcc|}
\hline & Coefficients & Standard Error \\
\hline Intercept & -1.24 & 0.10 \\
$\sigma_{m}$ & 2.01 & 0.44 \\
$E_{s}($ Taft $)$ & 0.018 & 0.077 \\
\hline
\end{tabular}

Table S10. Multiple regression analysis for the dependence of $\log \alpha$ on $\mathrm{E}_{\mathrm{s}}$ (Taft) and $\sigma_{m}$

\begin{tabular}{|cccc|}
\hline Compound & $\sigma_{\mathrm{m}}$ & $\mathrm{E}_{\mathrm{s}}($ Taft $)$ & $\log \alpha$ \\
\hline DP-Ac4 & -0.069 & 0 & -0.84 \\
DP-Ac3 & -0.07 & 0.07 & -0.89 \\
DP-Ac1 & 0 & -1.24 & -1.05 \\
DP-Ac6 & 0.06 & 2.54 & -1.02 \\
DP-Ac5 & 0.115 & -0.69 & -1.12 \\
DP-Ac7 & 0.56 & -0.73 & 0.02 \\
\hline
\end{tabular}

\begin{tabular}{|lr|}
\hline \multicolumn{2}{|c|}{ Regression Statistics } \\
\hline Multiple R & 0.8560 \\
R Square & 0.7328 \\
Adjusted R Square & 0.7328 \\
Standard Error & 0.2827 \\
Observations & 6 \\
\hline
\end{tabular}

\begin{tabular}{|lcc|}
\hline & Coefficients & Standard Error \\
\hline Intercept & -0.97 & 0.13 \\
$\sigma_{m}$ & 1.51 & 0.55 \\
$E_{s}$ (Taft) & -0.015 & 0.096 \\
\hline
\end{tabular}

Overall, the coefficients associated with measures of steric strain $\left(\varphi_{\text {acid }}, \varphi_{\text {acid }}\right.$, and $\left.\mathrm{E}_{\mathrm{s}}(\mathrm{Taft})\right)$ are indistinguishable from 0 . The regression statistics were also calculated by comparing the steric or electronic parameters 
individually with the kinetic parameters. We tried all possibilities and concluded that kinetics are not affected by the sterics but affected only by electronics.
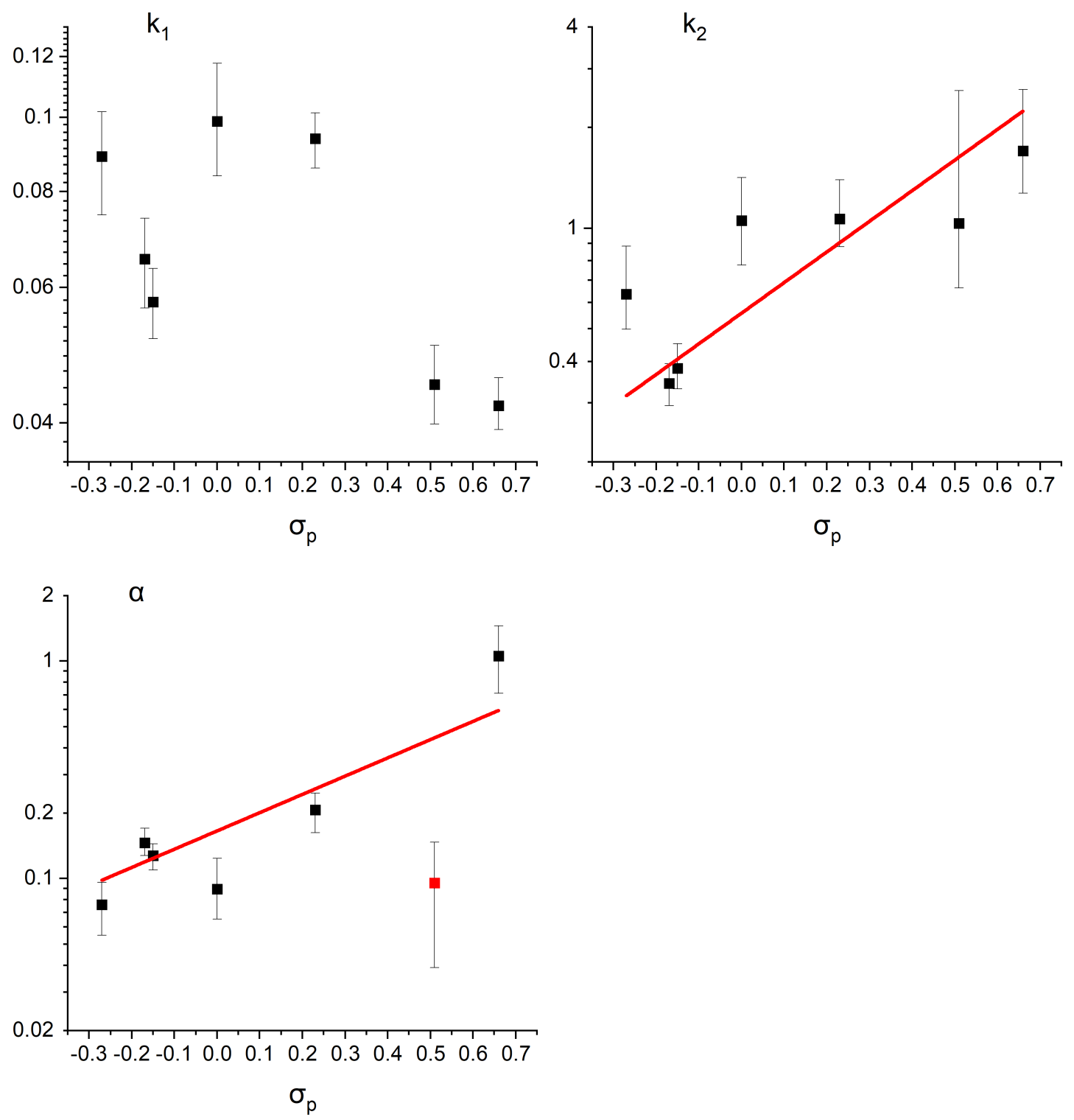

Figure S38. Dependence of kinetic parameters on $\sigma_{\mathrm{p}}$. The uncertainties are $95 \%$ confidence intervals based on the global fit to multiple data sets.

As shown in Figure S37, using $\sigma_{p}$ instead of $\sigma_{m}$ (because the substituents are formally conjugated with the carbonyl on the adjacent ring) does not improve the fits. 


\section{NMR spectra of synthesized compounds}

${ }^{13} \mathrm{H}$ NMR (500 MHz, DMSO- $\left.d_{6}\right)$

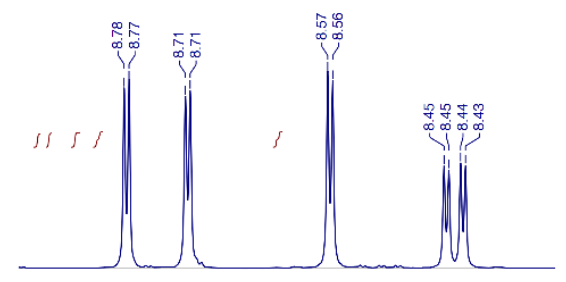<smiles>COc1cc(-c2c(OC)cc([N+](=O)[O-])cc2OC(C)(C)C(C)(C)C)cc([N+](=O)[O-])c1</smiles>

$\begin{array}{lllllllllllllll}8.85 & 8.80 & 8.75 & 8.70 & 8.65 & 8.60 & 8.55 & 8.50 & 8.45 & 8.40 & 8.35\end{array}$
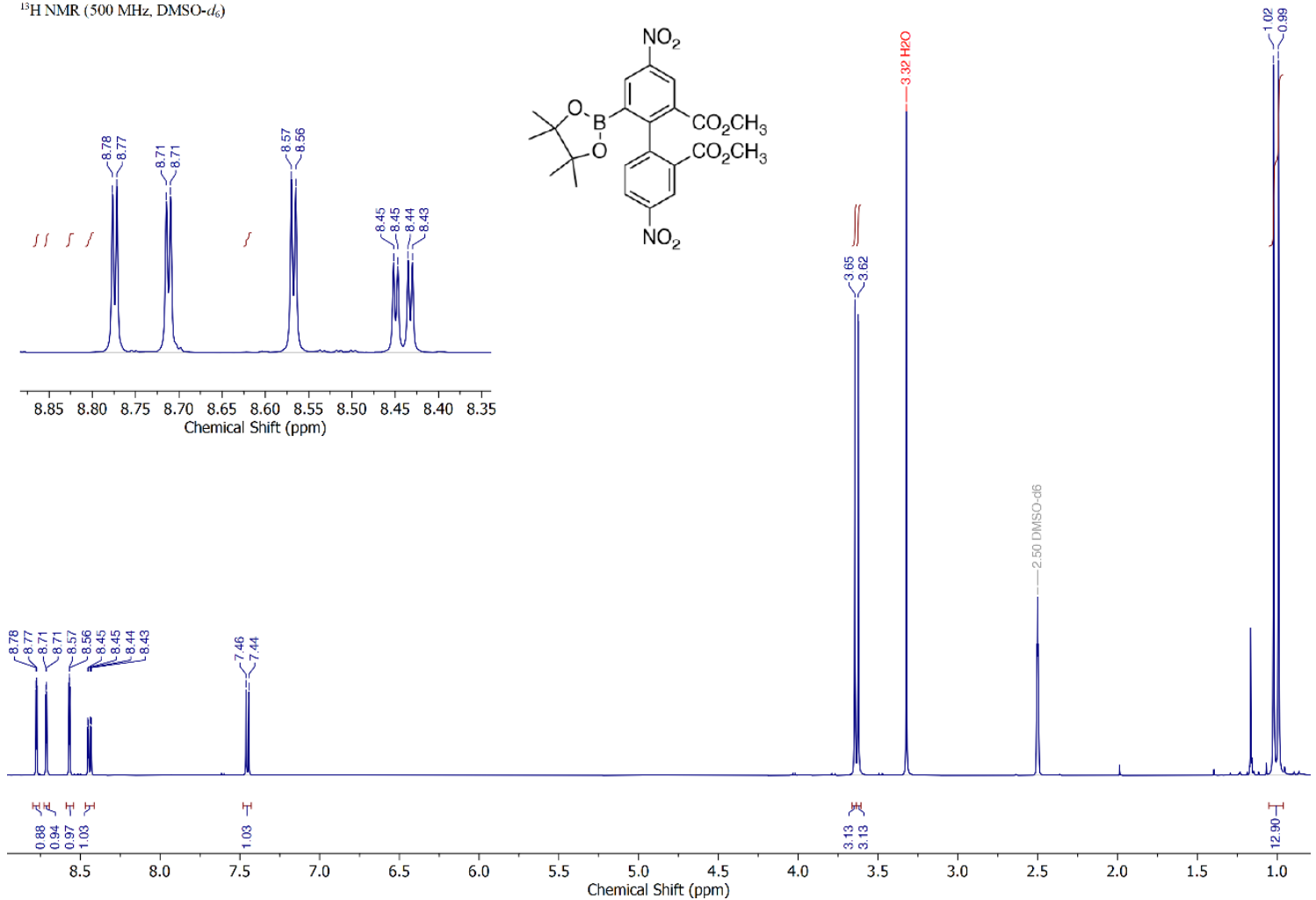

Figure S39. ${ }^{1} \mathrm{H}$ NMR spectrum $\left(500 \mathrm{MHz}, \mathrm{DMSO}-d_{6}\right)$ of dimethyl [1,1'-biphenyl]-6-(4,4,5,5-tetramethyl1,3,2-dioxaborolan-2-yl)-4,4'-dinitro-2,2'-dicarboxylate (3).

${ }^{15} \mathrm{C} \mathrm{NMR}\left(126 \mathrm{MHz}, \mathrm{DMSO}-d_{i}\right)$<smiles>COc1cc(-c2c(OC)cc([N+](=O)[O-])cc2OP(=O)(OC(C)(C)C)C(C)(C)C)cc([N+](=O)[O-])c1</smiles>

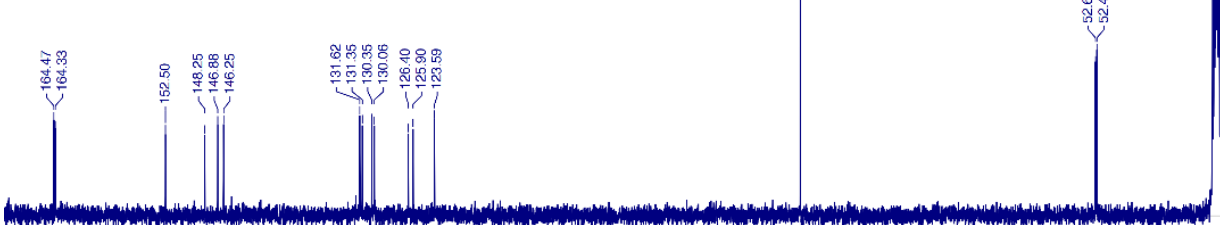

$\begin{array}{lllllllllllllllllllllllllllllll}165 & 160 & 155 & 150 & 145 & 140 & 135 & 130 & 125 & 120 & 115 & 110 & 105 & 100 & 95 & 90 & 85 & 80 & 75 & 70 & 65 & 60 & 55 & 50 & 45 & 40 & 35 & 30 & 25 & 20 \\ \text { Chemical Shift (ppm) }\end{array}$

Figure S40. ${ }^{13} \mathrm{C}\left\{{ }^{1} \mathrm{H}\right\}$ NMR spectrum (126 MHz, DMSO- $\left.d_{6}\right)$ of dimethyl [1,1'-biphenyl]-6-(4,4,5,5tetramethyl-1,3,2-dioxaborolan-2-yl)-4,4'-dinitro-2,2'-dicarboxylate (3). 

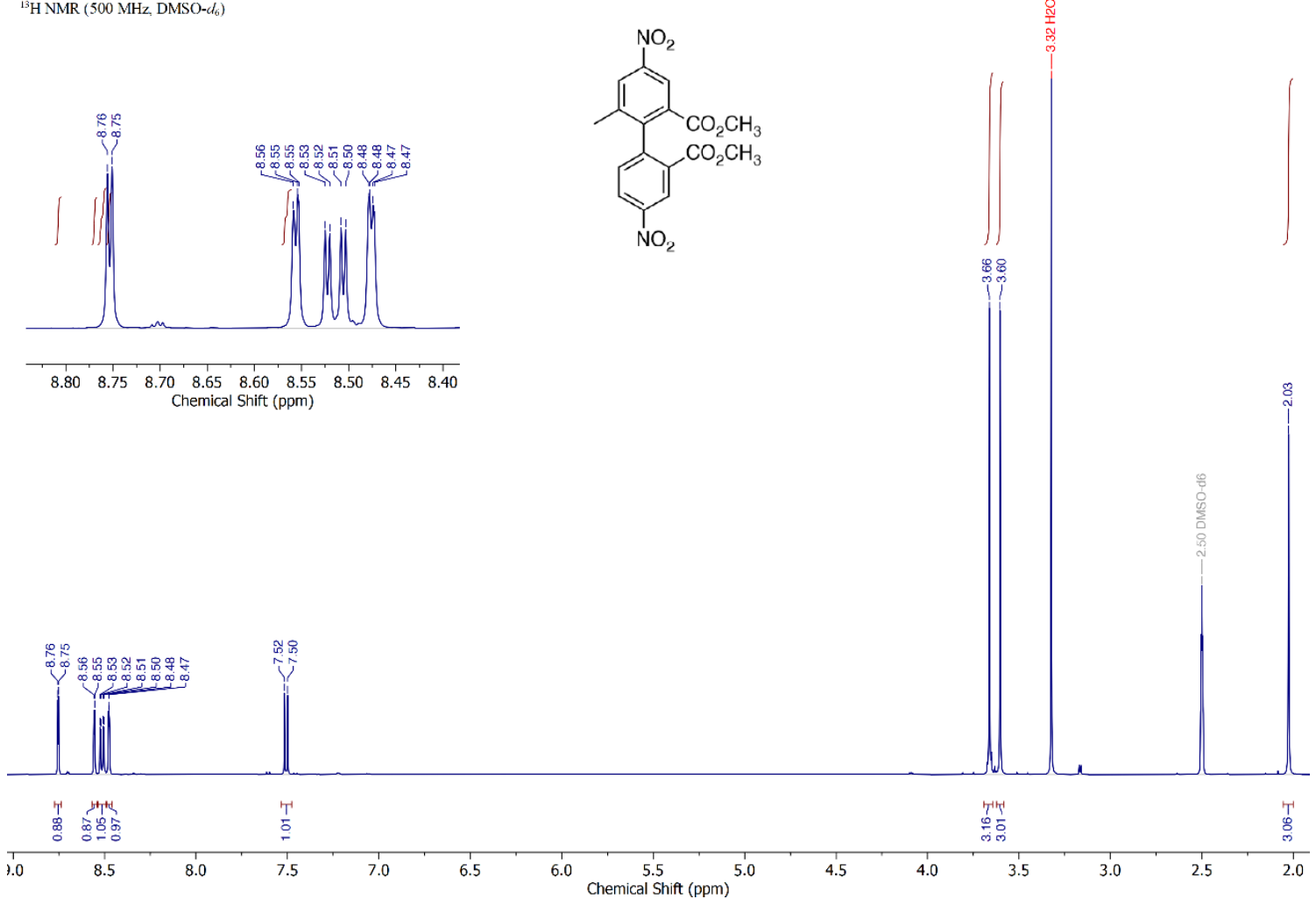

Figure S41. ${ }^{1} \mathrm{H}$ NMR spectrum (500 MHz, DMSO- $\left.d_{6}\right)$ of dimethyl [1,1'-biphenyl]-6-methyl-4,4'-dinitro-2,2'dicarboxylate (4).

${ }^{1 *} \mathrm{C}$ NMR (126 MLl\%, DMSO- $\left.d_{6}\right)$<smiles>COc1cc(-c2ccc([N+](=O)[O-])cc2OC)cc([N+](=O)[O-])c1</smiles>

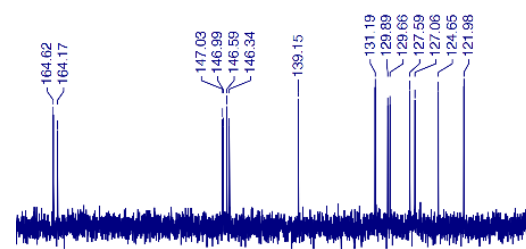

$\begin{array}{lllllllllllllllllllllllllllllllllll}165 & 160 & 155 & 150 & 145 & 140 & 135 & 130 & 125 & 120 & 115 & 110 & 105 & 100 & 95 & 90 & 85 & 80 & 75 & 70 & 65 & 60 & 55 & 50 & 45 & 40 & 35 & 30 & 25 & 20\end{array}$

Figure S42. ${ }^{13} \mathrm{C}\left\{{ }^{1} \mathrm{H}\right\}$ NMR spectrum (126 MHz, DMSO- $\left.d_{6}\right)$ of dimethyl [1,1'-biphenyl]-6-methyl-4,4'-dinitro2,2'-dicarboxylate (4). 
'II NMR (500 MIL, DMSO-d $d_{6}$ )
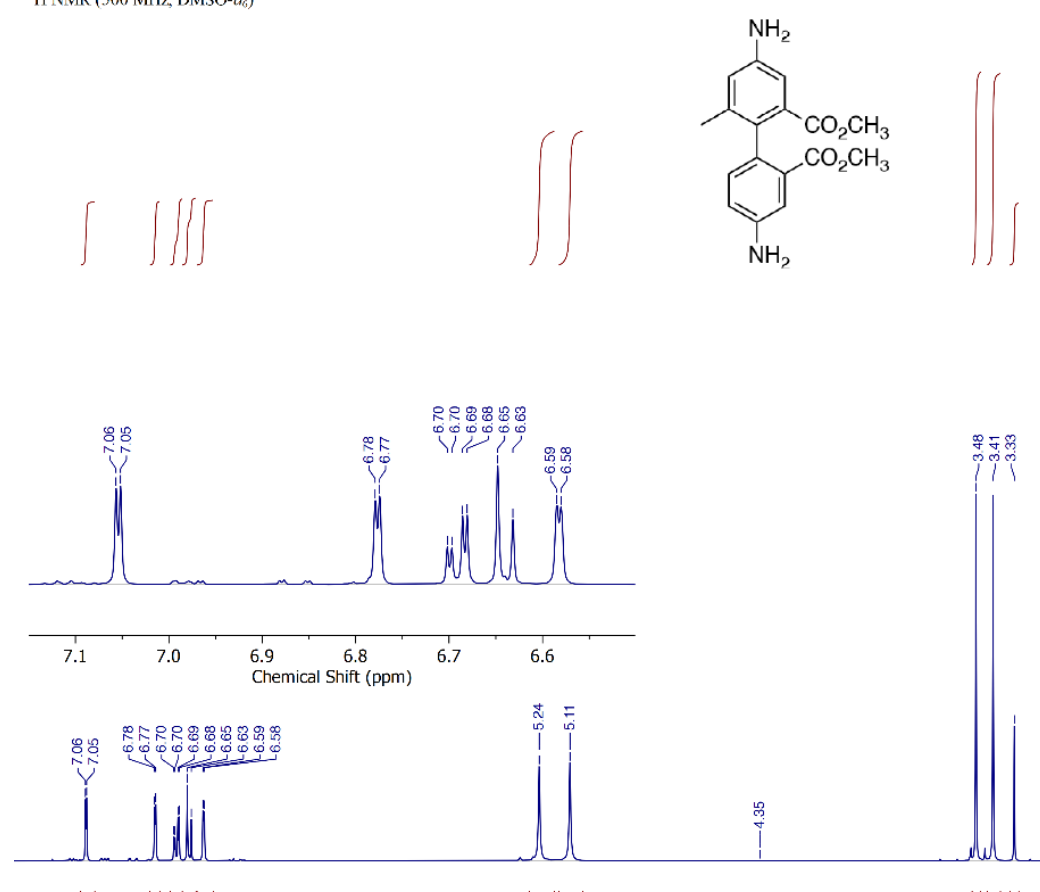

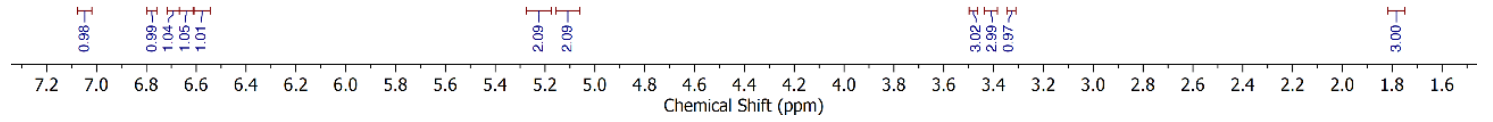

Figure S43. ${ }^{1} \mathrm{H}$ NMR spectrum (500 MHz, DMSO- $d_{6}$ ) of dimethyl [1,1'-biphenyl]-4,4'-diamino-6-methyl2,2'-dicarboxylate (5).

${ }^{13} \mathrm{C}$ NMR (126 MHz, DMSO-d $)$<smiles>CC(=O)c1cc(N)cc(C(C)=O)c1C(C)=O</smiles>

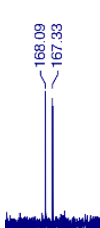
(1)

(25) 
${ }^{1} \mathrm{H}$ NMR (500 MHz, DMSO-d $d_{6}$ )

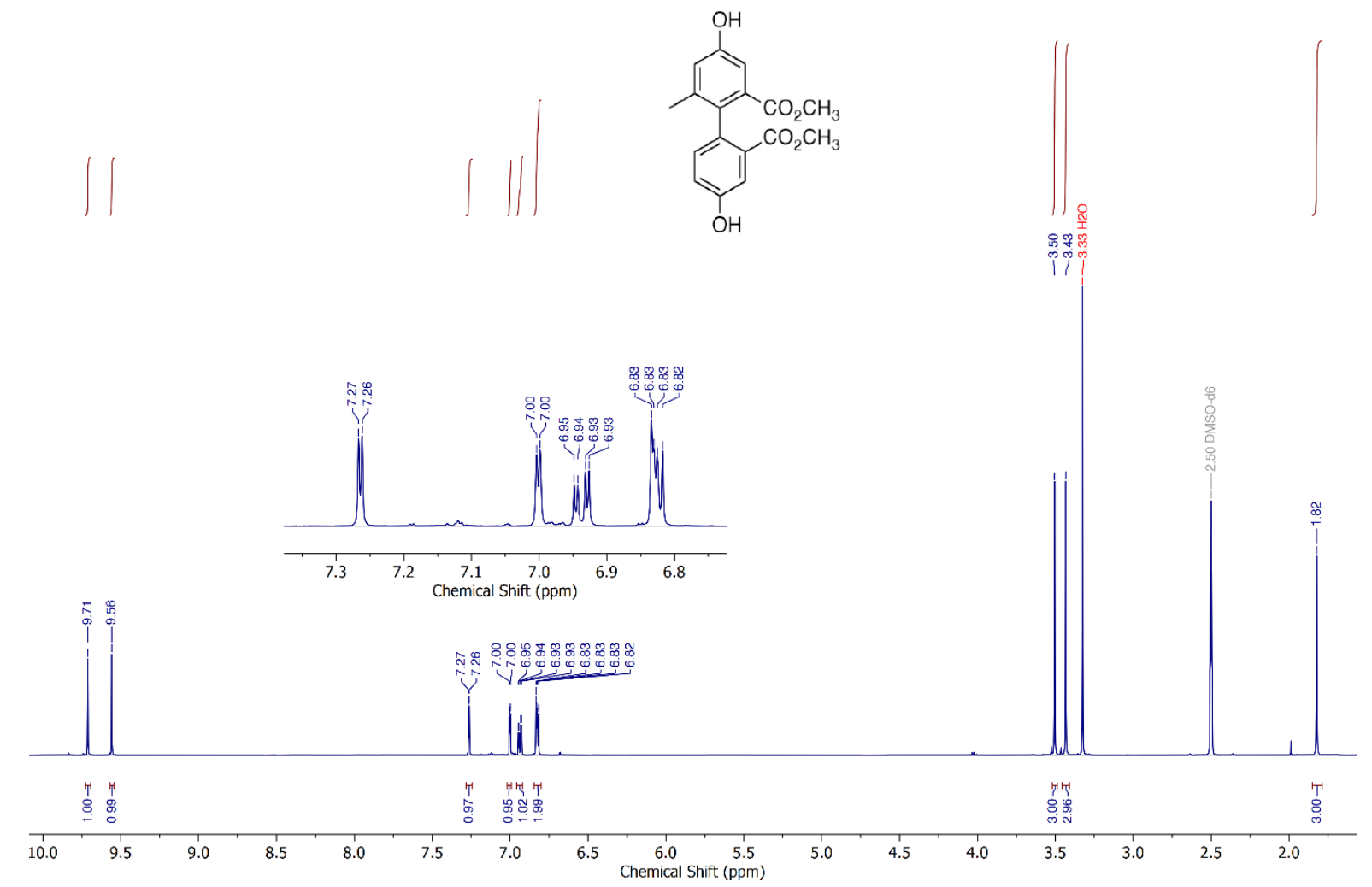

Figure S45. ${ }^{1} \mathrm{H}$ NMR spectrum (500 MHz, DMSO- $\left.d_{6}\right)$ of dimethyl [1,1'-biphenyl]-4,4'-dihydroxy-6-methyl$2,2^{\prime}$-dicarboxylate (6). 
$\left.{ }^{13} \mathrm{C} \mathrm{NMR} \mathrm{(126} \mathrm{MHz,} \mathrm{DMSO-} d_{6}\right)$
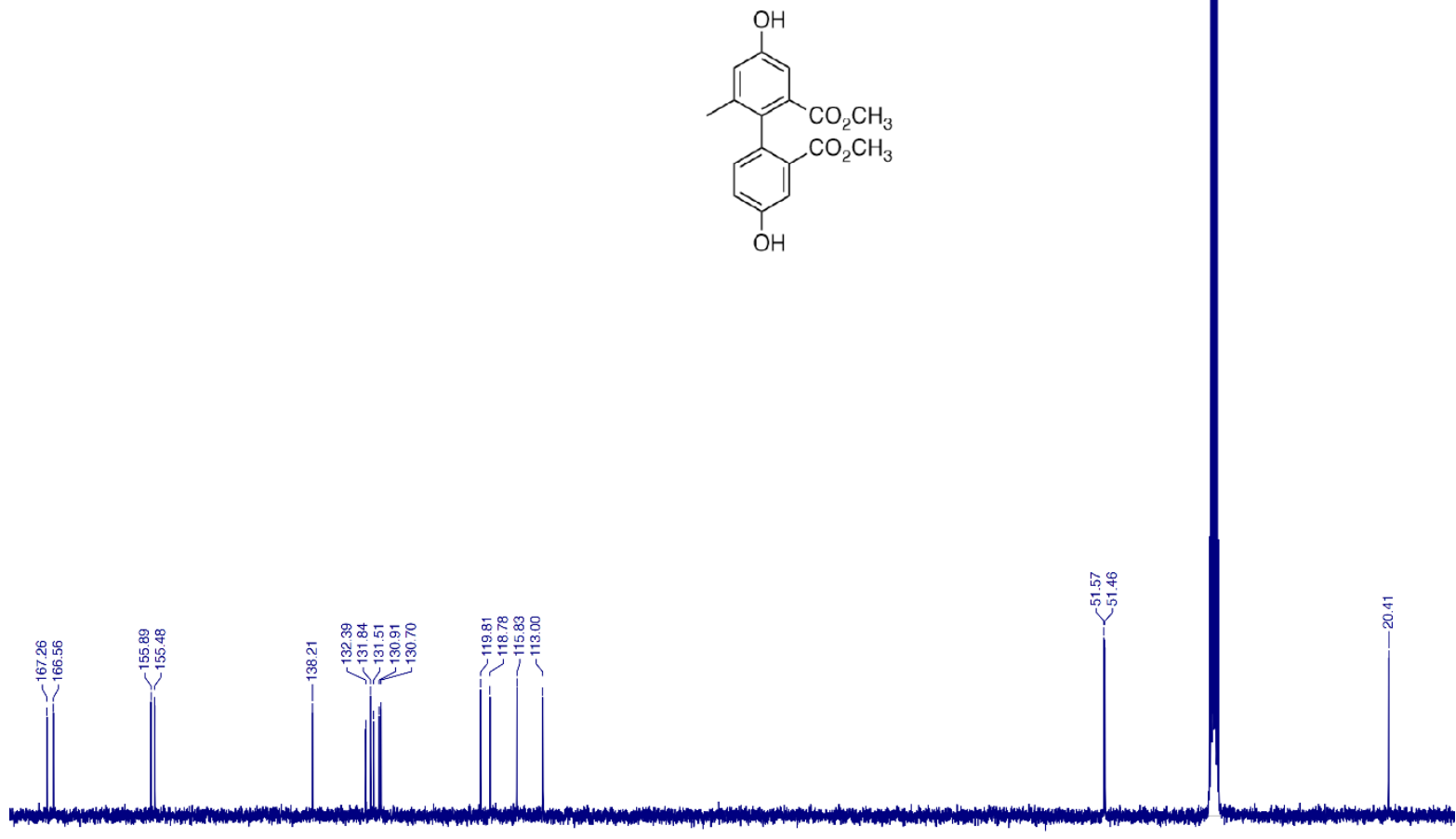

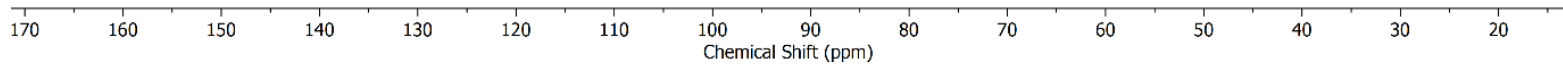

Figure S46. ${ }^{13} \mathrm{C}\left\{{ }^{1} \mathrm{H}\right\}$ NMR spectrum $\left(126 \mathrm{MHz}\right.$, DMSO- $\left.d_{6}\right)$ of dimethyl [1,1'-biphenyl]-4,4'-dihydroxy-6methyl-2,2'-dicarboxylate (6).

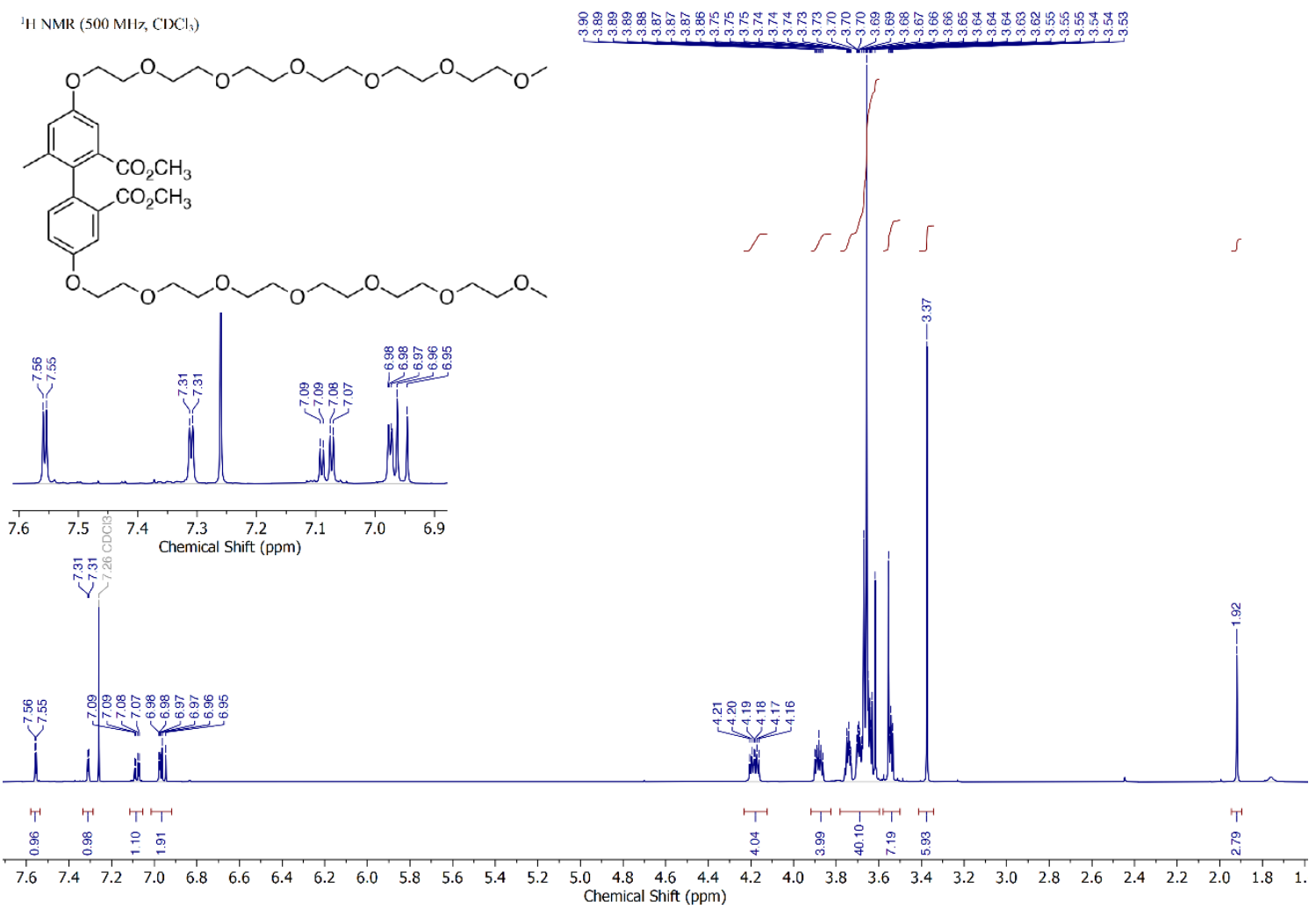

Figure S47. ${ }^{1} \mathrm{H}$ NMR spectrum $\left(500 \mathrm{MHz}, \mathrm{CDCl}_{3}\right)$ of dimethyl [1,1'-biphenyl]-4,4'-bis(3,6,9,12,15,18hexaoxanonadec-1-yloxy)-6-methyl-2,2'-dicarboxylate (7). 


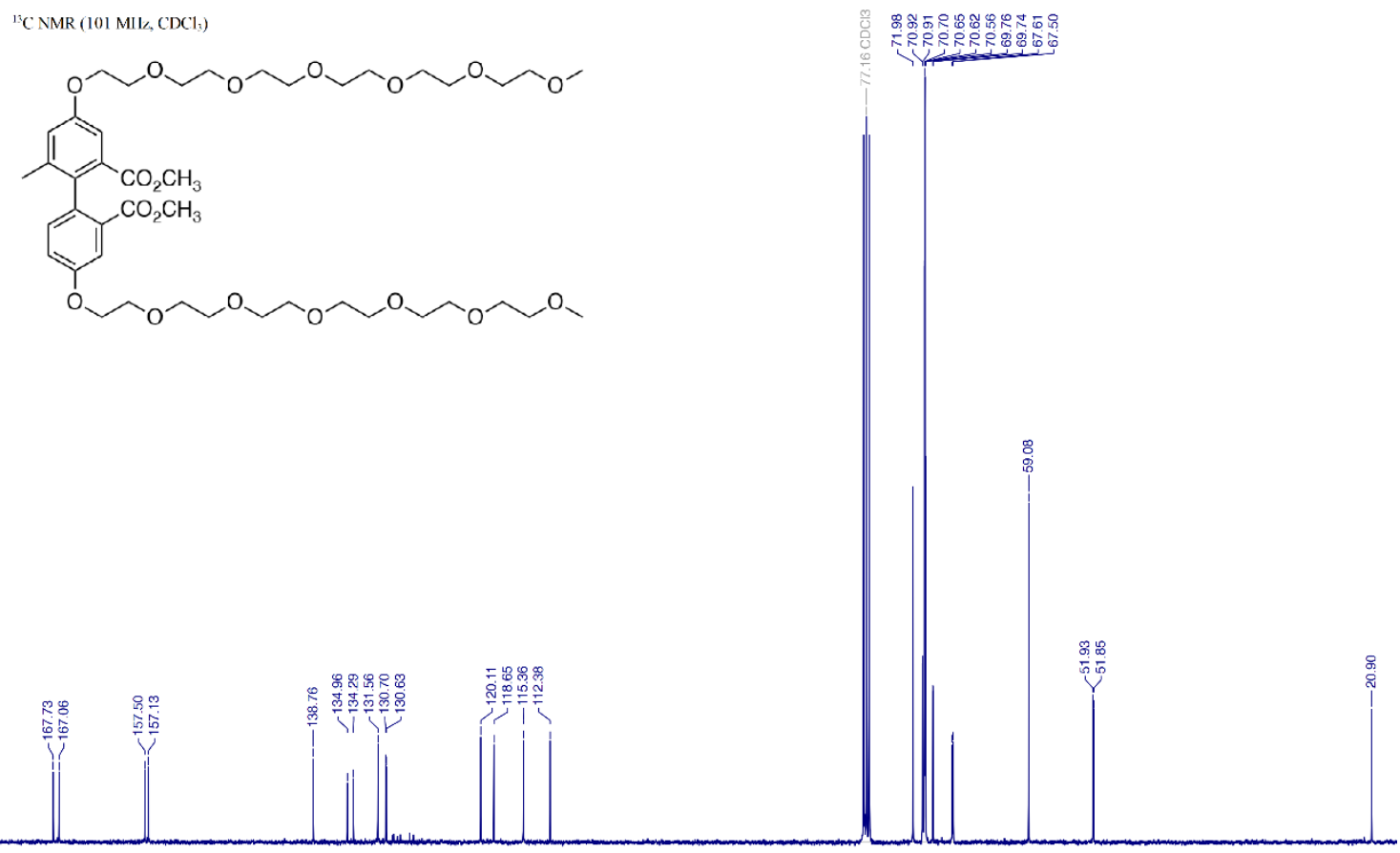

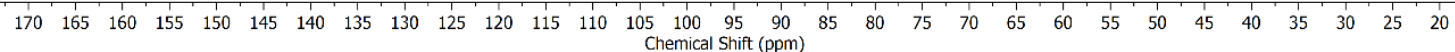

Figure S48. ${ }^{13} \mathrm{C}\left\{{ }^{1} \mathrm{H}\right\}$ NMR spectrum $\left(101 \mathrm{MHz}, \mathrm{CDCl}_{3}\right)$ of dimethyl [1,1'-biphenyl]-4,4'-bis(3,6,9,12,15,18hexaoxanonadec-1-yloxy)-6-methyl-2,2'-dicarboxylate (7).

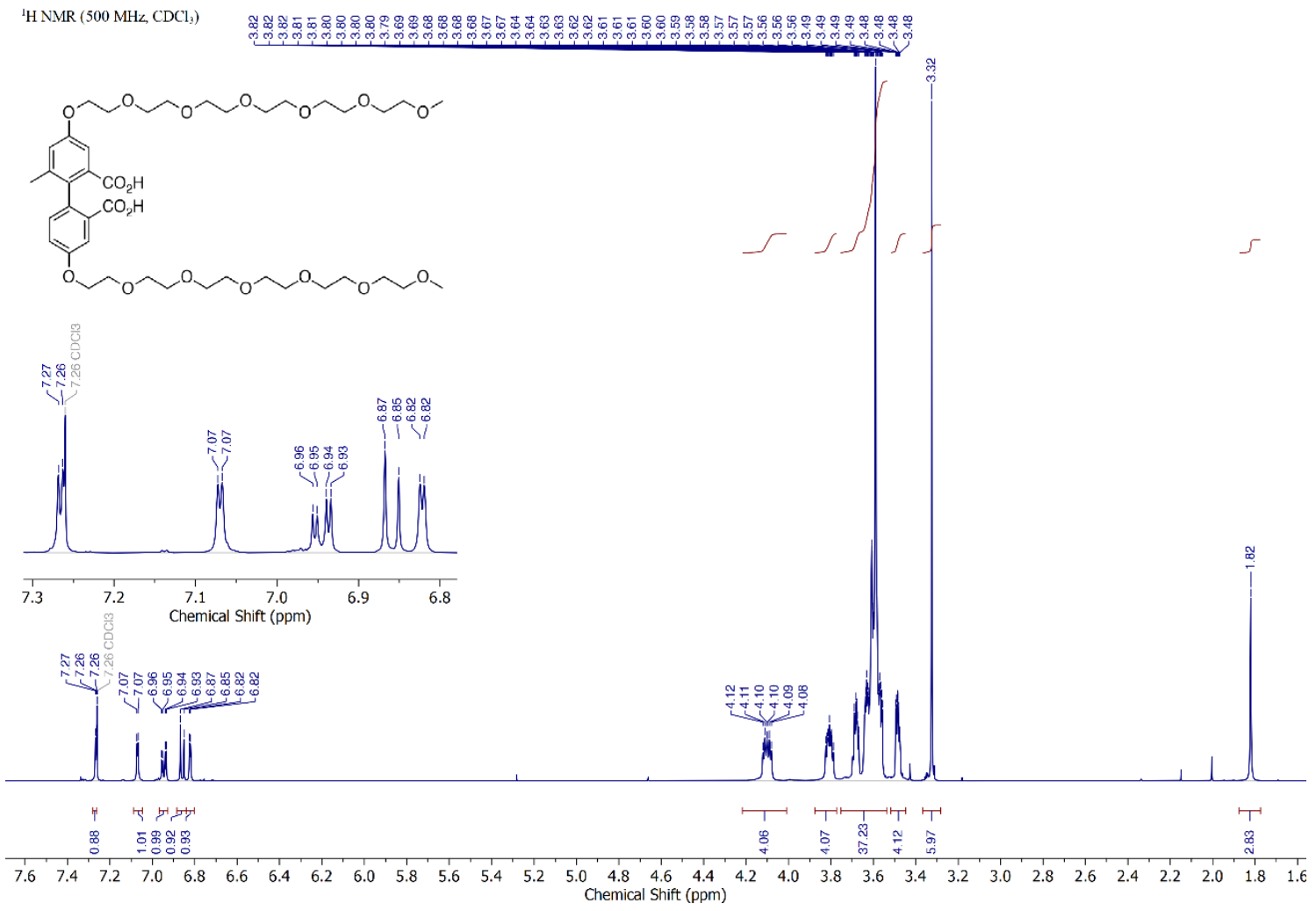

Figure S49. ${ }^{1} \mathrm{H} \quad \mathrm{NMR}$ spectrum $\quad\left(500 \mathrm{MHz}, \mathrm{CDCl}_{3}\right)$ of $\quad\left[1,1^{\prime}\right.$-biphenyl $]-4,4$ '-bis $(3,6,9,12,15,18-$ hexaoxanonadec-1-yloxy)-6-methyl-2,2'-dicarboxylic acid (DP-Ac4). 
${ }^{13} \mathrm{C}$ NMR (126 MIIz, $\mathrm{CDCl}_{3}$ )
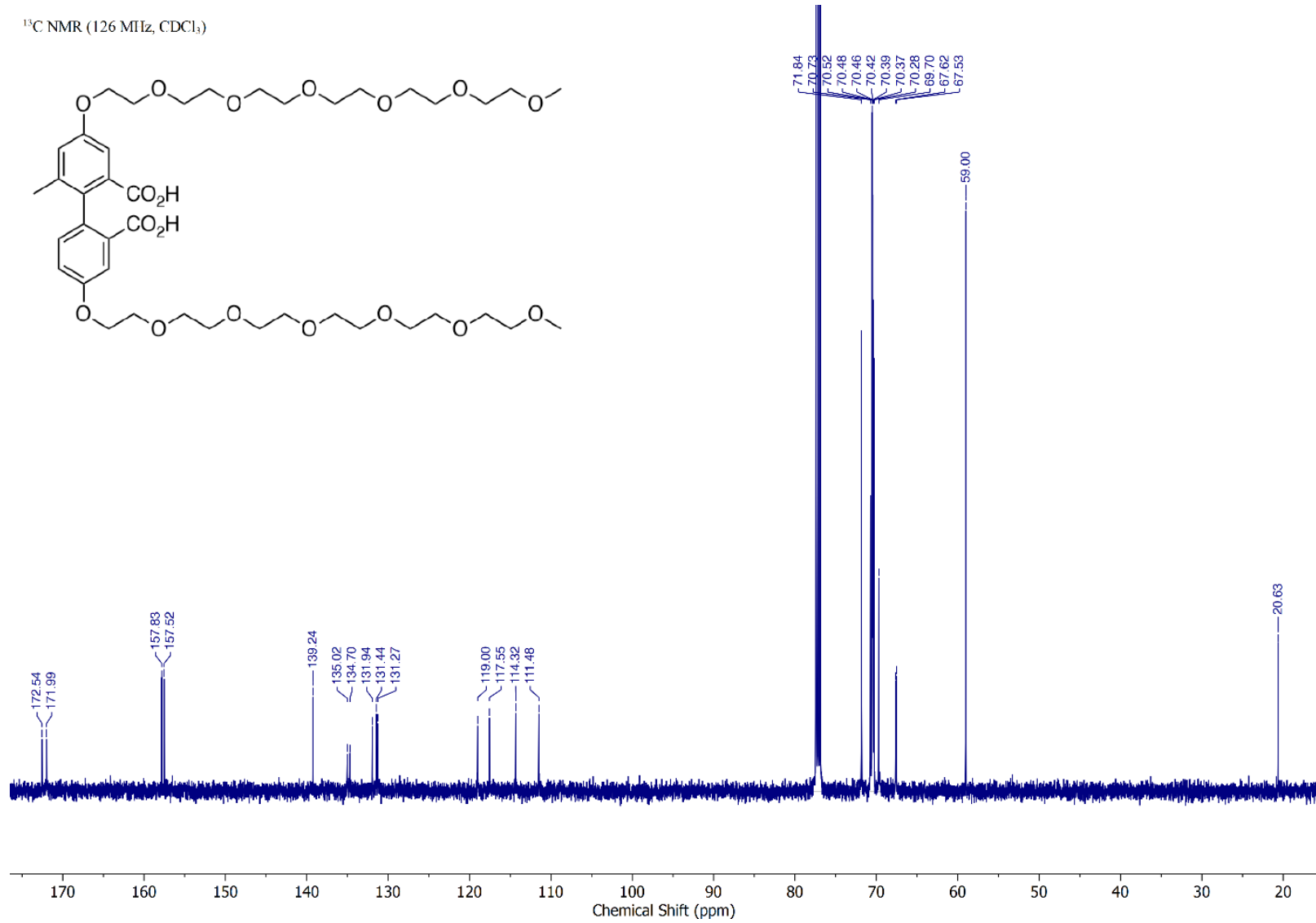

Figure S50. ${ }^{13} \mathrm{C}\left\{{ }^{1} \mathrm{H}\right\} \quad \mathrm{NMR}$ spectrum $\left(126 \mathrm{MHz}, \mathrm{CDCl}_{3}\right)$ of $\left[1,1^{\prime}\right.$-biphenyl]-4,4'-bis $(3,6,9,12,15,18$ hexaoxanonadec-1-yloxy)-6-methyl-2,2'-dicarboxylic acid (DP-Ac4). 
${ }^{1} \mathrm{H}$ NMR $\left(500 \mathrm{MHz}, \mathrm{DMSO}-d_{6}\right)$
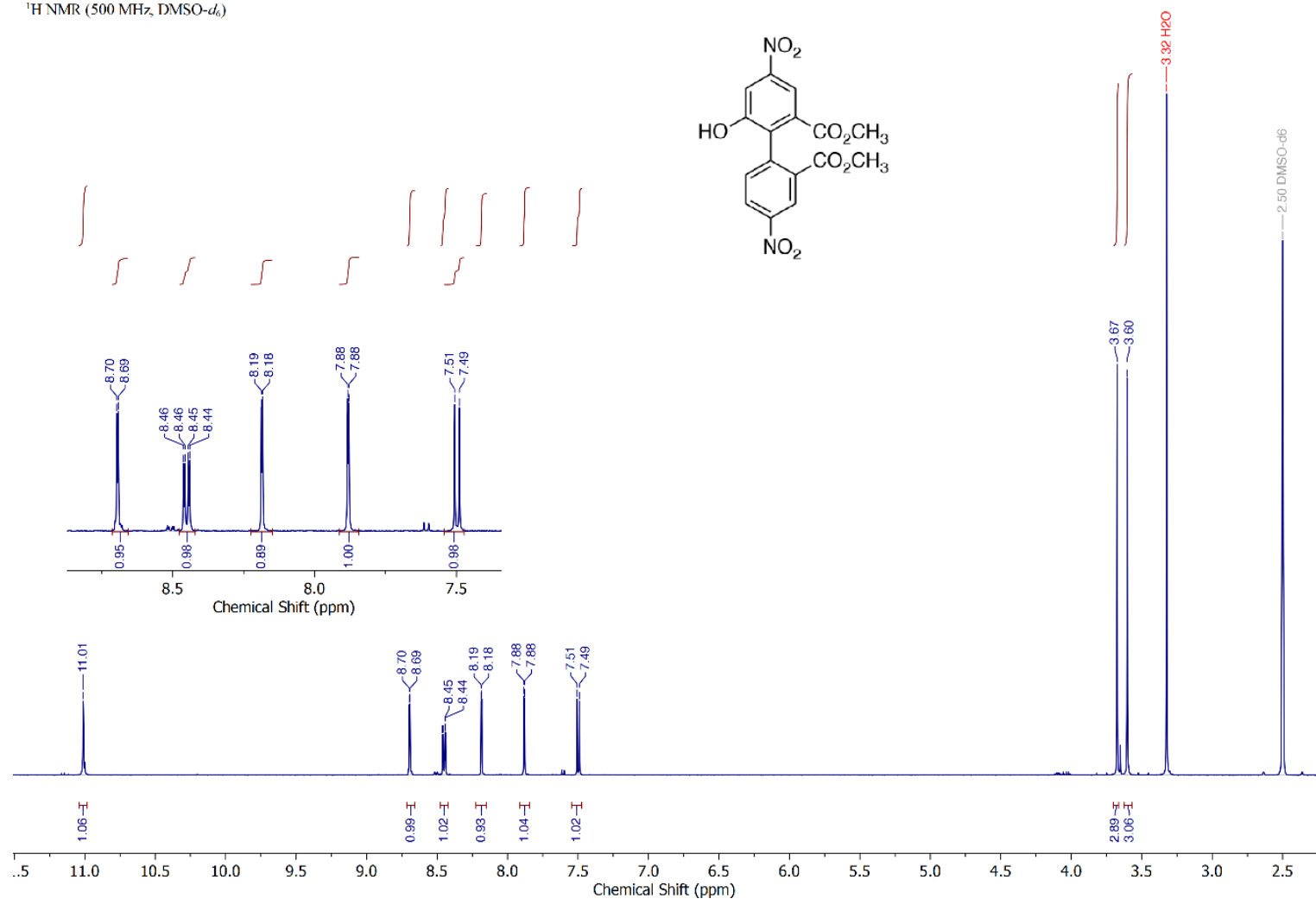

Figure S51. ${ }^{1} \mathrm{H}$ NMR spectrum $\left(500 \mathrm{MHz}\right.$, DMSO- $\left.d_{6}\right)$ of dimethyl [1,1'-biphenyl]-6-hydroxy-4,4'-dinitro2,2'-dicarboxylate (8).

${ }^{15} \mathrm{C}$ NMR (101 MLL, DMSO- $\left.d_{6}\right)$<smiles>COc1cc([N+](=O)[O-])ccc1OC(C)=O</smiles>

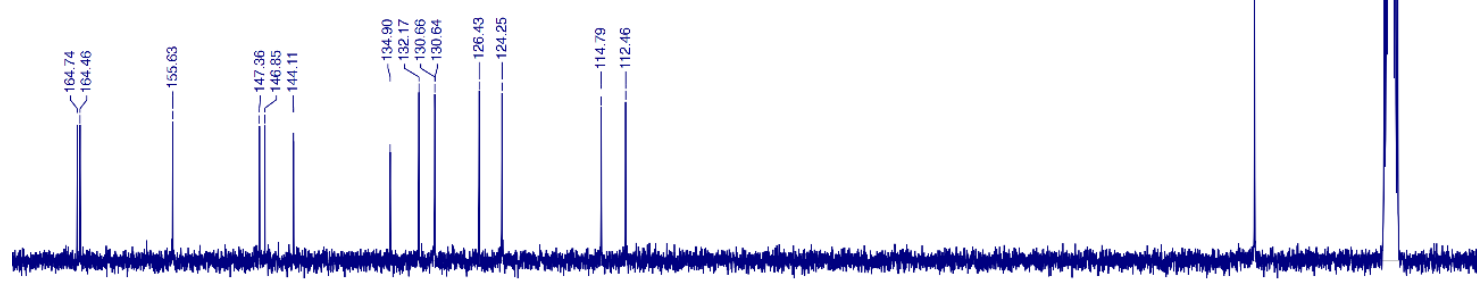

\begin{tabular}{llllllllllllllllllllllllllllllllll}
\hline 70 & 165 & 160 & 155 & 150 & 145 & 140 & 135 & 130 & 125 & 120 & 115 & 110 & 105 & 100 & 95 & 90 & 85 & 80 & 75 & 70 & 65 & 60 & 55 & 50 & 45 & 40 & 35
\end{tabular}

Figure S52. ${ }^{13} \mathrm{C}\left\{{ }^{1} \mathrm{H}\right\}$ NMR spectrum $\left(101 \mathrm{MHz}\right.$, DMSO- $\left.d_{6}\right)$ of dimethyl [1,1'-biphenyl]-6-hydroxy-4,4'dinitro-2,2'-dicarboxylate (8). 


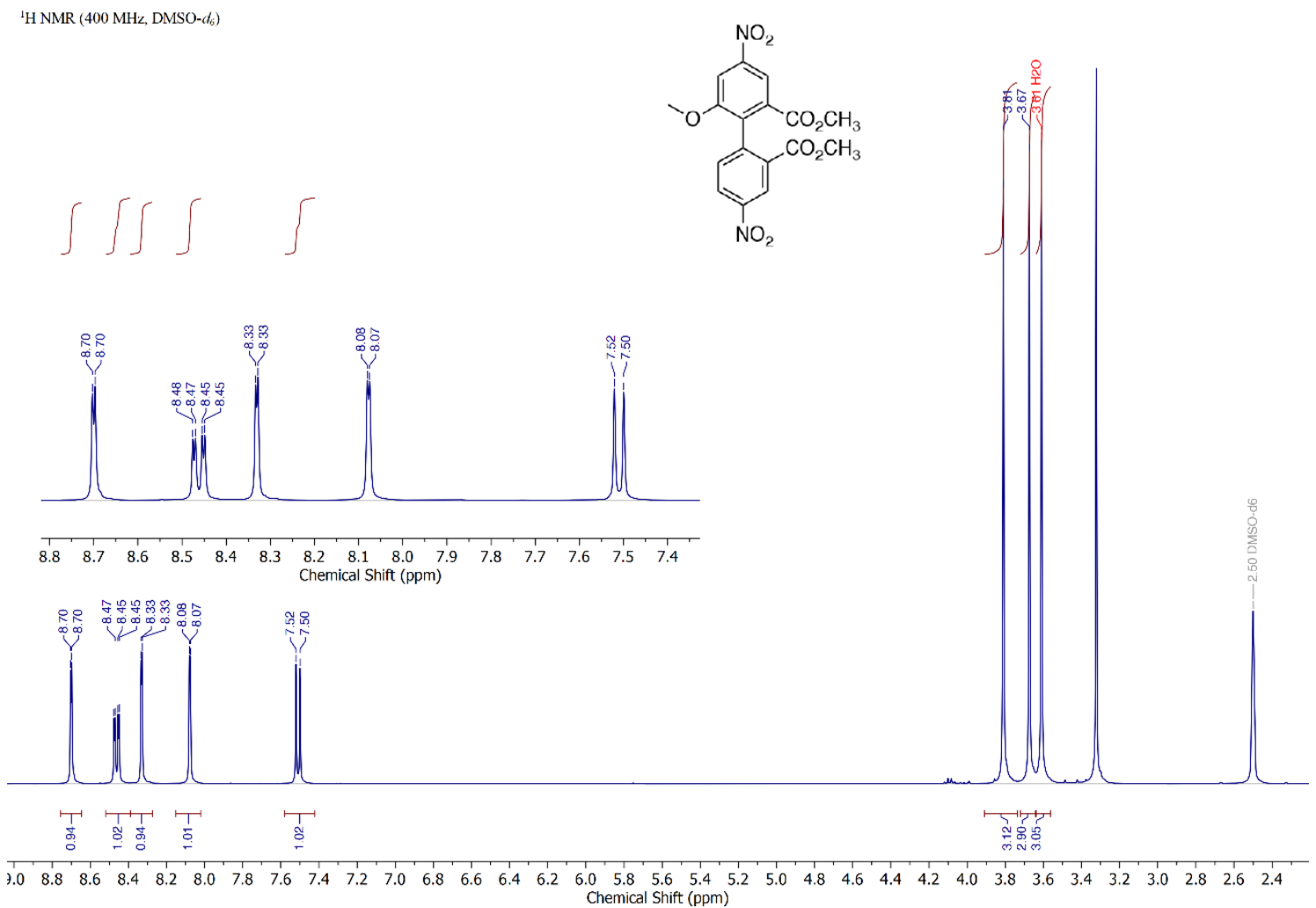

Figure S53. ${ }^{1} \mathrm{H}$ NMR spectrum $\left(400 \mathrm{MHz}\right.$, DMSO- $\left.d_{6}\right)$ of dimethyl [1,1'-biphenyl]-6-methoxy-4,4'-dinitro2,2'-dicarboxylate (9).

${ }^{13} \mathrm{C}$ NMR (101 MI Iz, DMSO- $d_{5}$ )
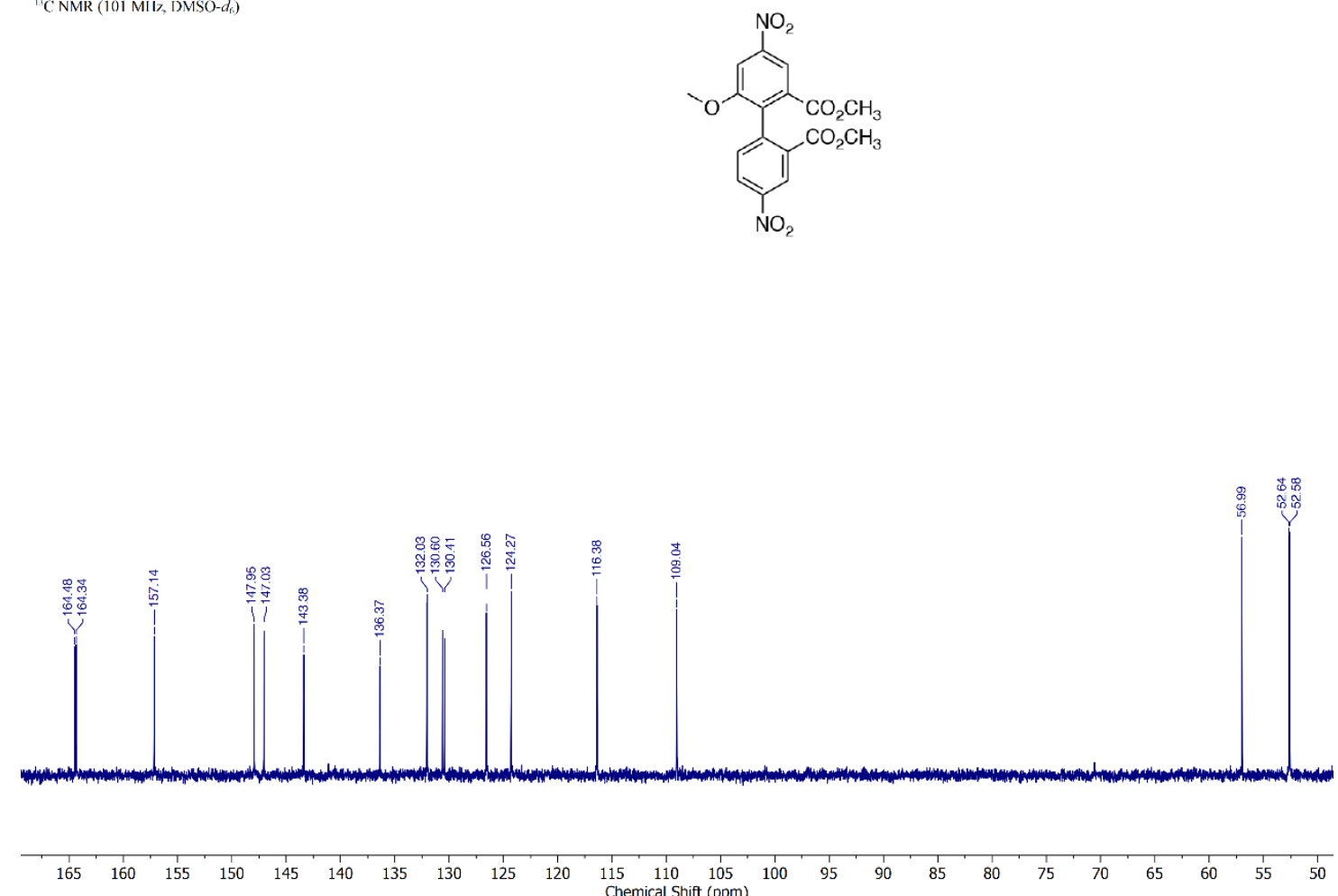

Figure S54. ${ }^{13} \mathrm{C}\left\{{ }^{1} \mathrm{H}\right\}$ NMR spectrum $\left(101 \mathrm{MHz}\right.$, DMSO- $\left.d_{6}\right)$ of dimethyl [1,1'-biphenyl]-6-methoxy-4,4'dinitro-2,2'-dicarboxylate (9). 


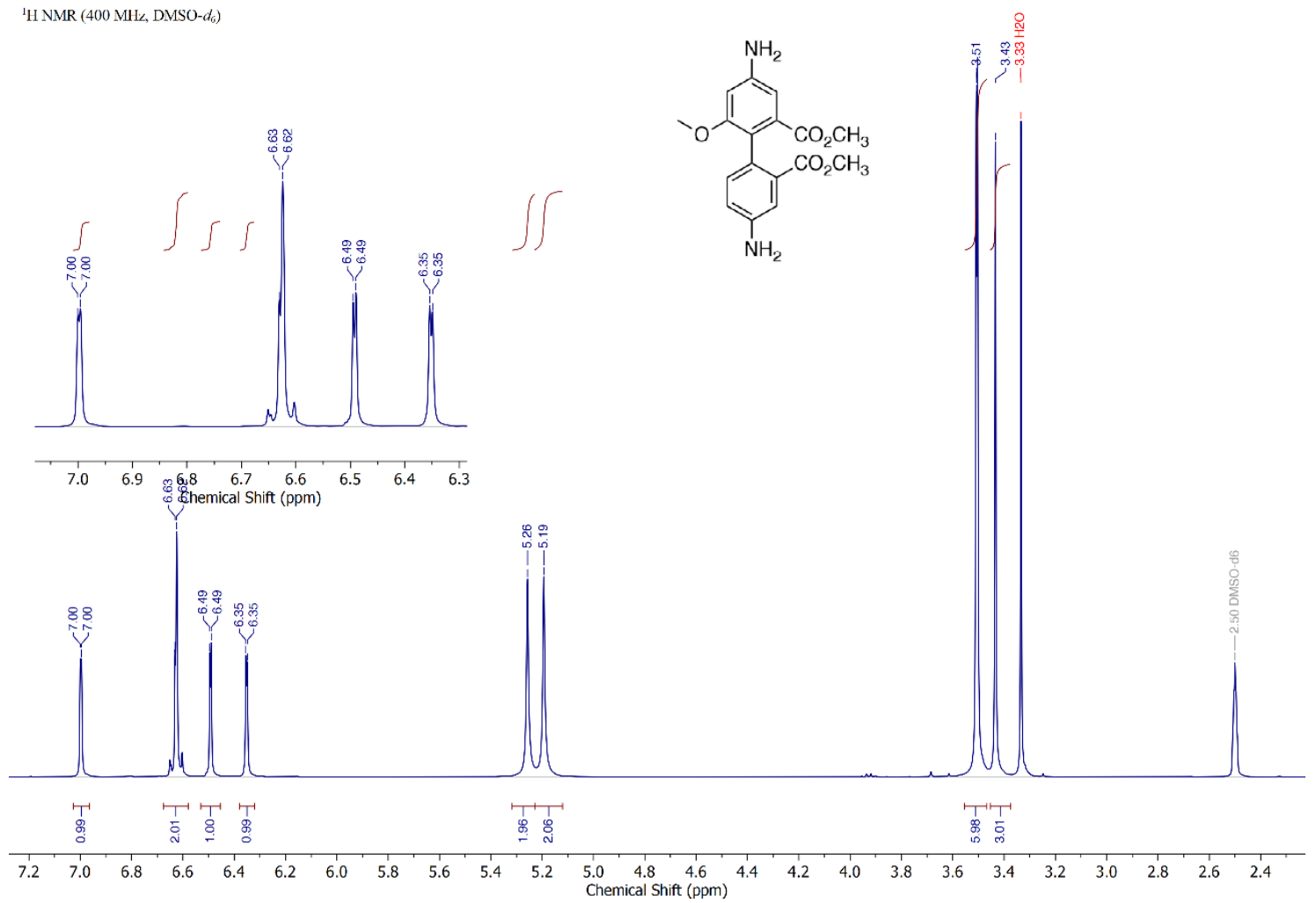

Figure S55. ${ }^{1} \mathrm{H}$ NMR spectrum (400 MHz, DMSO- $d_{6}$ ) of dimethyl [1,1'-biphenyl]-4,4'-diamino-6-methoxy2,2'-dicarboxylate (10).

${ }^{15} \mathrm{C}$ NMR (101 MH«, DMSO- $\left.d_{6}\right)$<smiles>COC(=O)c1cc(N)ccc1C(OC)c1c(OC)cc(N)cc1C(=O)OC</smiles>
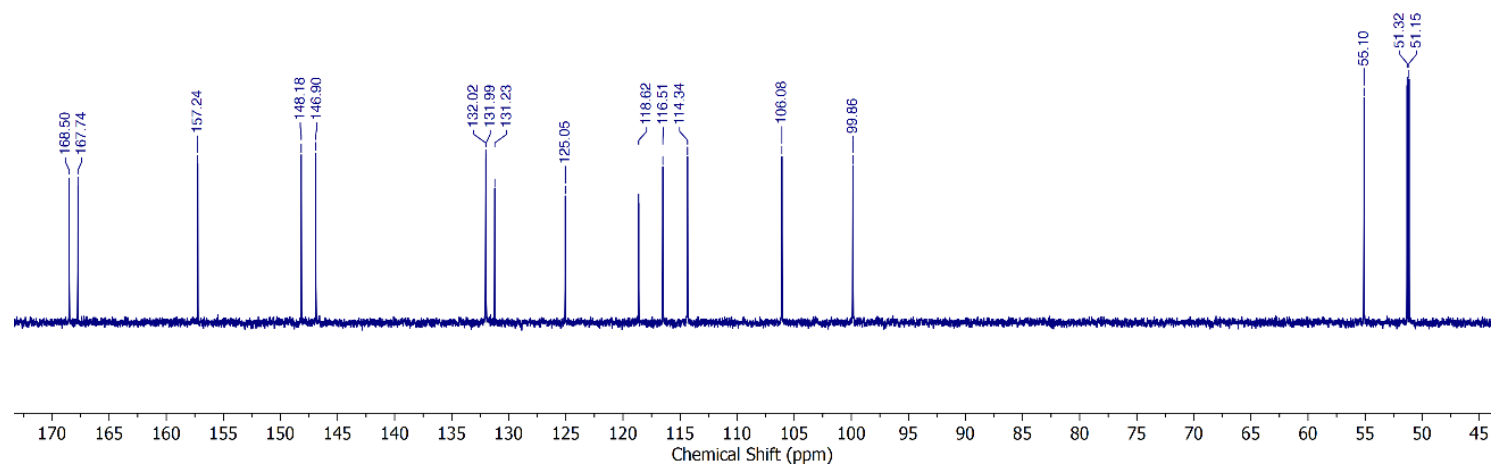

Figure S56. ${ }^{13} \mathrm{C}\left\{{ }^{1} \mathrm{H}\right\}$ NMR spectrum $\left(101 \mathrm{MHz}\right.$, DMSO- $\left.d_{6}\right)$ of dimethyl [1,1'-biphenyl]-4,4'-diamino-6methoxy-2,2'-dicarboxylate (10). 
${ }^{1} \mathrm{H}$ NMR (300 MHz, DMSO- $\left.d_{6}\right)$
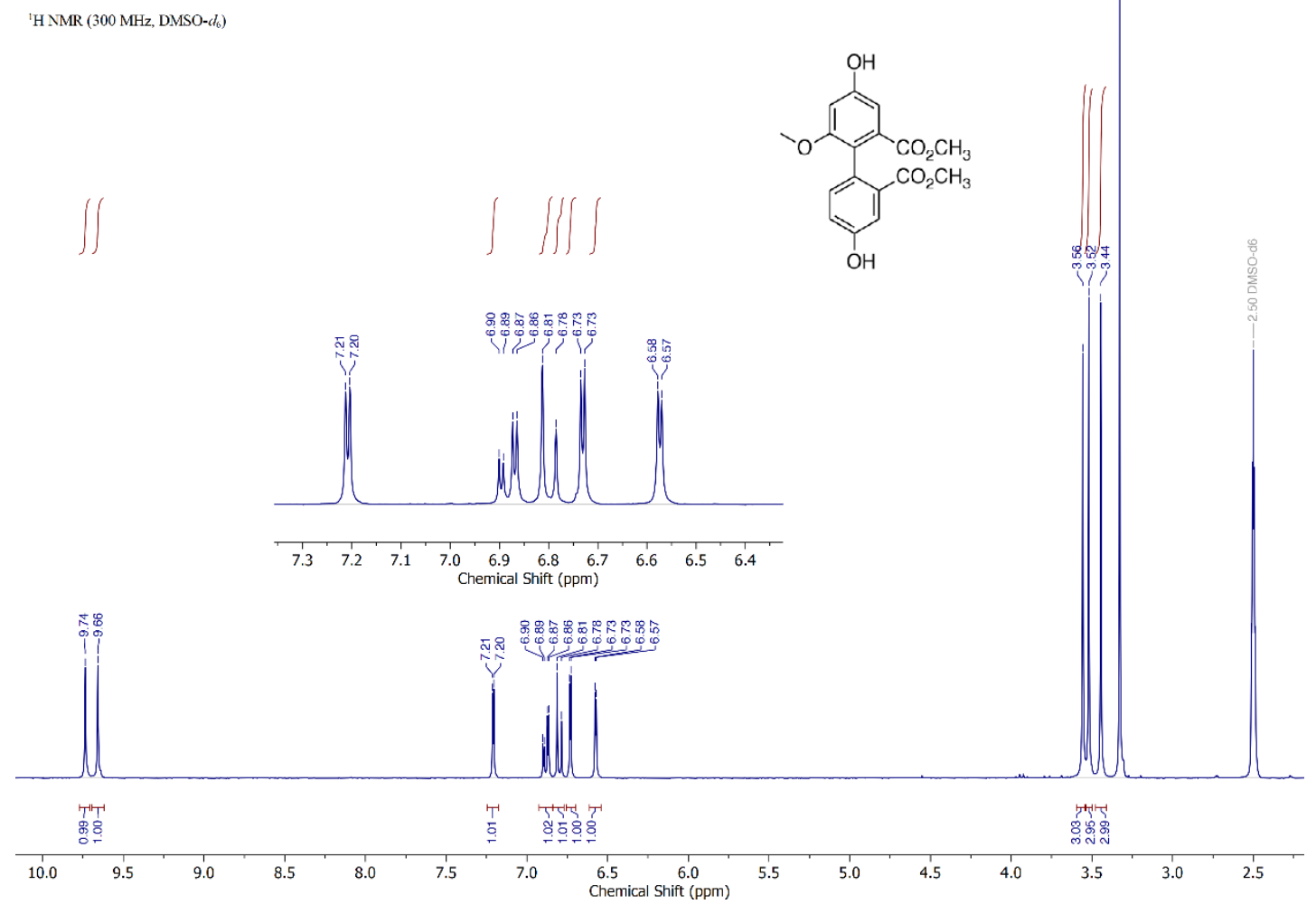

Figure S57. ${ }^{1} \mathrm{H}$ NMR spectrum $\left(300 \mathrm{MHz}, \mathrm{DMSO}-d_{6}\right)$ of dimethyl [1,1'-biphenyl]-4,4'-dihydroxy-6methoxy-2,2'-dicarboxylate (11).

${ }^{13} \mathrm{C}$ NMR (I0I MI\%\%, DMSO- $d_{5}$ )
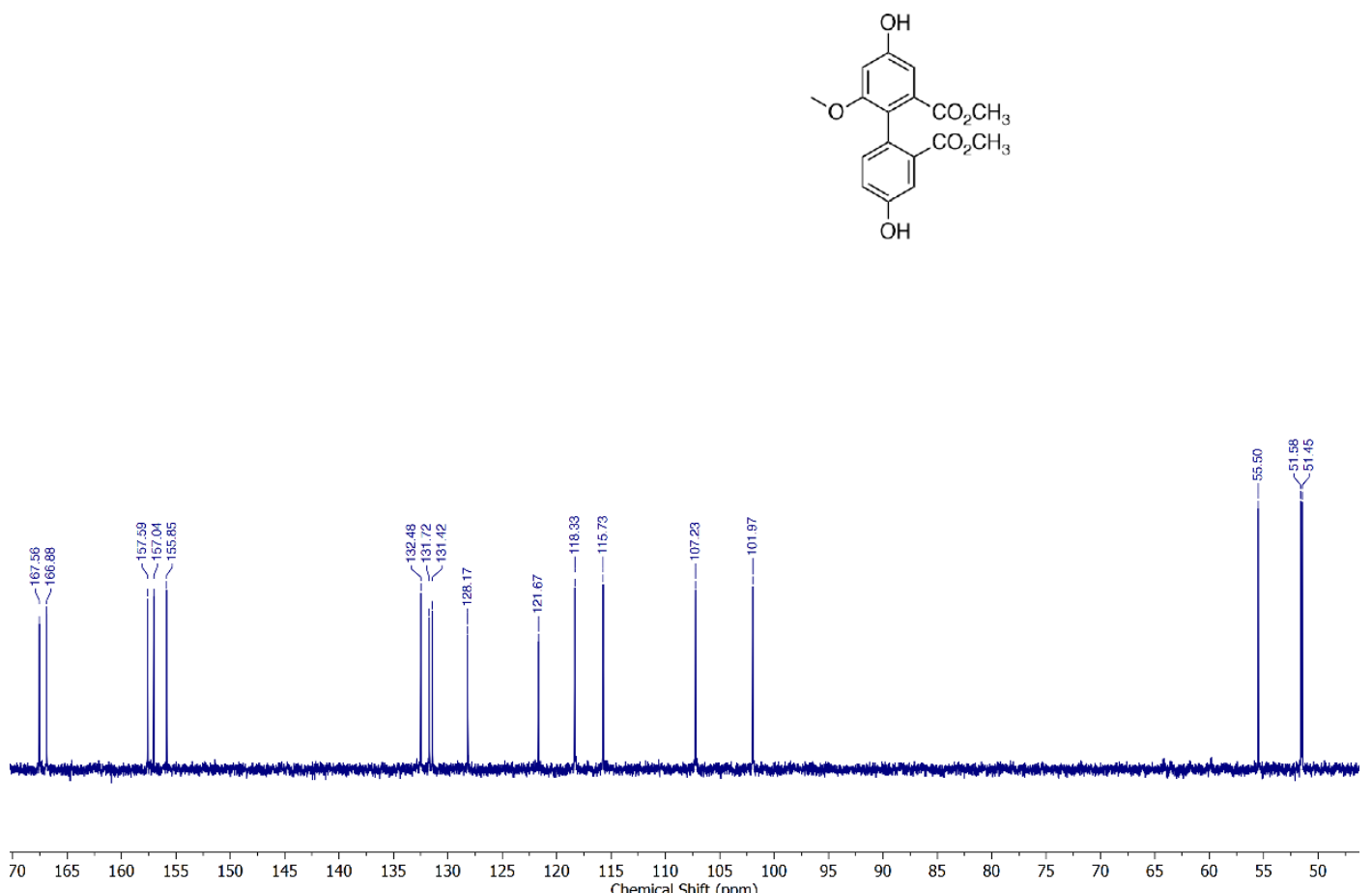

Figure S58. ${ }^{13} \mathrm{C}\left\{{ }^{1} \mathrm{H}\right\}$ NMR spectrum $\left(101 \mathrm{MHz}\right.$, DMSO- $\left.d_{6}\right)$ of dimethyl [1,1'-biphenyl]-4,4'-dihydroxy-6methoxy-2,2'-dicarboxylate (11). 


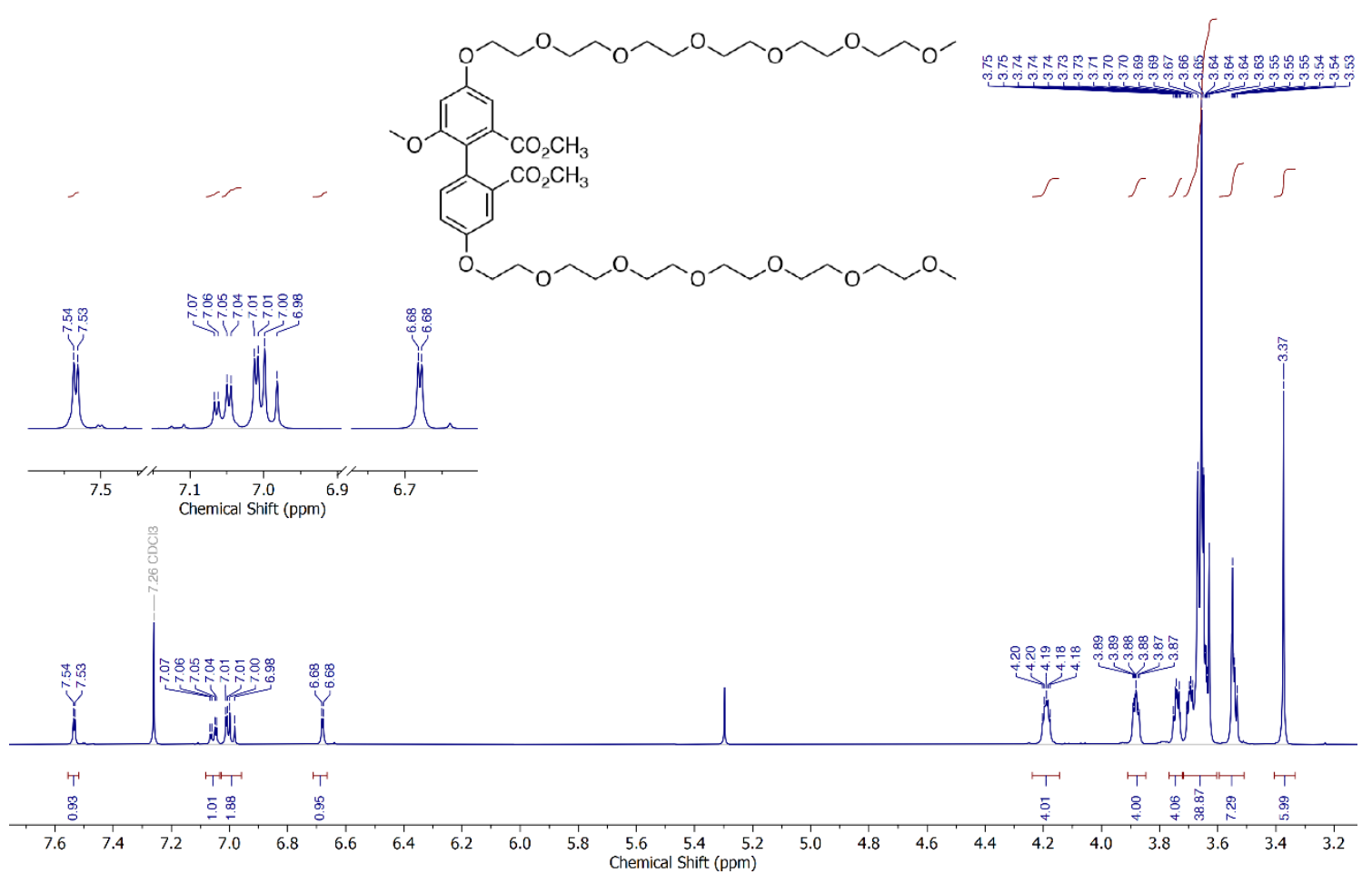

Figure S59. ${ }^{1} \mathrm{H}$ NMR spectrum $\left(500 \mathrm{MHz}, \mathrm{CDCl}_{3}\right)$ of dimethyl [1,1'-biphenyl]-4,4'-bis(3,6,9,12,15,18hexaoxanonadec-1-yloxy)-6-methoxy-2,2'-dicarboxylate (12).

${ }^{11} \mathrm{CNMR}(101 \mathrm{MIl}, \mathrm{CDCl}$ )
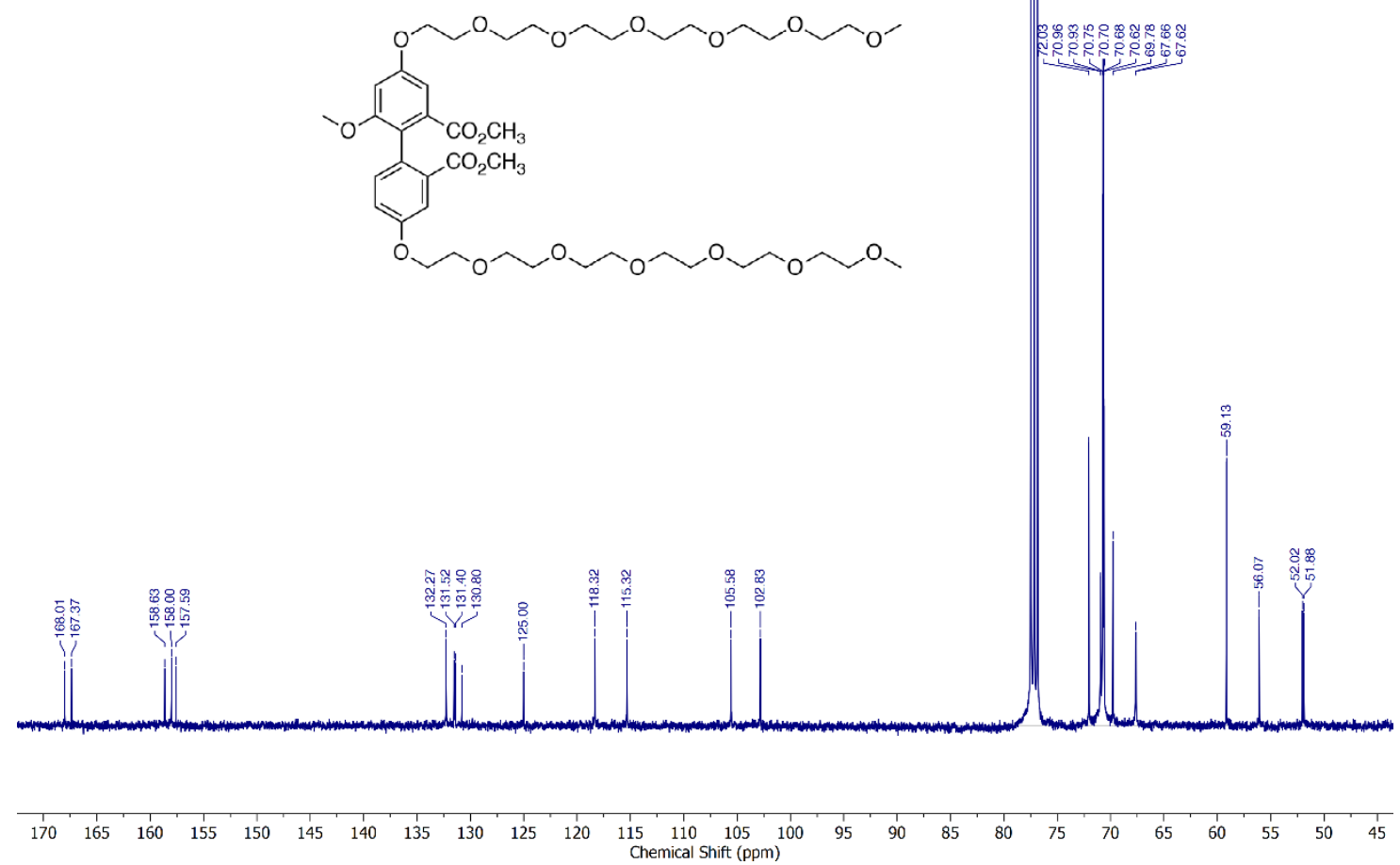

Figure S60. ${ }^{13} \mathrm{C}\left\{{ }^{1} \mathrm{H}\right\}$ NMR spectrum $\left(101 \mathrm{MHz}, \mathrm{CDCl}_{3}\right)$ of dimethyl [1,1'-biphenyl]-4,4'-bis(3,6,9,12,15,18hexaoxanonadec-1-yloxy)-6-methoxy-2,2'-dicarboxylate (12). 


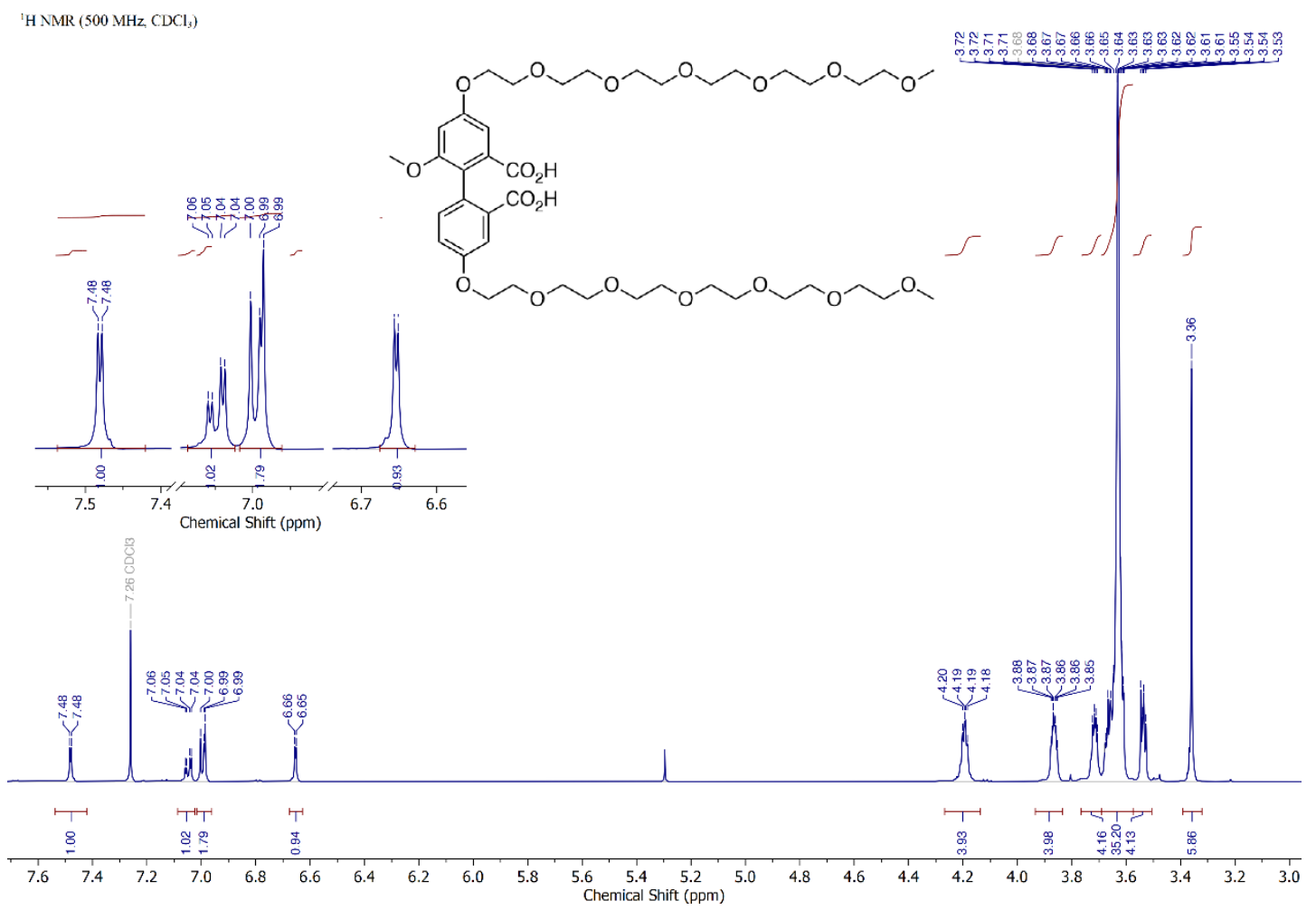

Figure S61. ${ }^{1} \mathrm{H} \quad \mathrm{NMR}$ spectrum $\left(500 \mathrm{MHz}, \mathrm{CDCl}_{3}\right)$ of $\left[1,1^{\prime}\right.$-biphenyl]-4,4'-bis $(3,6,9,12,15,18-$ hexaoxanonadec-1-yloxy)-6-methoxy-2,2'-dicarboxylic acid (DP-Ac5).

${ }^{15} \mathrm{C} \mathrm{NMR}\left(101 \mathrm{MLL}_{2}, \mathrm{CDCl}_{3}\right)$
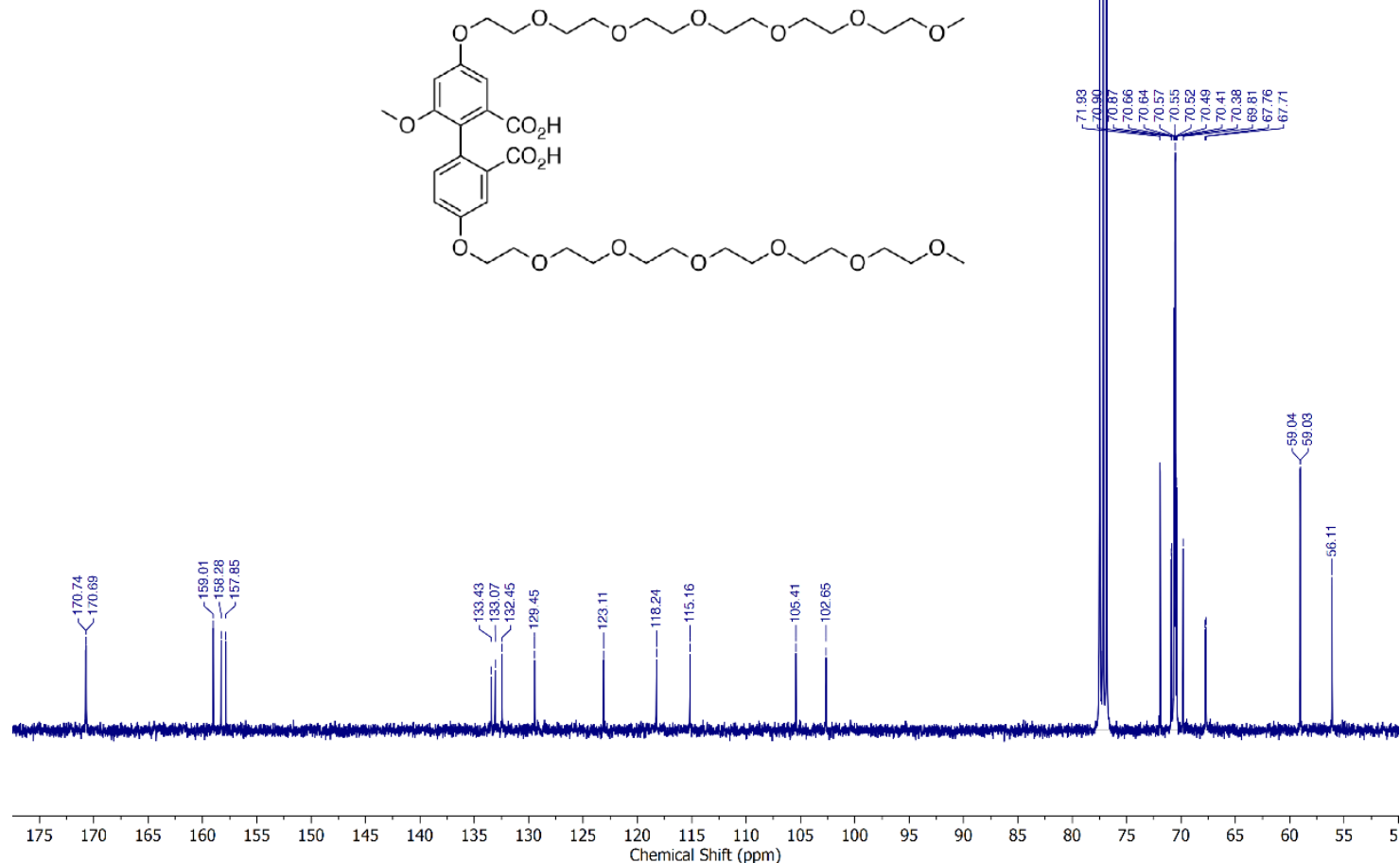

Figure S62. ${ }^{13} \mathrm{C}\left\{{ }^{1} \mathrm{H}\right\} \quad \mathrm{NMR}$ spectrum $\left(101 \mathrm{MHz}, \mathrm{CDCl}_{3}\right)$ of [1,1'-biphenyl]-4,4'-bis(3,6,9,12,15,18hexaoxanonadec-1-yloxy)-6-methoxy-2,2'-dicarboxylic acid (DP-Ac5). 


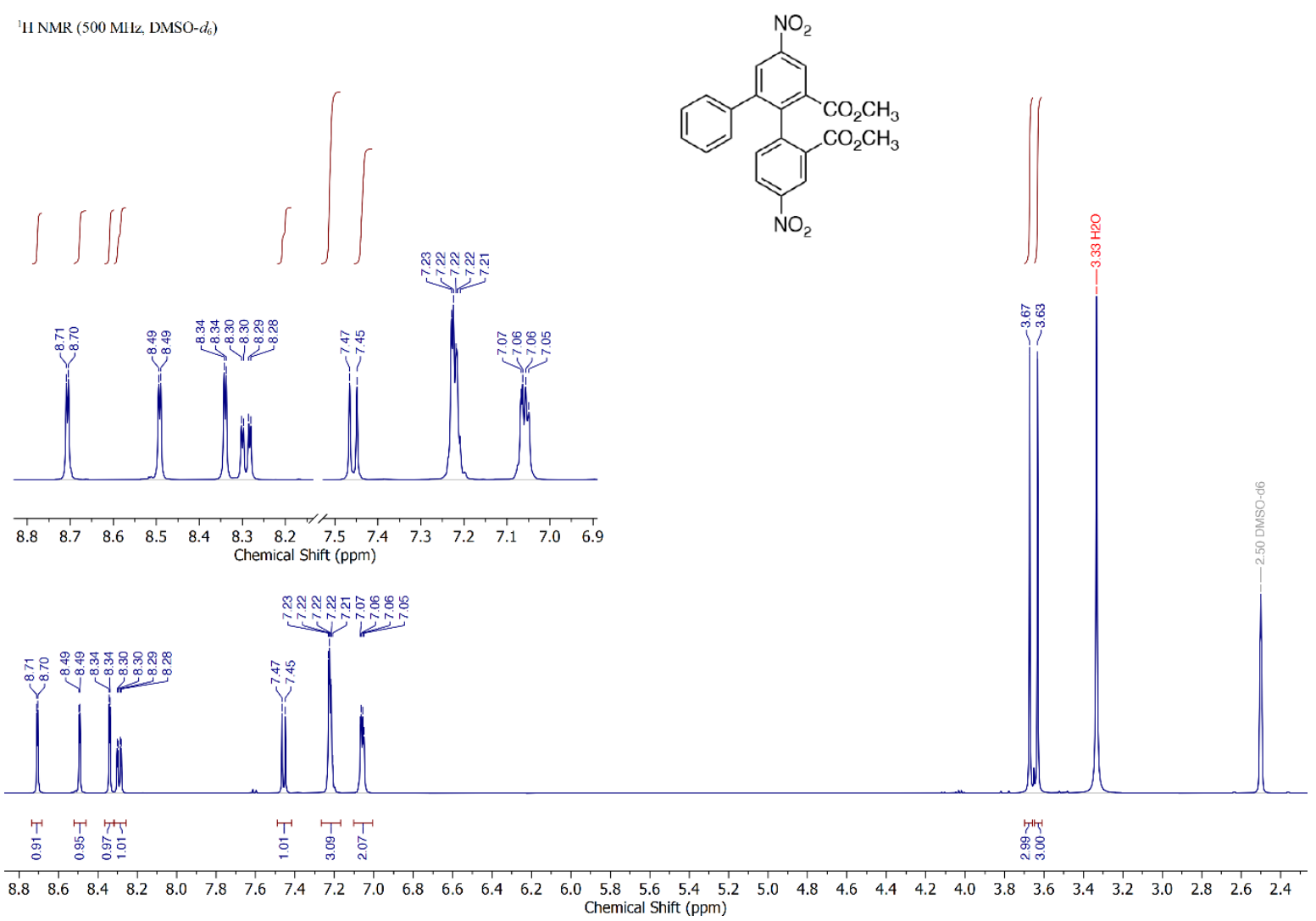

Figure S63. ${ }^{1} \mathrm{H}$ NMR spectrum $\left(500 \mathrm{MHz}\right.$, DMSO- $\left.d_{6}\right)$ of dimethyl [1,1'-biphenyl]-4,4'-dinitro-6-phenyl-2,2'dicarboxylate (13). 
${ }^{13} \mathrm{C}$ NMR (126 MHz, DMSO- $d_{n}$ )
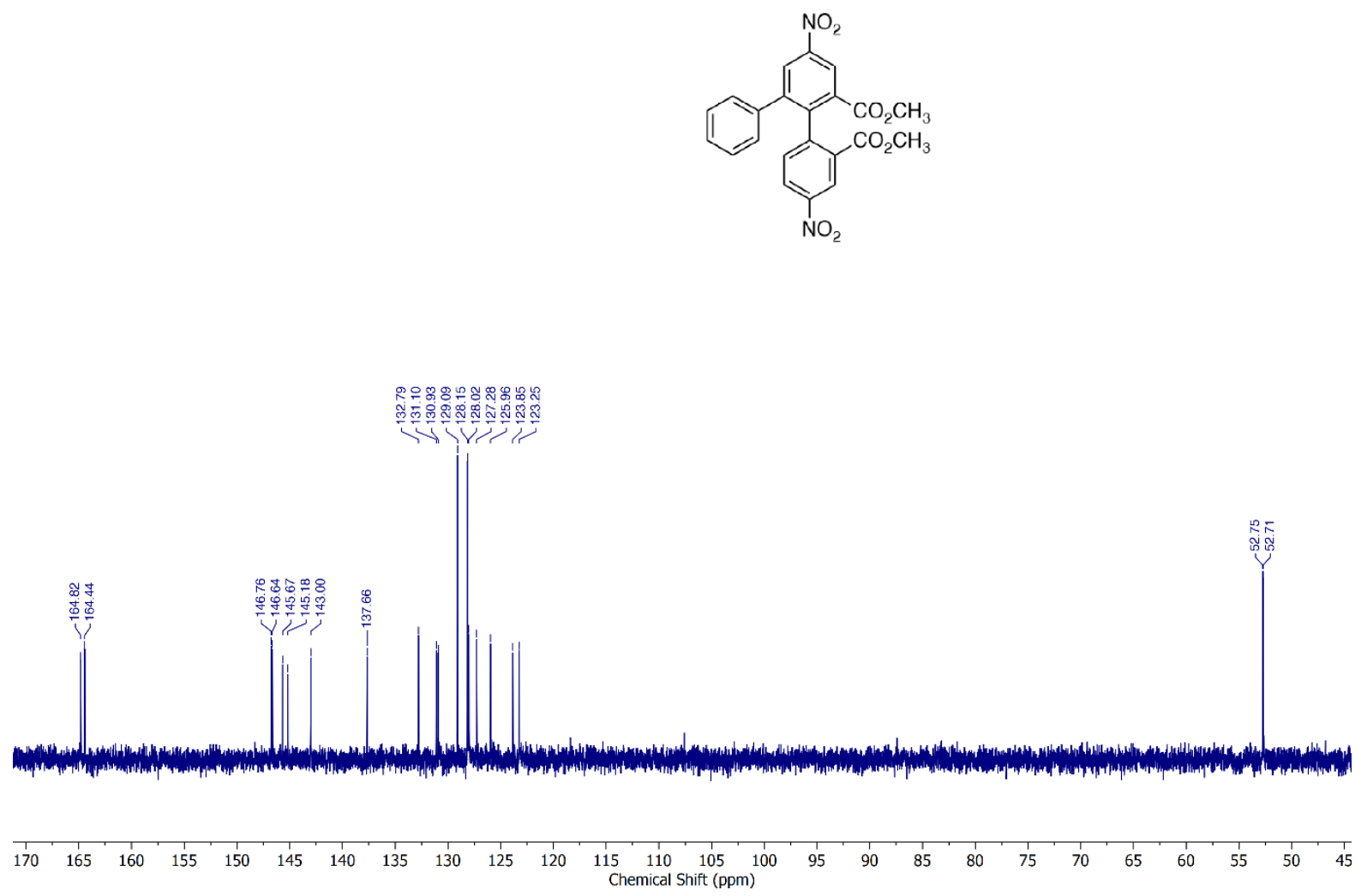

Figure S64. ${ }^{13} \mathrm{C}\left\{{ }^{1} \mathrm{H}\right\}$ NMR spectrum (126 MHz, DMSO- $\left.d_{6}\right)$ of dimethyl [1,1'-biphenyl]-4,4'-dinitro-6-phenyl2,2'-dicarboxylate (13). 
${ }^{1} \mathrm{H}$ NMR (500 MHz, DMSO- $\left.d_{6}\right)$
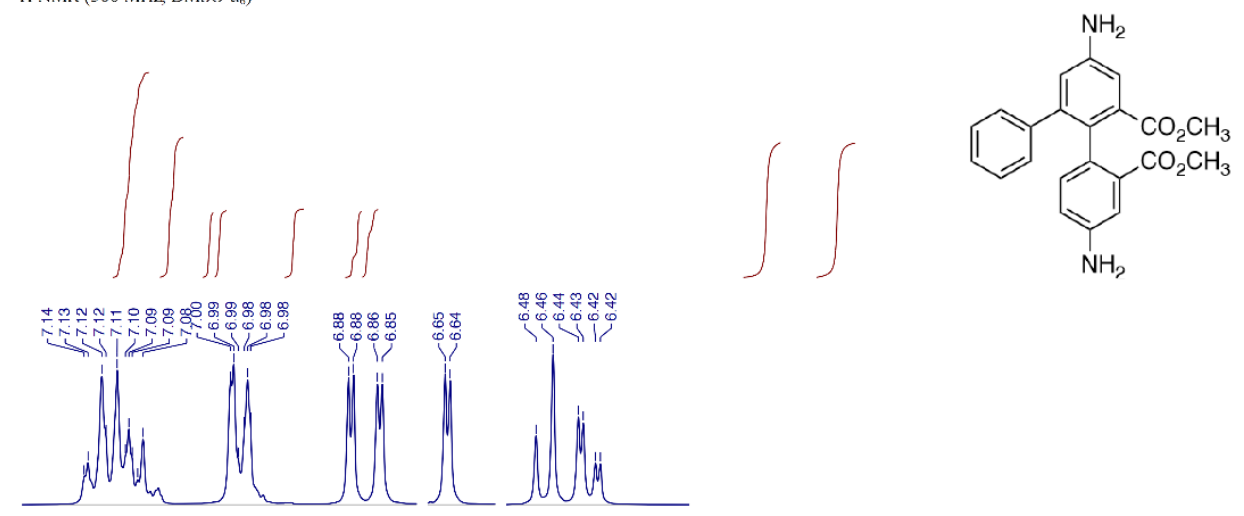

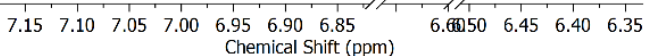
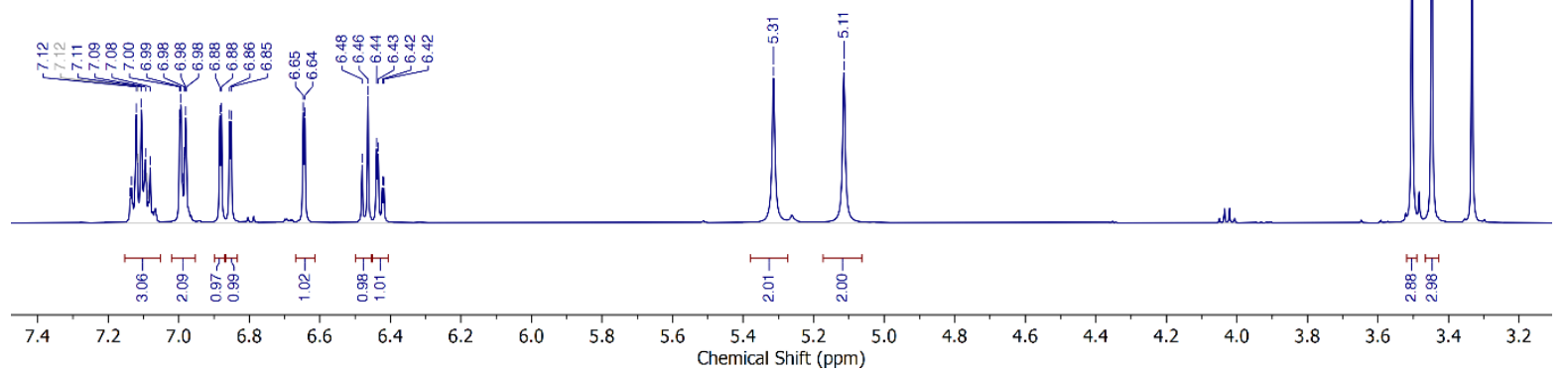

Figure S65. ${ }^{1} \mathrm{H}$ NMR spectrum $\left(500 \mathrm{MHz}\right.$, DMSO- $\left.d_{6}\right)$ of dimethyl [1,1'-biphenyl]-4,4'-diamino-6-phenyl$2,2^{\prime}$-dicarboxylate (14).

${ }^{13} \mathrm{C}$ NMR (126 MIL, DMSO- $\left.d_{6}\right)$<smiles>COC(=O)c1cc(N)cc(-c2ccccc2)c1C(C)=O</smiles>

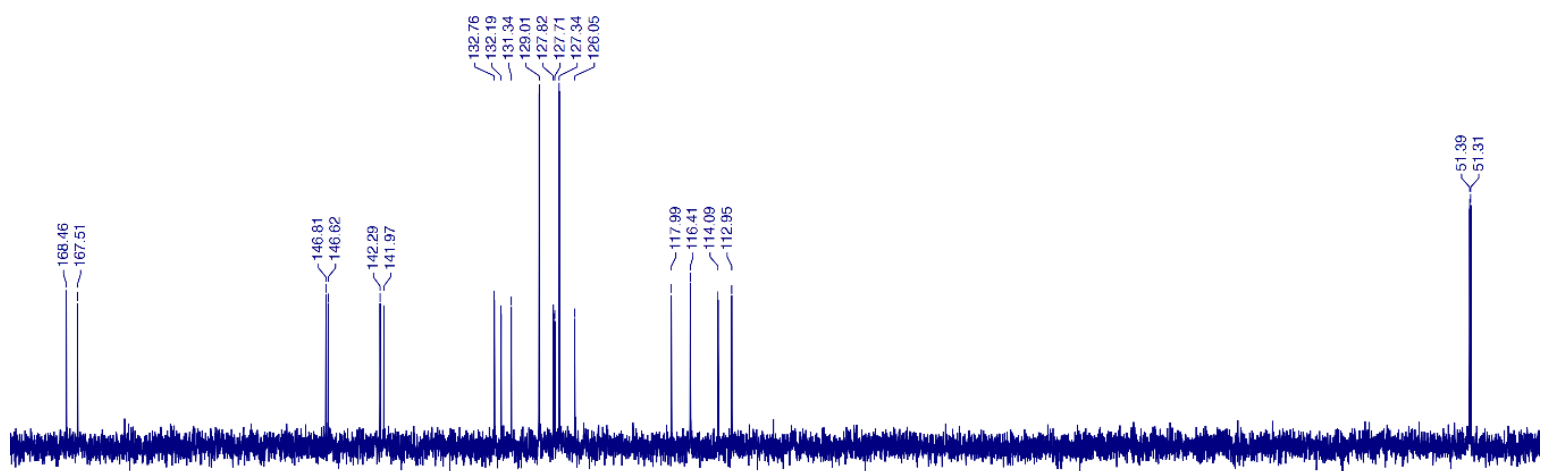

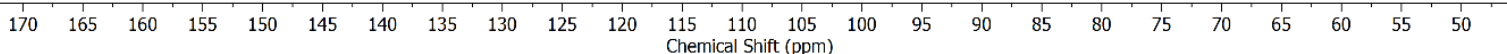

Figure S66. ${ }^{13} \mathrm{C}\left\{{ }^{1} \mathrm{H}\right\}$ NMR spectrum $\left(126 \mathrm{MHz}\right.$, DMSO- $\left.d_{6}\right)$ of dimethyl [1,1'-biphenyl]-4,4'-diamino-6phenyl-2,2'-dicarboxylate (14). 
'H NMR ( $500 \mathrm{MHz}$, DMSO- $\left.d_{6}\right)$

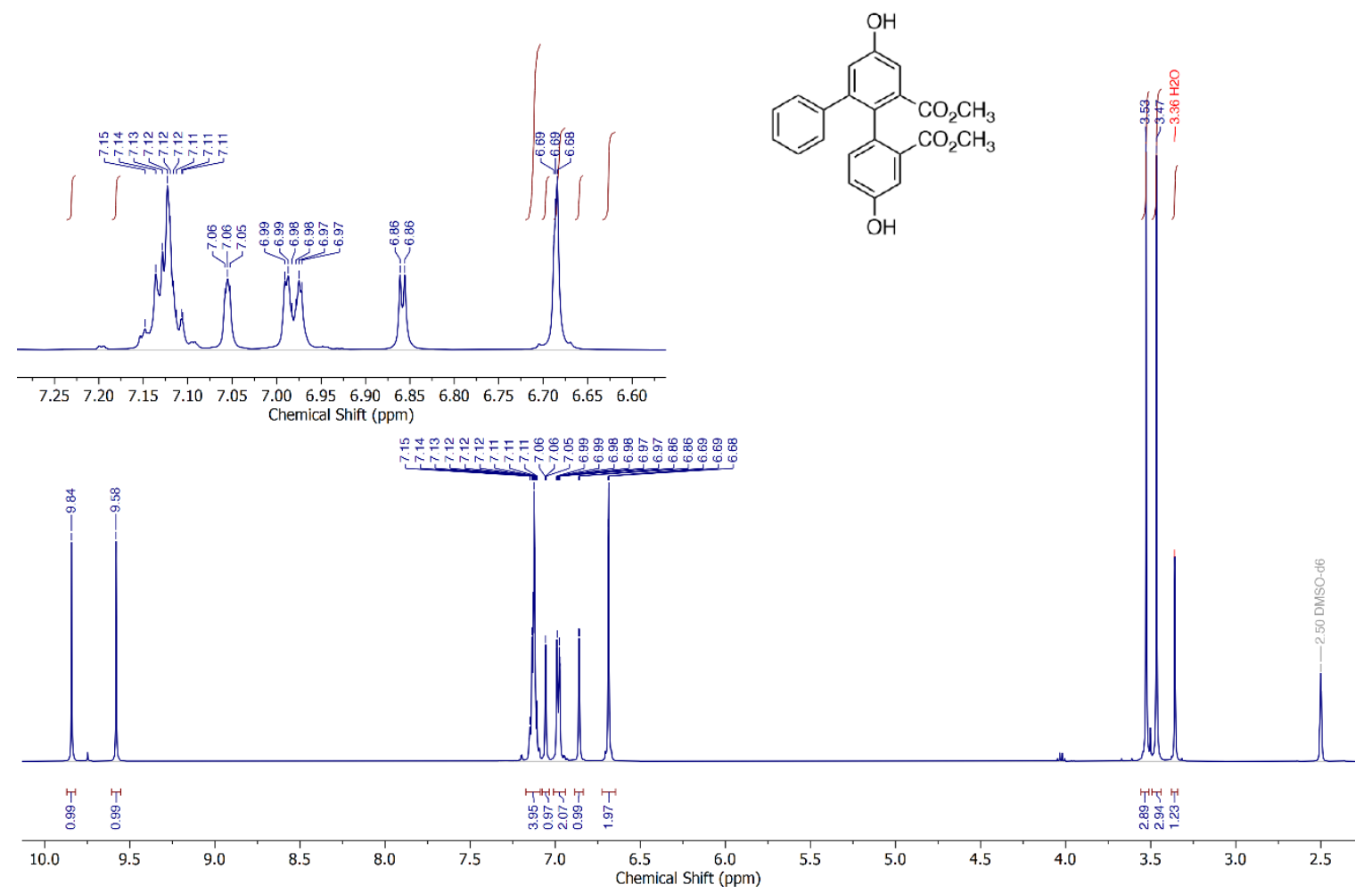

Figure S67. ${ }^{1} \mathrm{H}$ NMR spectrum (500 MHz, DMSO- $d_{6}$ ) of dimethyl [1,1'-biphenyl]-4,4'-dihydroxy-6-phenyl2,2'-dicarboxylate (15).

${ }^{13} \mathrm{C}$ NMR (126 MIIZ, DMSO- $\left.d_{6}\right)$

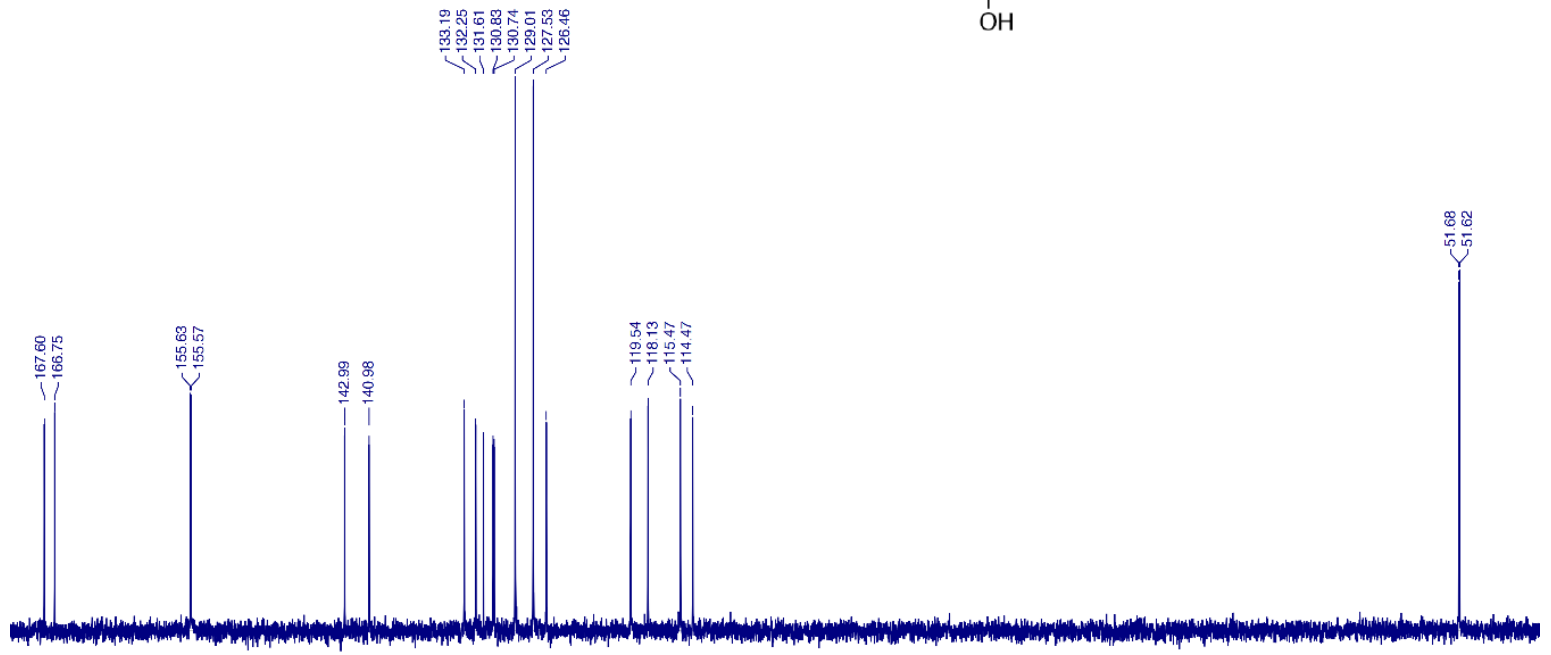<smiles>CC(=O)c1cc(O)ccc1-c1c(C(C)=O)cc(O)cc1-c1ccccc1</smiles>

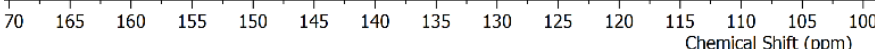

Figure S68. ${ }^{13} \mathrm{C}\left\{{ }^{1} \mathrm{H}\right\}$ NMR spectrum $\left(126 \mathrm{MHz}\right.$, DMSO- $\left.d_{6}\right)$ of dimethyl [1,1'-biphenyl]-4,4'-dihydroxy-6phenyl-2,2'-dicarboxylate (15). 
${ }^{\mathrm{H}} \mathrm{H} \mathrm{NMR}\left(500 \mathrm{MHz}, \mathrm{CDCl}_{3}\right)$

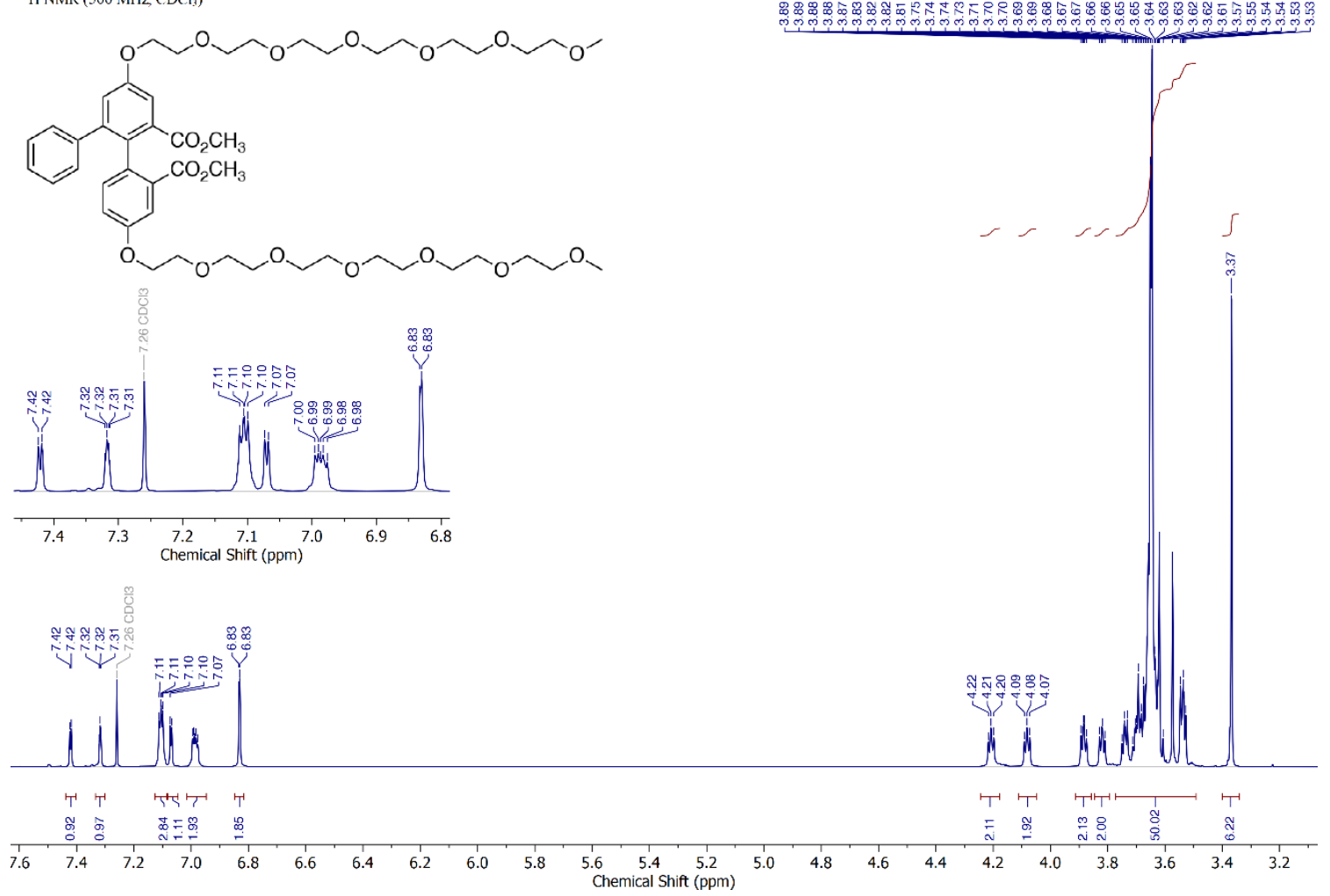

Figure S69. ${ }^{1} \mathrm{H}$ NMR spectrum $\left(500 \mathrm{MHz}, \mathrm{CDCl}_{3}\right)$ of dimethyl [1,1'-biphenyl]-4,4'-bis(3,6,9,12,15,18hexaoxanonadec-1-yloxy)-6-phenyl-2,2'-dicarboxylate (16).

${ }^{13} \mathrm{C} \mathrm{NMR}\left(126 \mathrm{MHz}, \mathrm{CDCl}_{3}\right)$
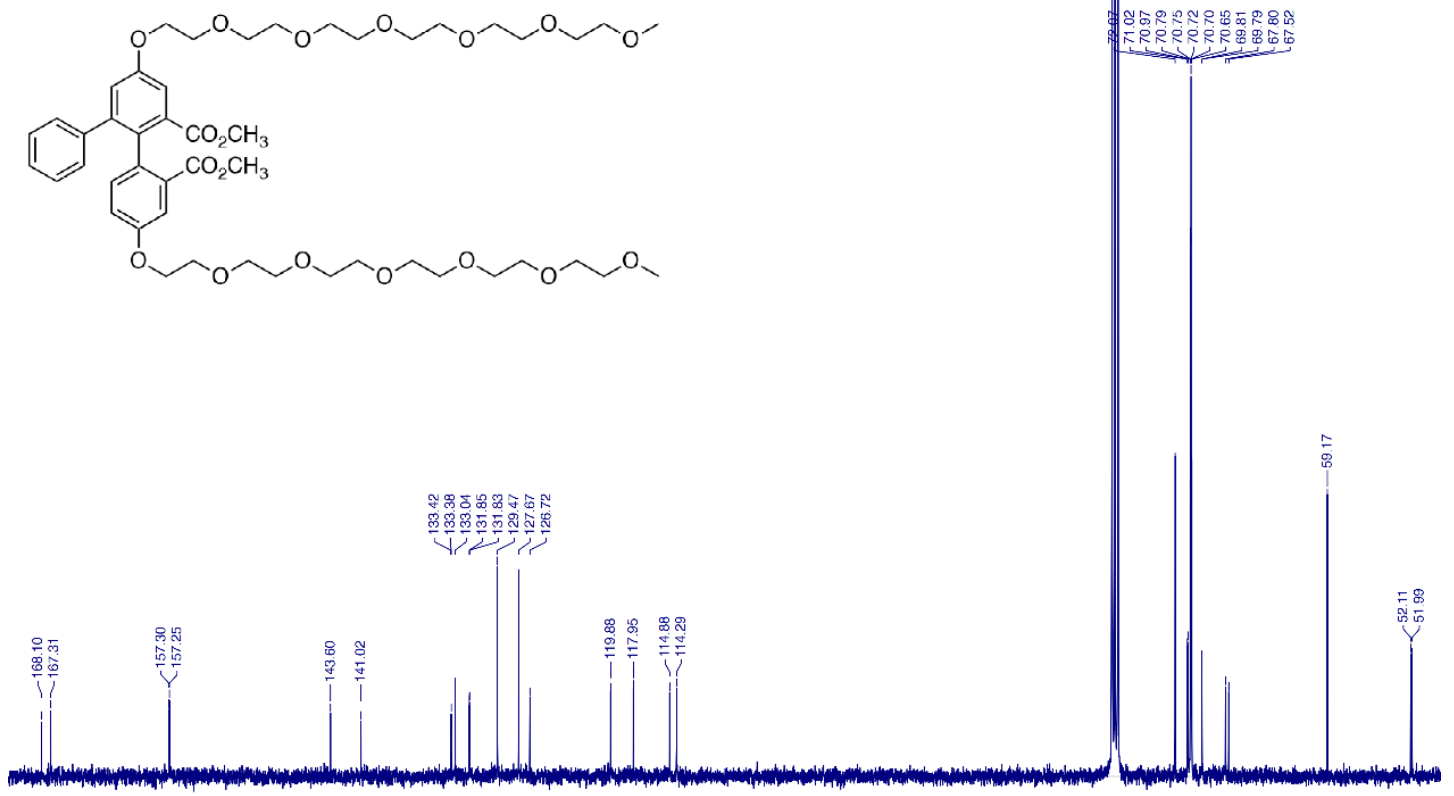

$\begin{array}{lllllllllllllllllllllllll}170 & 165 & 160 & 155 & 150 & 145 & 140 & 135 & 130 & 125 & 120 & 115 & 110 & 105 & 100 & 95 & 90 & 85 & 80 & 75 & 70 & 65 & 60 & 55 & 56 \\ \text { Chemical Shift (ppm) }\end{array}$

Figure S70. ${ }^{13} \mathrm{C}\left\{{ }^{1} \mathrm{H}\right\}$ NMR spectrum $\left(126 \mathrm{MHz}, \mathrm{CDCl}_{3}\right)$ of dimethyl [1,1'-biphenyl]-4,4'-bis(3,6,9,12,15,18hexaoxanonadec-1-yloxy)-6-phenyl-2,2'-dicarboxylate (16). 
'H NMR ( $\left.500 \mathrm{MHz}, \mathrm{CDCl}_{3}\right)$
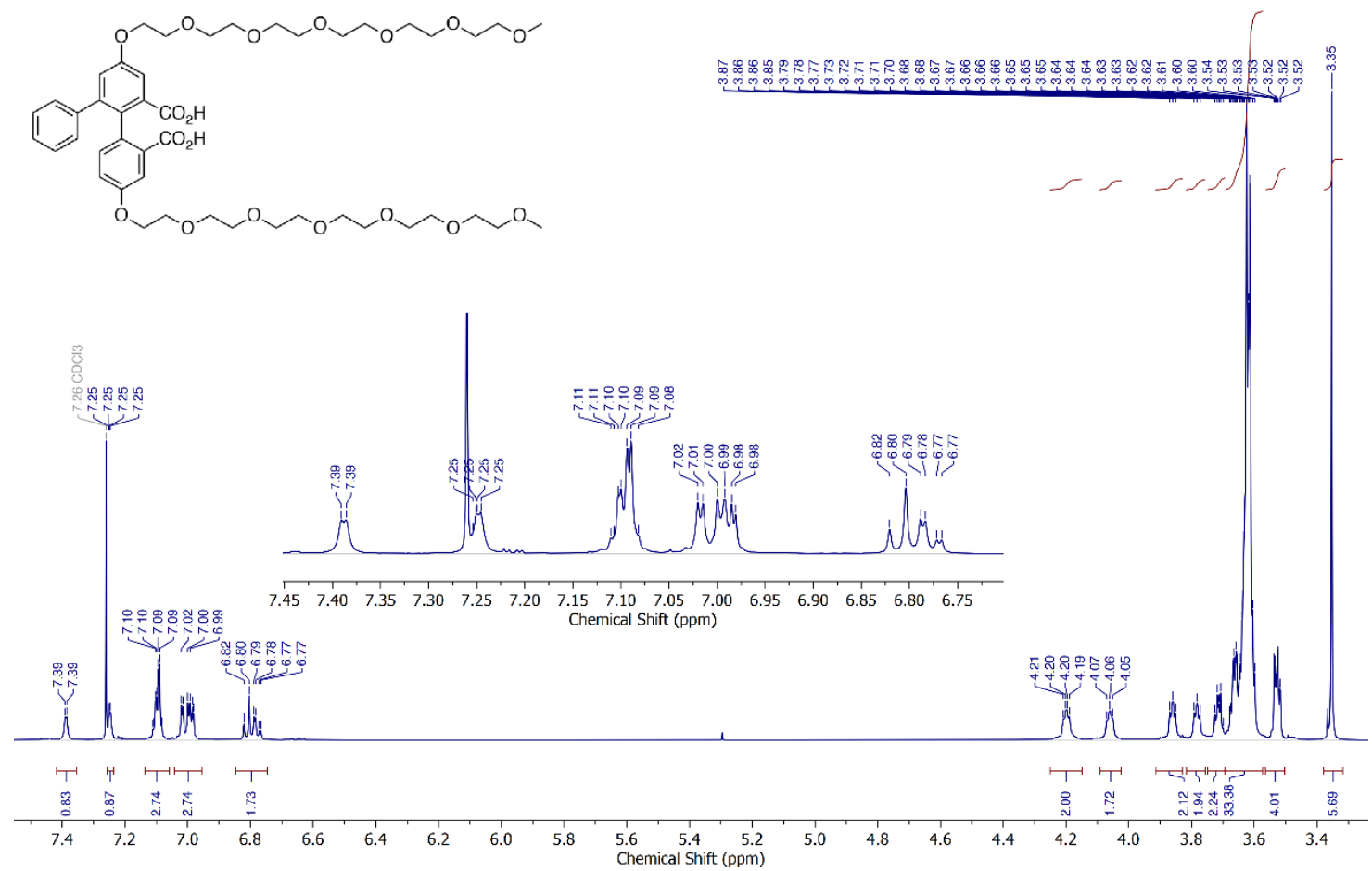

Figure S71. $\quad{ }^{1} \mathrm{H} \quad \mathrm{NMR}$ spectrum $\left(500 \mathrm{MHz}, \quad \mathrm{CDCl}_{3}\right)$ of $[1,1$ '-biphenyl]-4,4'-bis $(3,6,9,12,15,18$ hexaoxanonadec-1-yloxy)-6-phenyl-2,2'-dicarboxylic acid (DP-Ac6).

${ }^{13} \mathrm{CNMR}\left(101 \mathrm{MHz}, \mathrm{CDCl}_{3}\right.$
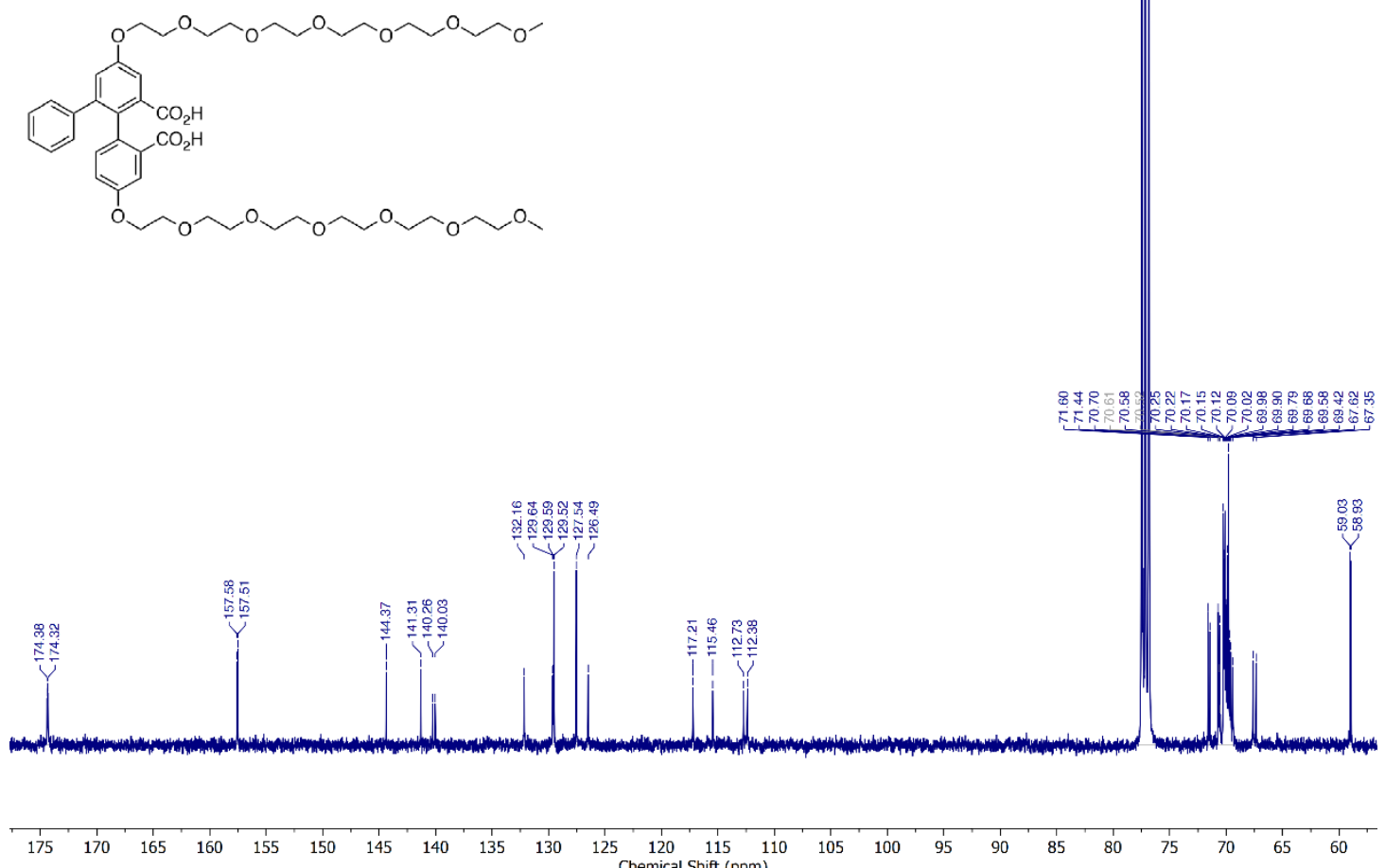

Figure S72. ${ }^{13} \mathrm{C}\left\{{ }^{1} \mathrm{H}\right\} \quad \mathrm{NMR}$ spectrum $\left(101 \mathrm{MHz}, \mathrm{CDCl}_{3}\right)$ of $\left[1,1^{\prime}\right.$-biphenyl]-4,4'-bis $(3,6,9,12,15,18-$ hexaoxanonadec-1-yloxy)-6-phenyl-2,2'-dicarboxylic acid (DP-Ac6). 


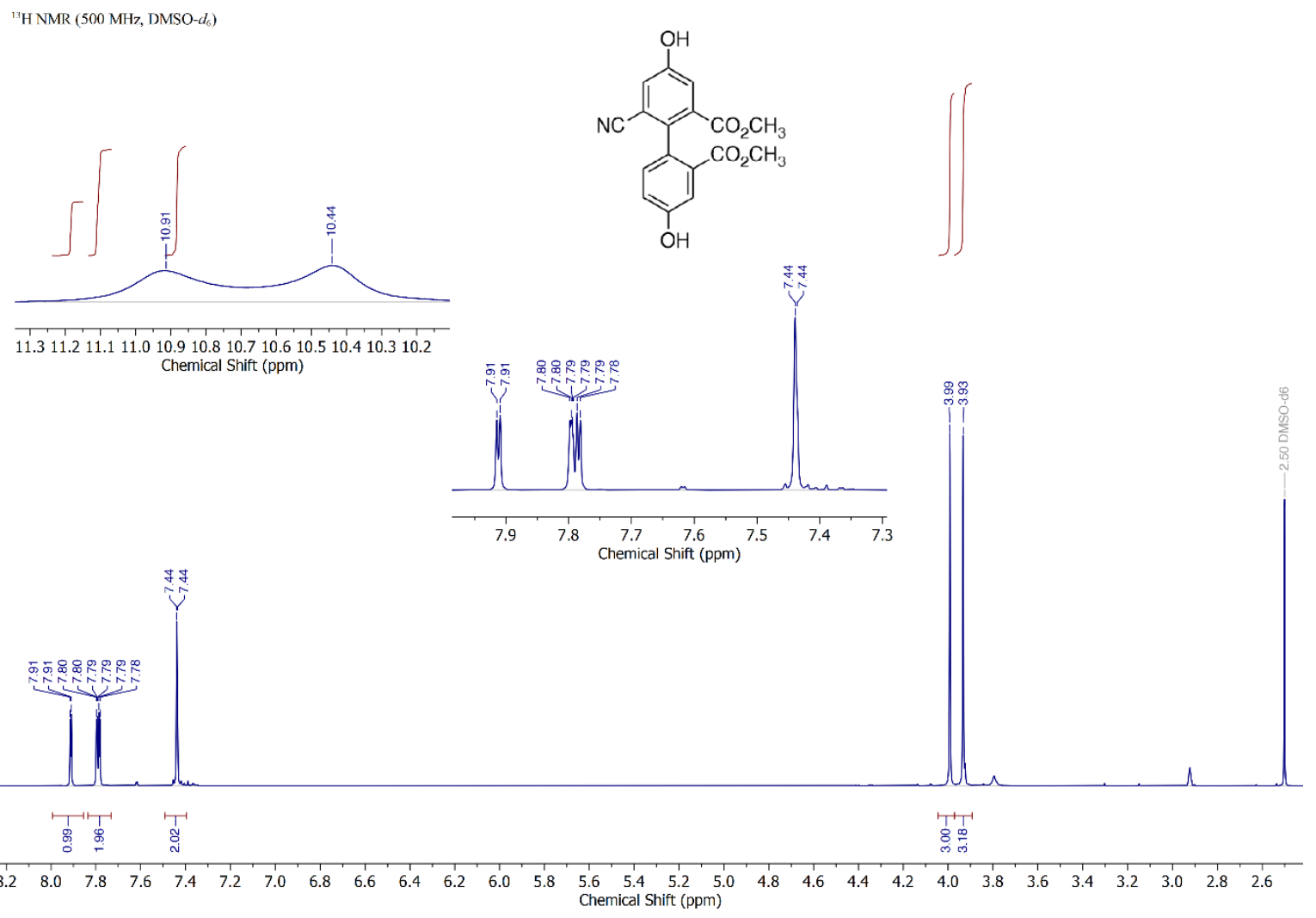

Figure S73. ${ }^{1} \mathrm{H}$ NMR spectrum $\left(500 \mathrm{MHz}\right.$, DMSO- $\left.d_{6}\right)$ of dimethyl [1,1'-biphenyl]-6-cyano-4,4'-dihydroxy2,2'-dicarboxylate (17).

${ }^{13} \mathrm{C}$ NMR (126 MHz, DMSO- $\left.d_{6}\right)$<smiles>COC(=O)c1cc(O)cc(C#N)c1C(=O)OC</smiles>
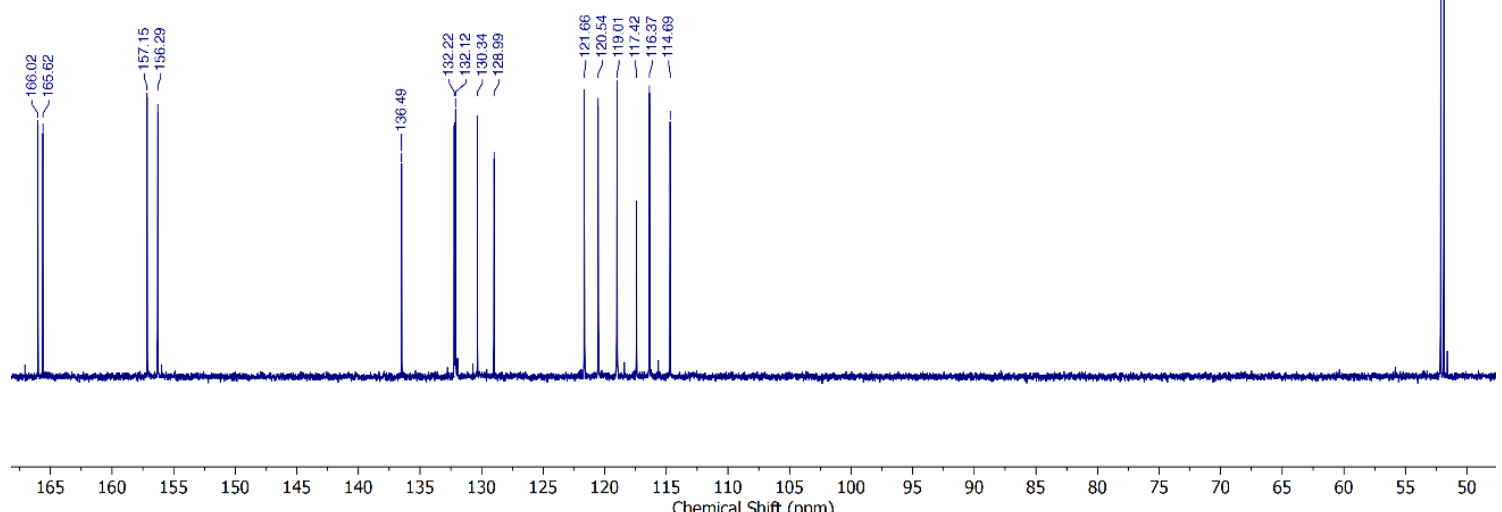

Figure S74. ${ }^{13} \mathrm{C}\left\{{ }^{1} \mathrm{H}\right\}$ NMR spectrum (126 MHz, DMSO- $\left.d_{6}\right)$ of dimethyl [1,1'-biphenyl]-6-cyano-4,4'dihydroxy-2,2'-dicarboxylate (17). 
<smiles>COCCOCCOCCOCCOCCOCCOc1cc(OC)c(C(=O)OC)c(OC)c1</smiles>
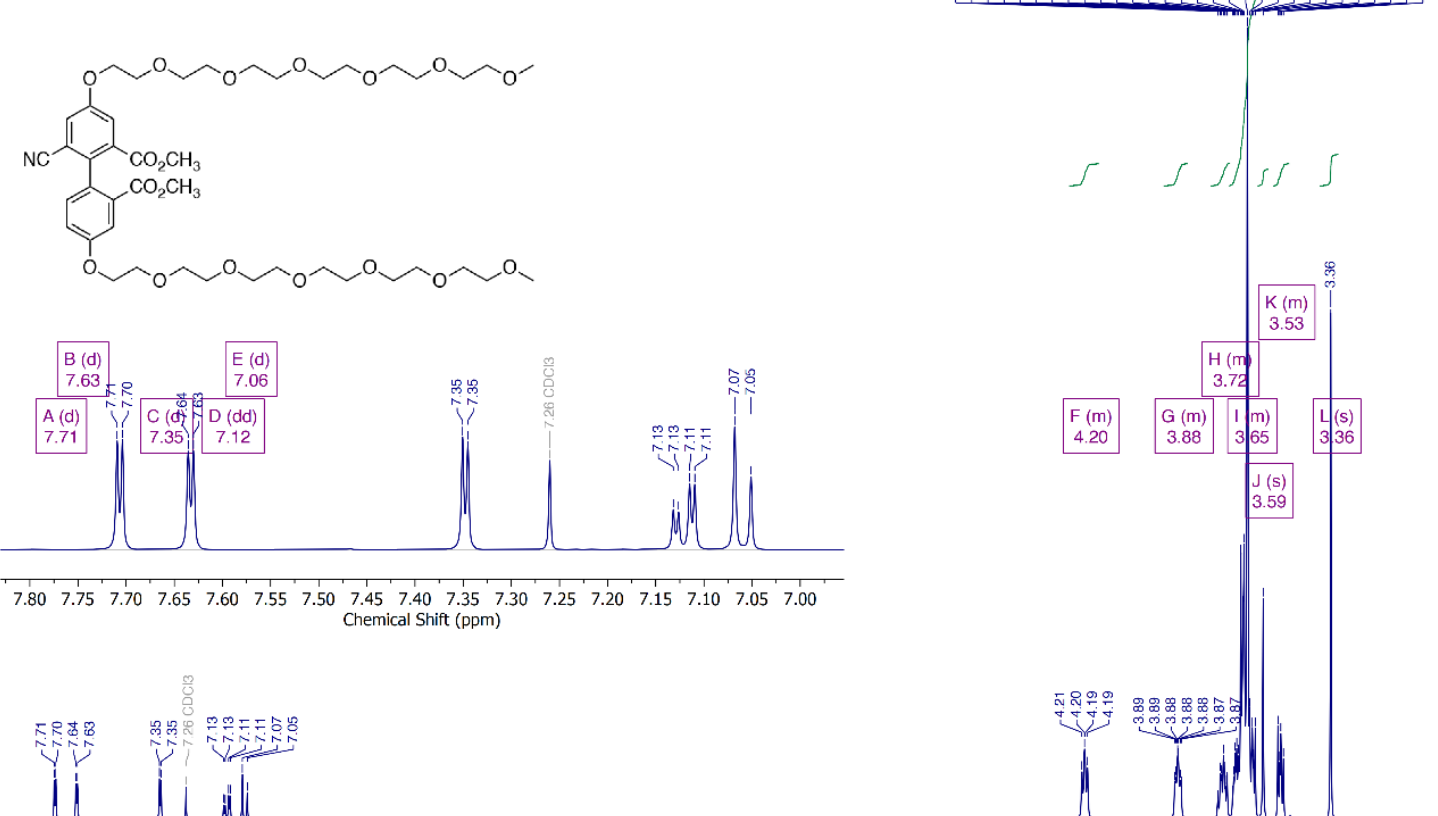

$\begin{array}{llllllllllllllllll}7.80 & 7.75 & 7.70 & 7.65 & 7.60 & 7.55 & 7.50 & 7.45 & 7.40 & 7.35 & 7.30 & 7.25 & 7.20 & 7.15 & 7.10 & 7.05 & 7.00 \\ \text { Chemical Shift (ppm) }\end{array}$

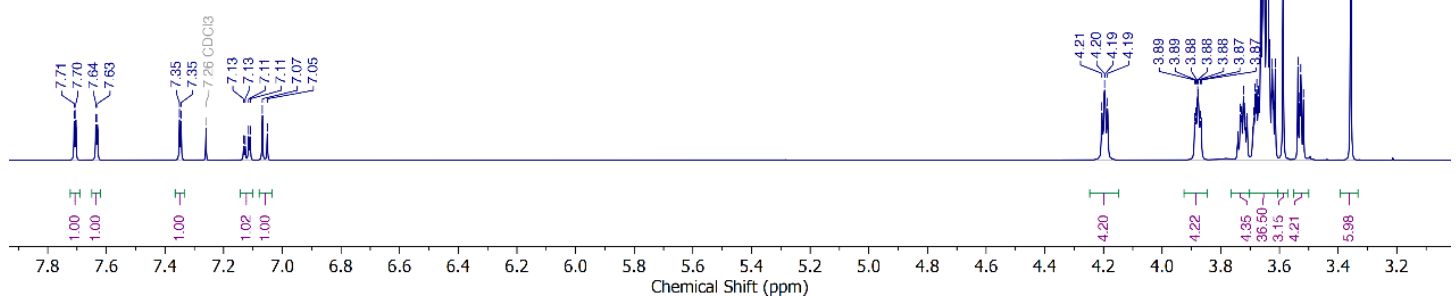

Figure S75. ${ }^{1} \mathrm{H}$ NMR spectrum $\left(500 \mathrm{MHz}, \mathrm{CDCl}_{3}\right)$ of dimethyl [1,1'-biphenyl]-4,4'-bis(3,6,9,12,15,18hexaoxanonadec-1-yloxy)-6-cyano-2,2'-dicarboxylate (18).

$\left.{ }^{13} \mathrm{C} \mathrm{NMR} \mathrm{(126} \mathrm{MHz,} \mathrm{CDCl}_{3}\right)$
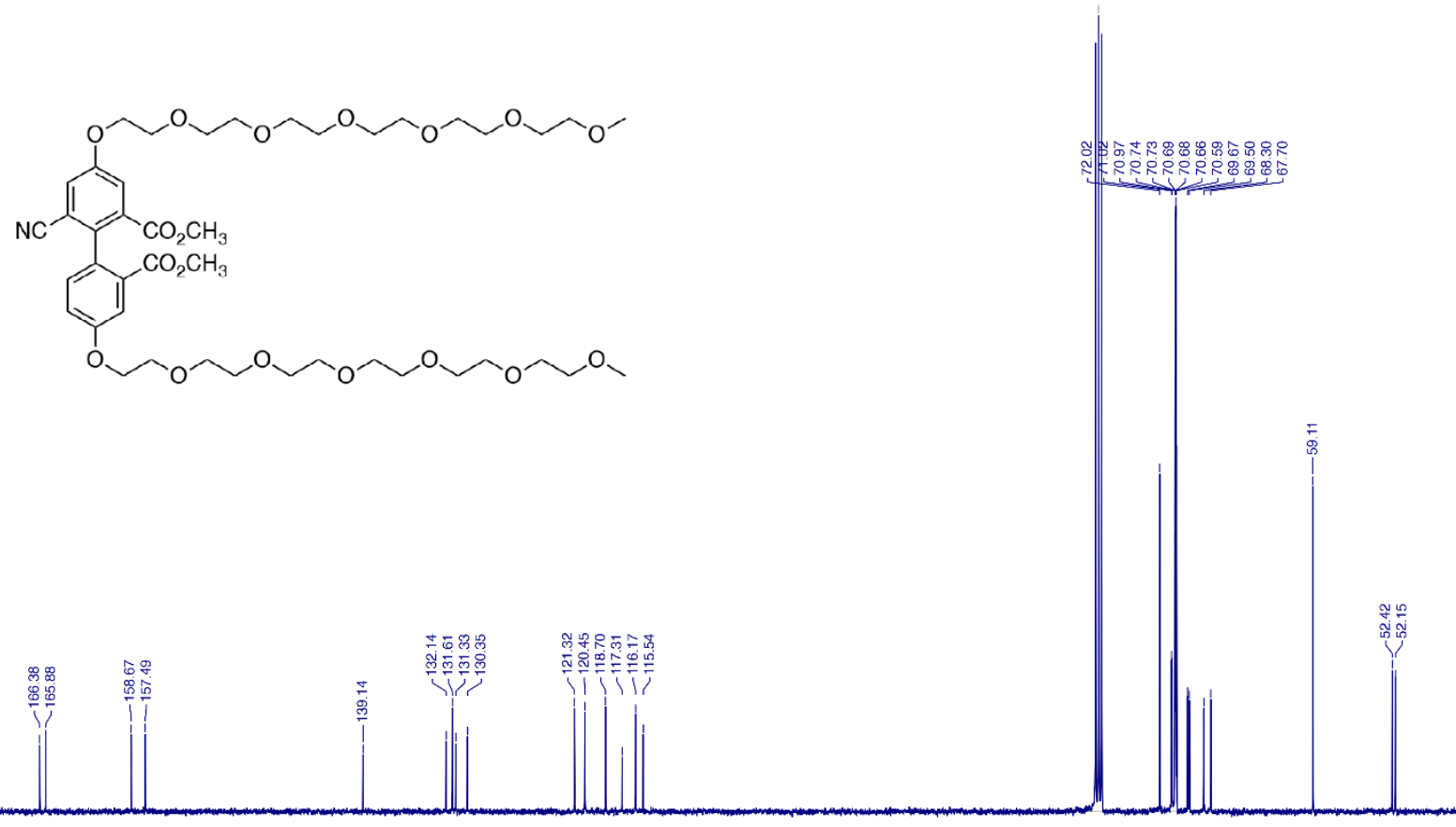

\begin{tabular}{lllllllllllllllllllllllllllllllllllll}
\hline 1 & 165 & 160 & 155 & 150 & 145 & 140 & 135 & 130 & 125 & 120 & 115 & 110 & 105 & 100 & 95 & 90 & 85 & 80 & 75 & 70 & 65 & 60 & 55 & 50
\end{tabular}

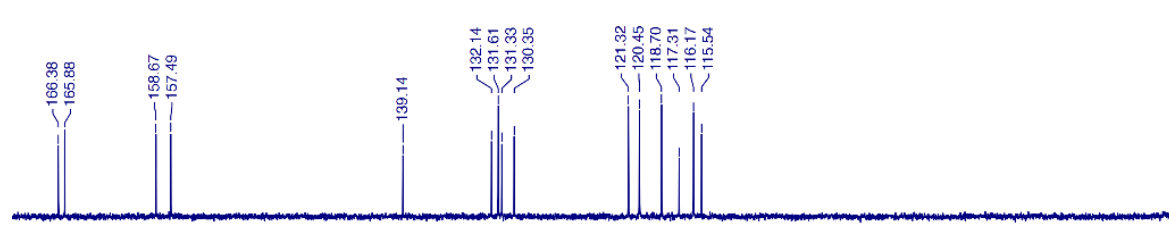

Figure S76. ${ }^{13} \mathrm{C}\left\{{ }^{1} \mathrm{H}\right\}$ NMR spectrum $\left(126 \mathrm{MHz}, \mathrm{CDCl}_{3}\right)$ of dimethyl [1,1'-biphenyl]-4,4'-bis(3,6,9,12,15,18hexaoxanonadec-1-yloxy)-6-cyano-2,2'-dicarboxylate (18). 
${ }^{1} \mathrm{H} \mathrm{NMR}\left(400 \mathrm{MHz}, \mathrm{CDCl}_{3}\right)$

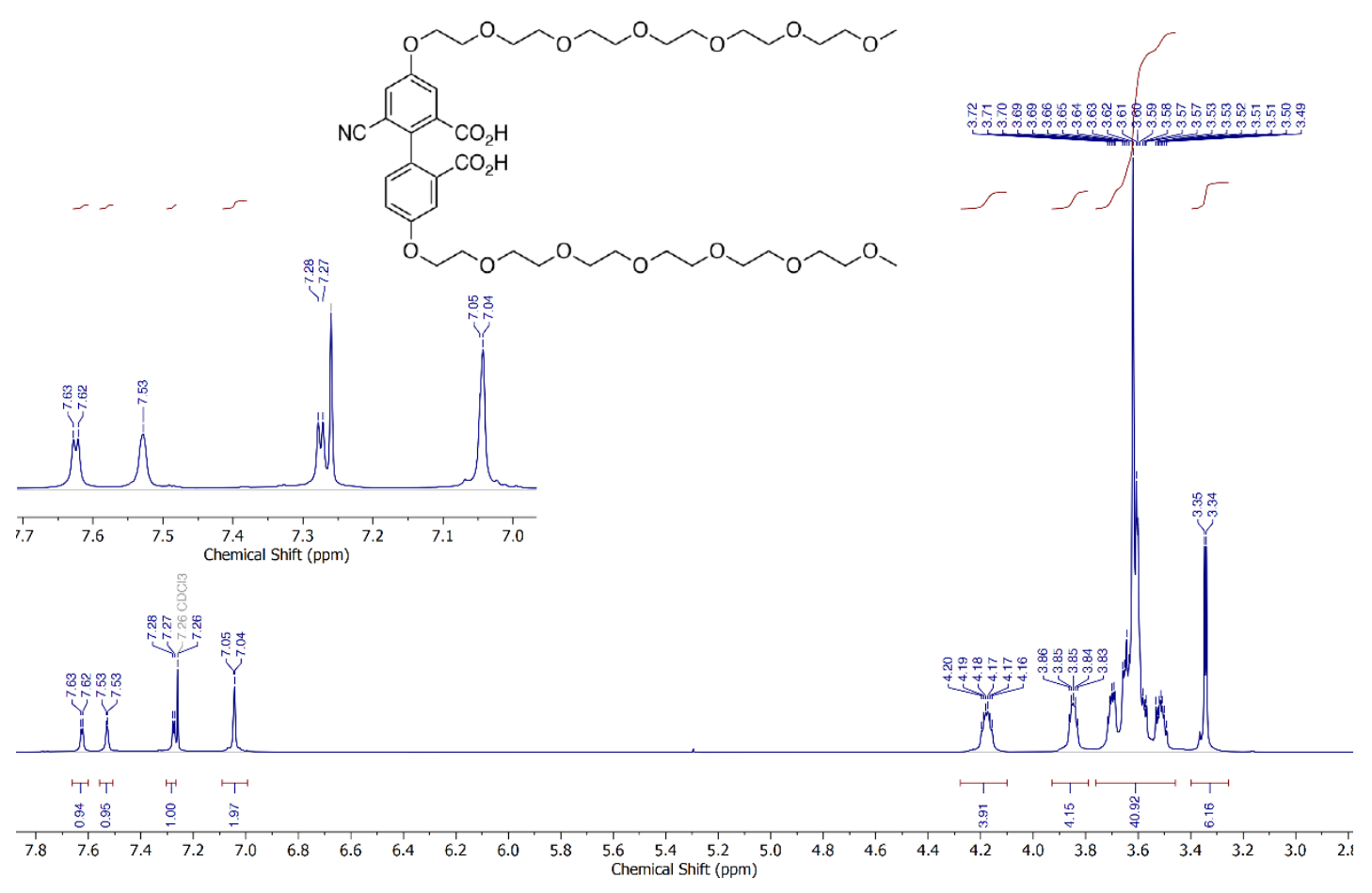

Figure S77. ${ }^{1} \mathrm{H} \quad \mathrm{NMR}$ spectrum $\left(400 \mathrm{MHz}, \mathrm{CDCl}_{3}\right)$ of $\quad\left[1,1^{\prime}\right.$-biphenyl $]-4,4$ '-bis $(3,6,9,12,15,18-$ hexaoxanonadec-1-yloxy)-6-cyano-2,2'-dicarboxylic acid (DP-Ac7).

${ }^{13} \mathrm{CNMR}\left(101 \mathrm{MIl}, \mathrm{CDCl}_{3}\right)$
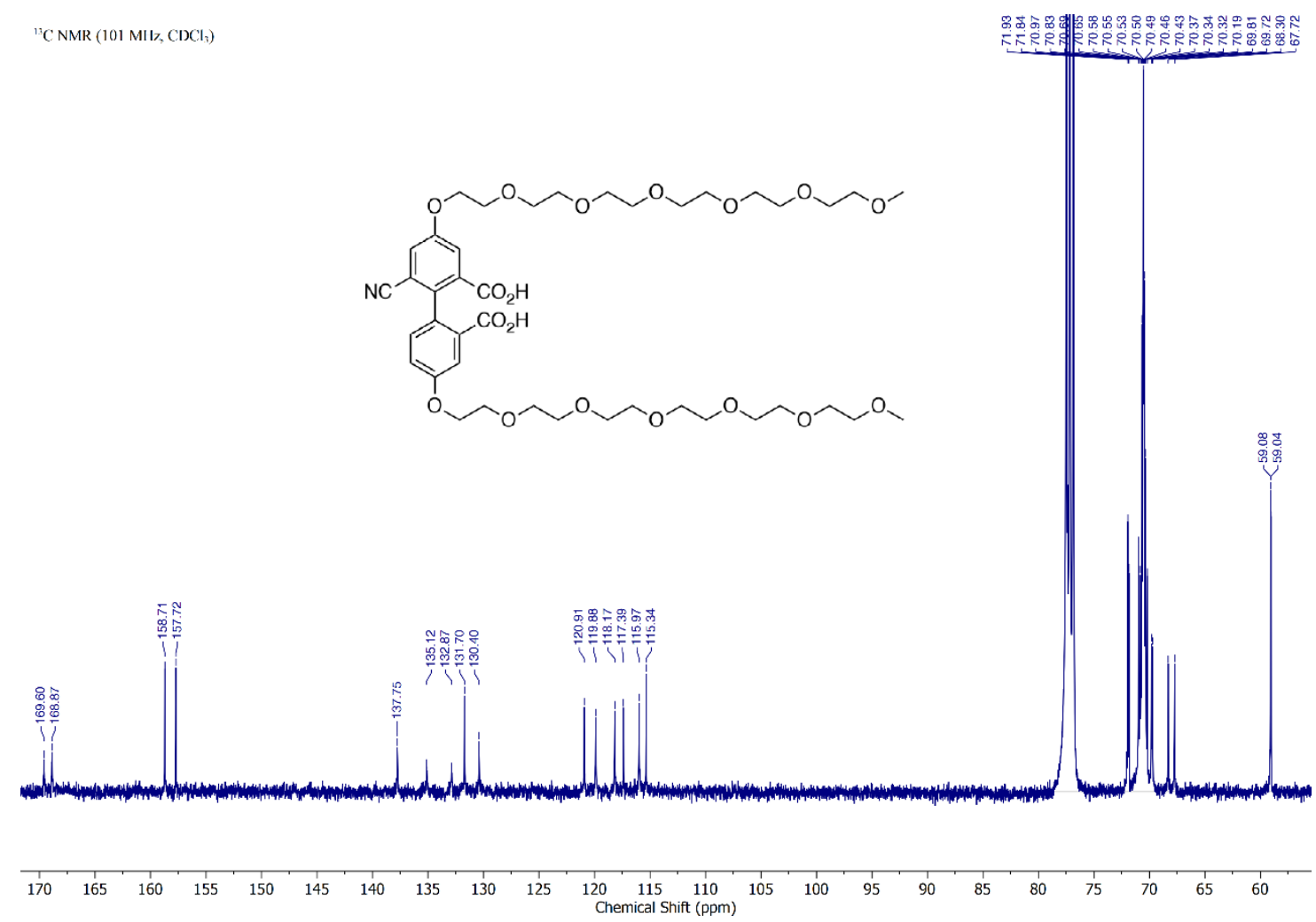

Figure S78. ${ }^{13} \mathrm{C}\left\{{ }^{1} \mathrm{H}\right\} \quad \mathrm{NMR}$ spectrum $\left(101 \mathrm{MHz}, \mathrm{CDCl}_{3}\right)$ of $[1,1$ '-biphenyl]-4,4'-bis(3,6,9,12,15,18hexaoxanonadec-1-yloxy)-6-cyano-2,2'-dicarboxylic acid (DP-Ac7). 


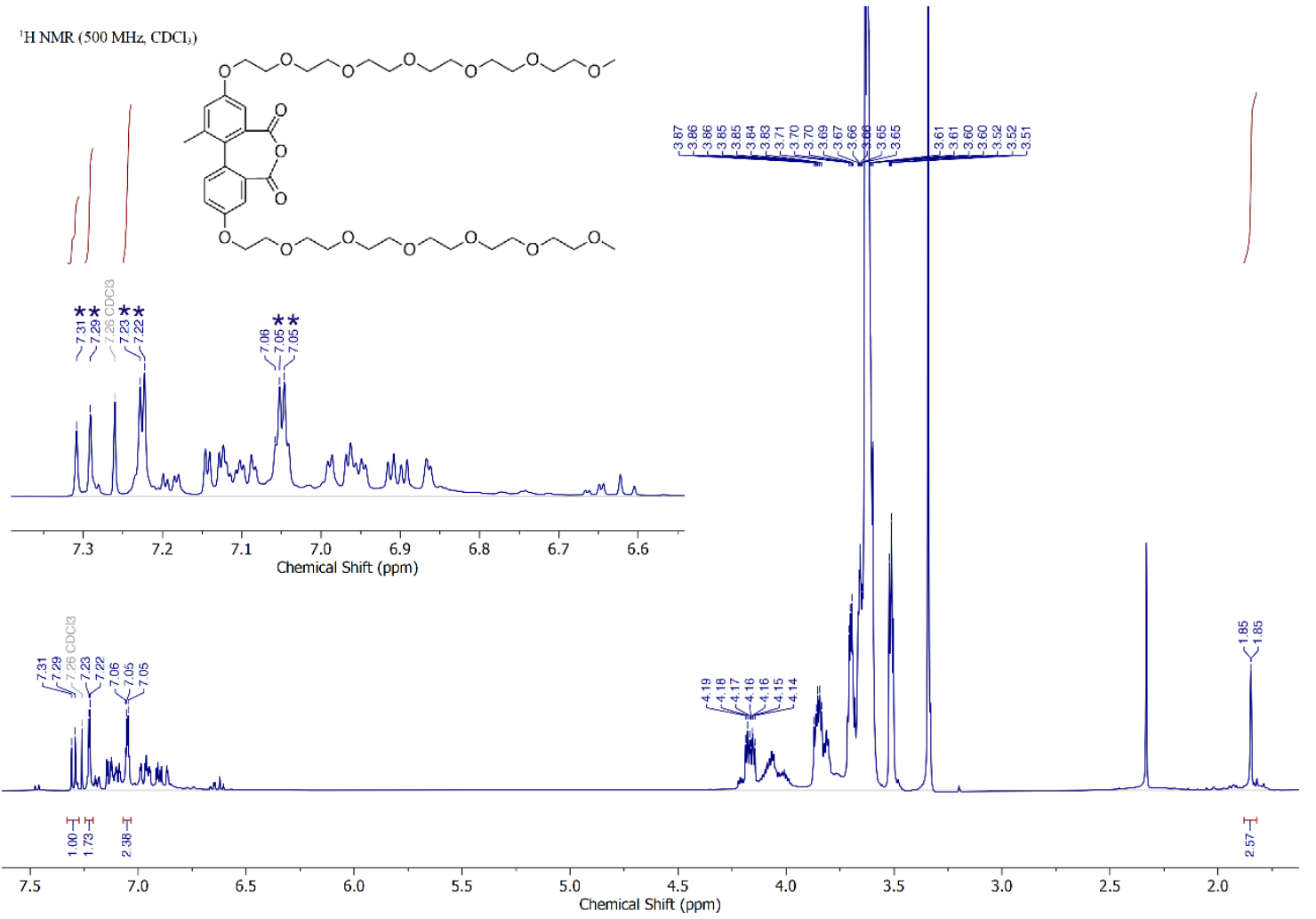

Figure S79. ${ }^{1} \mathrm{H}$ NMR spectrum $\left(500 \mathrm{MHz}, \mathrm{CDCl}_{3}\right)$ of DP-An4 (major product in a mixture, aromatic anhydride peaks are marked with asterisks).

${ }^{13} \mathrm{C}$ NMR $\left(126 \mathrm{MH}, \mathrm{CDCl}_{3}\right)$
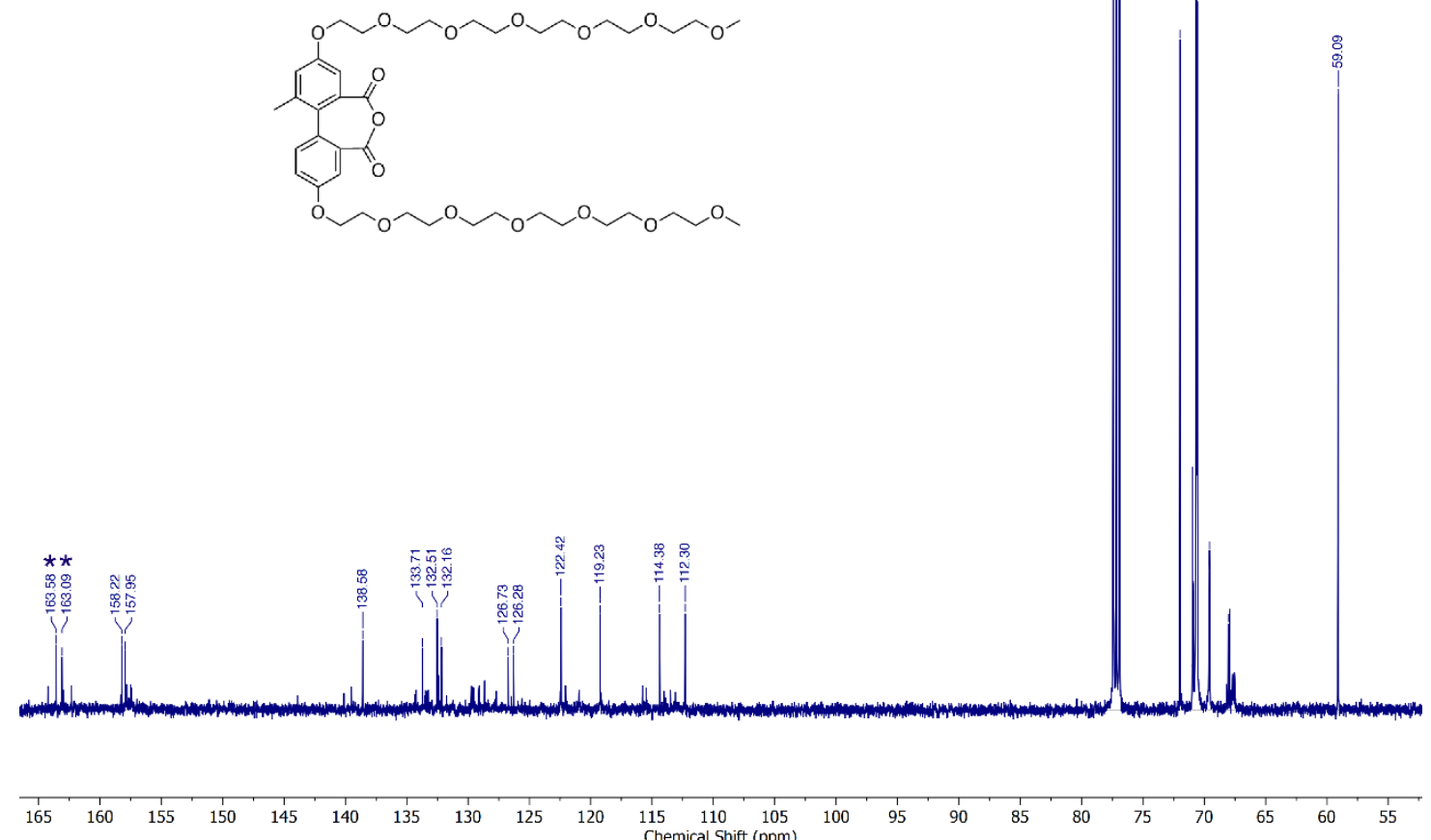

Figure S80. ${ }^{13} \mathrm{C}\left\{{ }^{1} \mathrm{H}\right\}$ NMR spectrum $\left(126 \mathrm{MHz}, \mathrm{CDCl}_{3}\right)$ of DP-An4 (major product in a mixture, anhydride carbonyl peaks are marked with asterisks). 


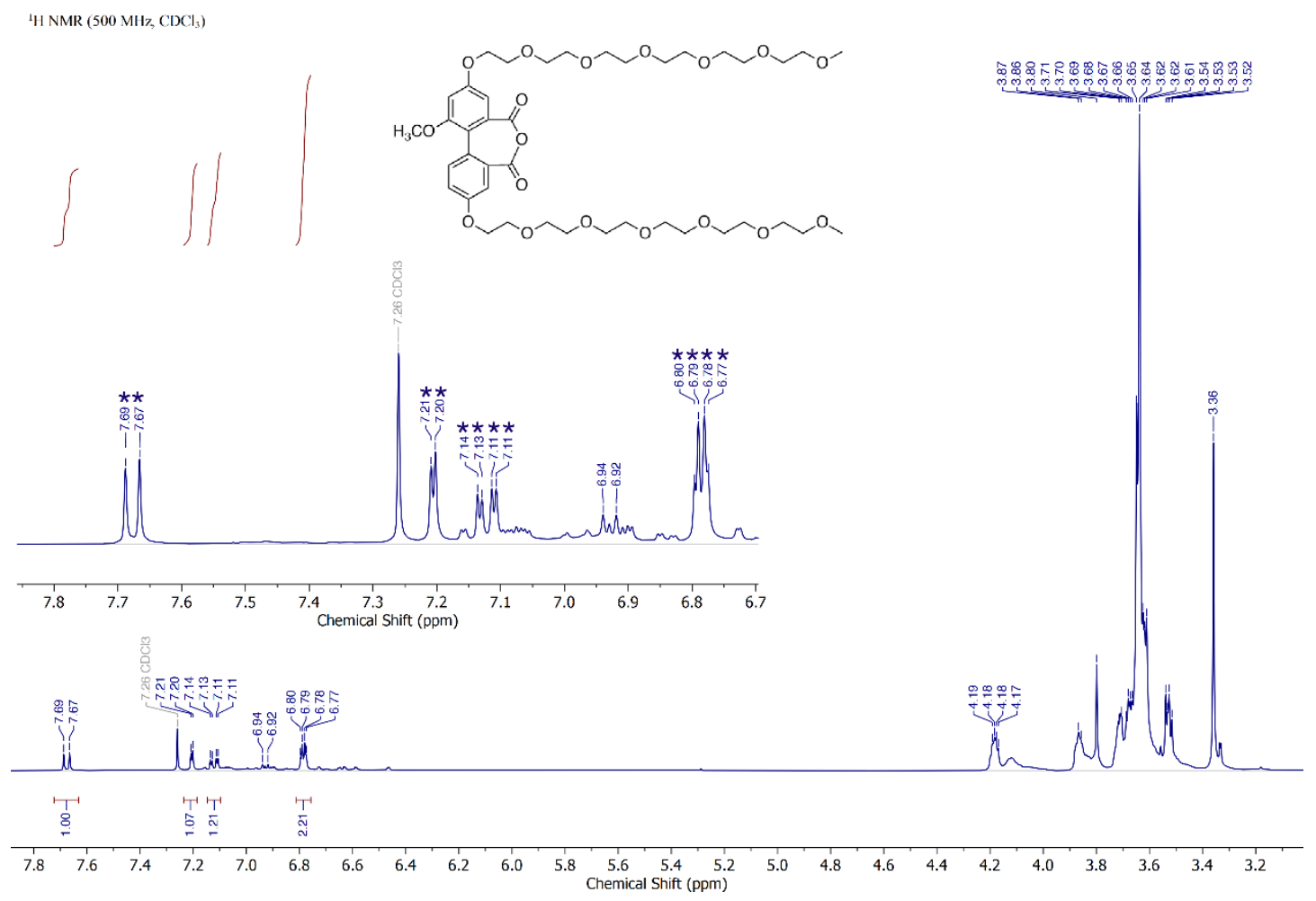

Figure S81. ${ }^{1} \mathrm{H}$ NMR spectrum $\left(400 \mathrm{MHz}, \mathrm{CDCl}_{3}\right)$ of DP-An5 (major product in a mixture, aromatic anhydride peaks are marked with asterisks).

$\left.{ }^{13} \mathrm{C} \mathrm{NMR} \mathrm{(101} \mathrm{MHz,} \mathrm{CDCl}_{3}\right)$
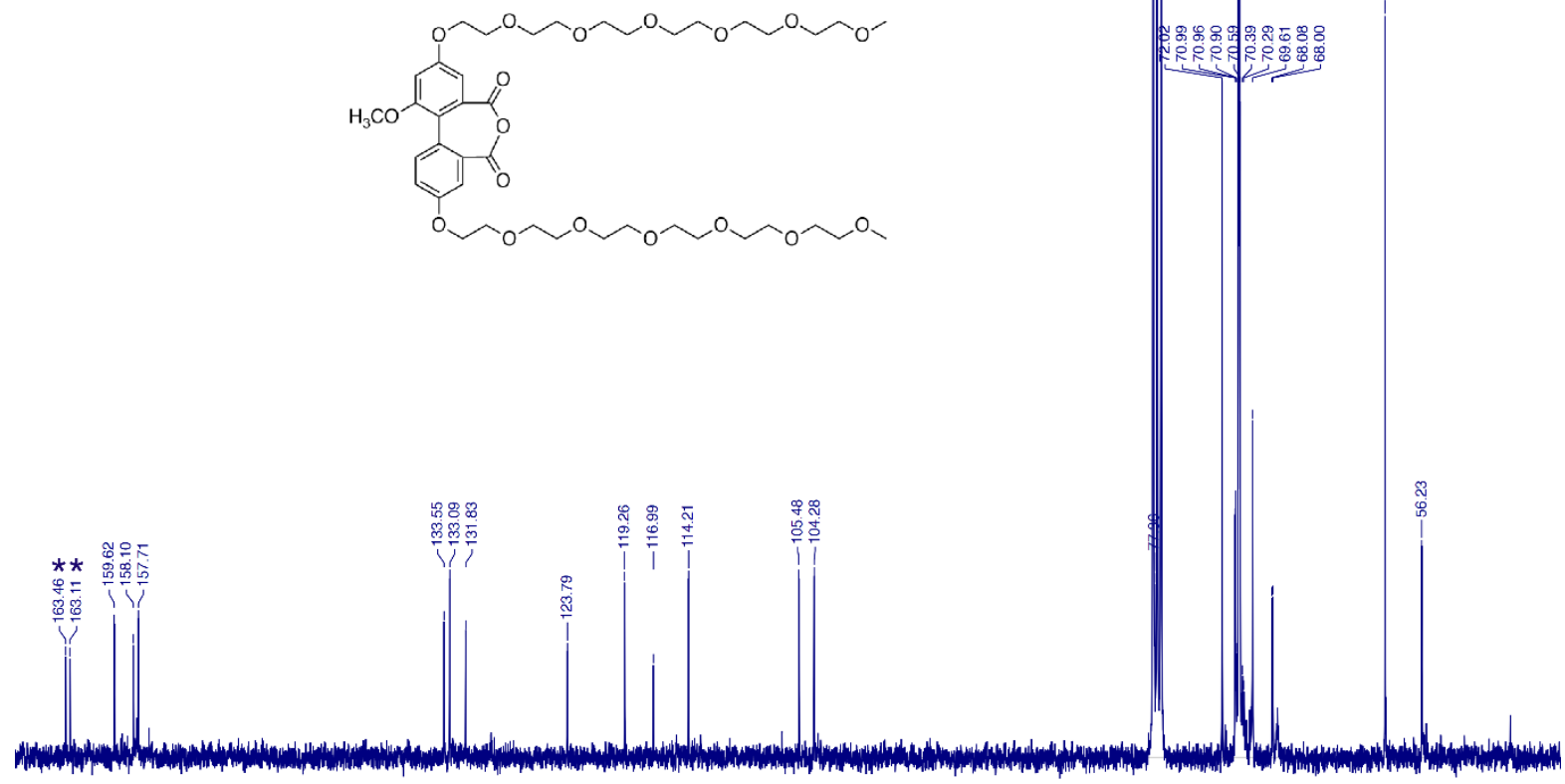

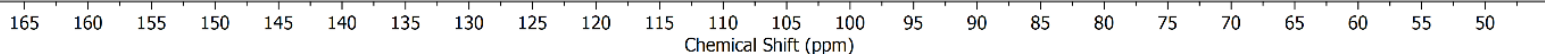

Figure S82. ${ }^{13} \mathrm{C}\left\{{ }^{1} \mathrm{H}\right\}$ NMR spectrum $\left(101 \mathrm{MHz}, \mathrm{CDCl}_{3}\right)$ of DP-An5 (major product in a mixture, anhydride carbonyl peaks are marked with asterisks). 


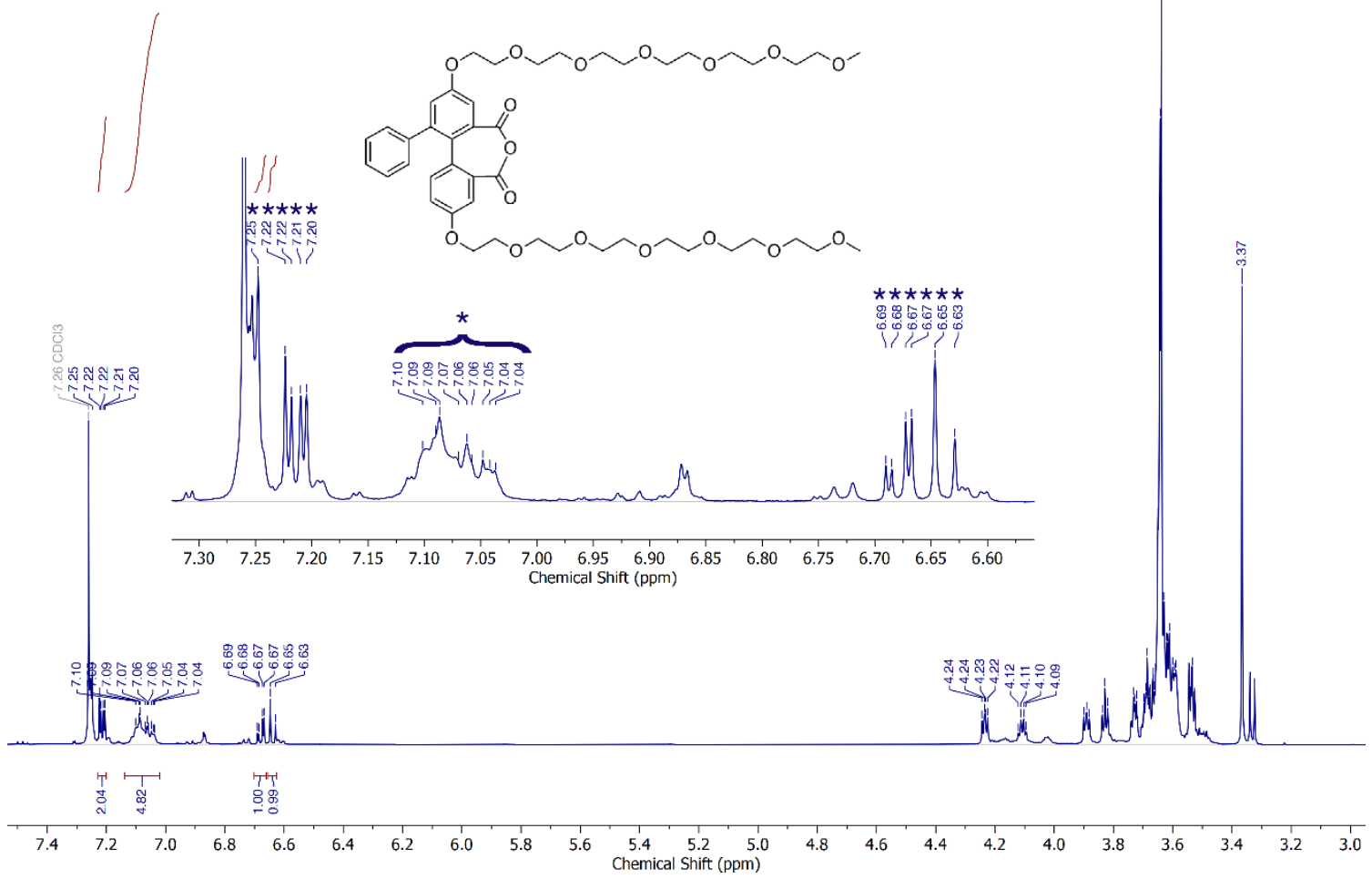

Figure S83. ${ }^{1} \mathrm{H}$ NMR spectrum $\left(500 \mathrm{MHz}, \mathrm{CDCl}_{3}\right)$ of DP-An6 (major product in a mixture, aromatic anhydride peaks are marked with asterisks).

${ }^{13} \mathrm{C}$ NMR $\left(101 \mathrm{MH}_{7}, \mathrm{ClOCl}_{3}\right)$
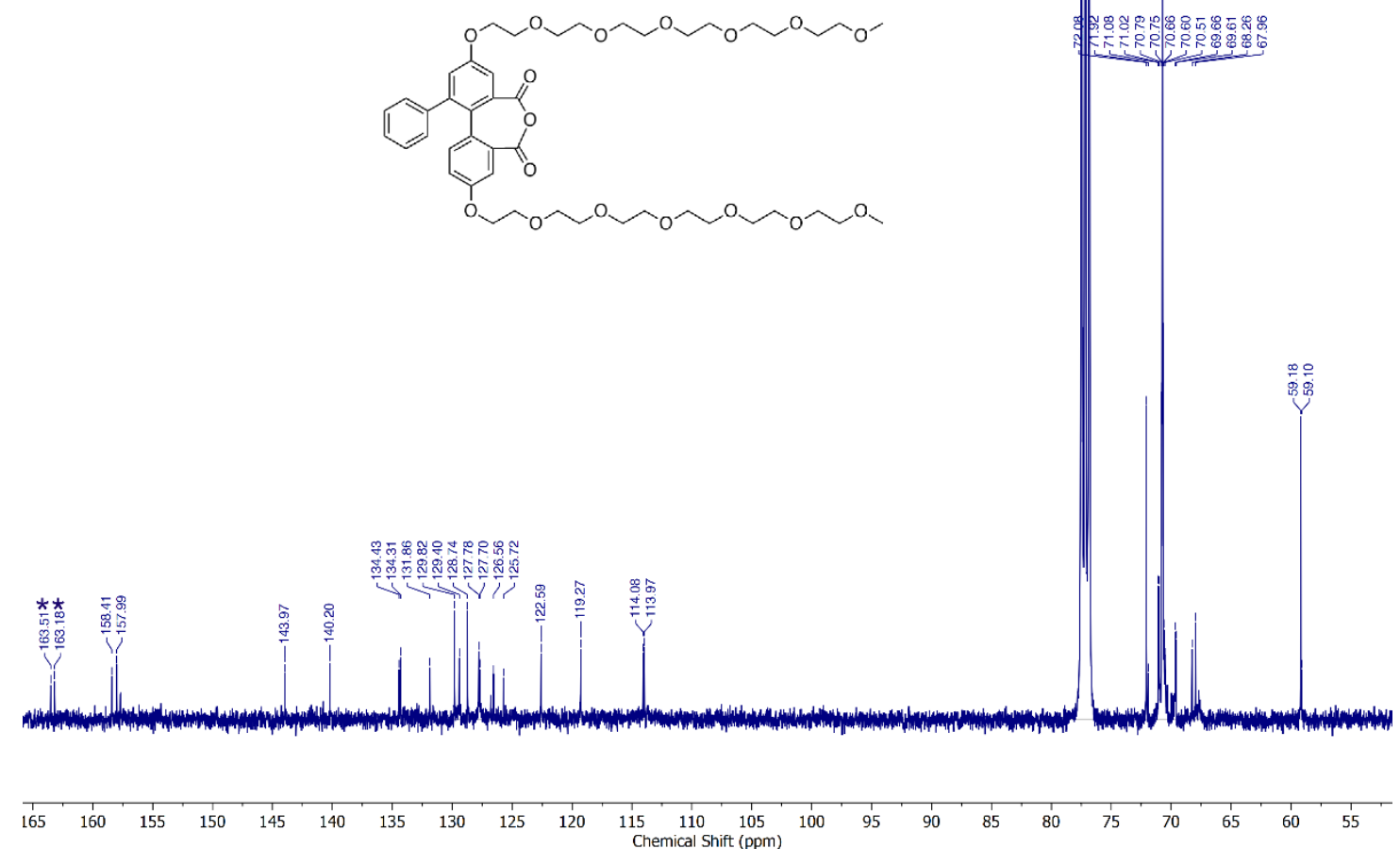

Figure S84. ${ }^{13} \mathrm{C}\left\{{ }^{1} \mathrm{H}\right\}$ NMR spectrum $\left(101 \mathrm{MHz}, \mathrm{CDCl}_{3}\right)$ of DP-An6 (major product in a mixture, anhydride carbonyl peaks are marked with asterisks). 


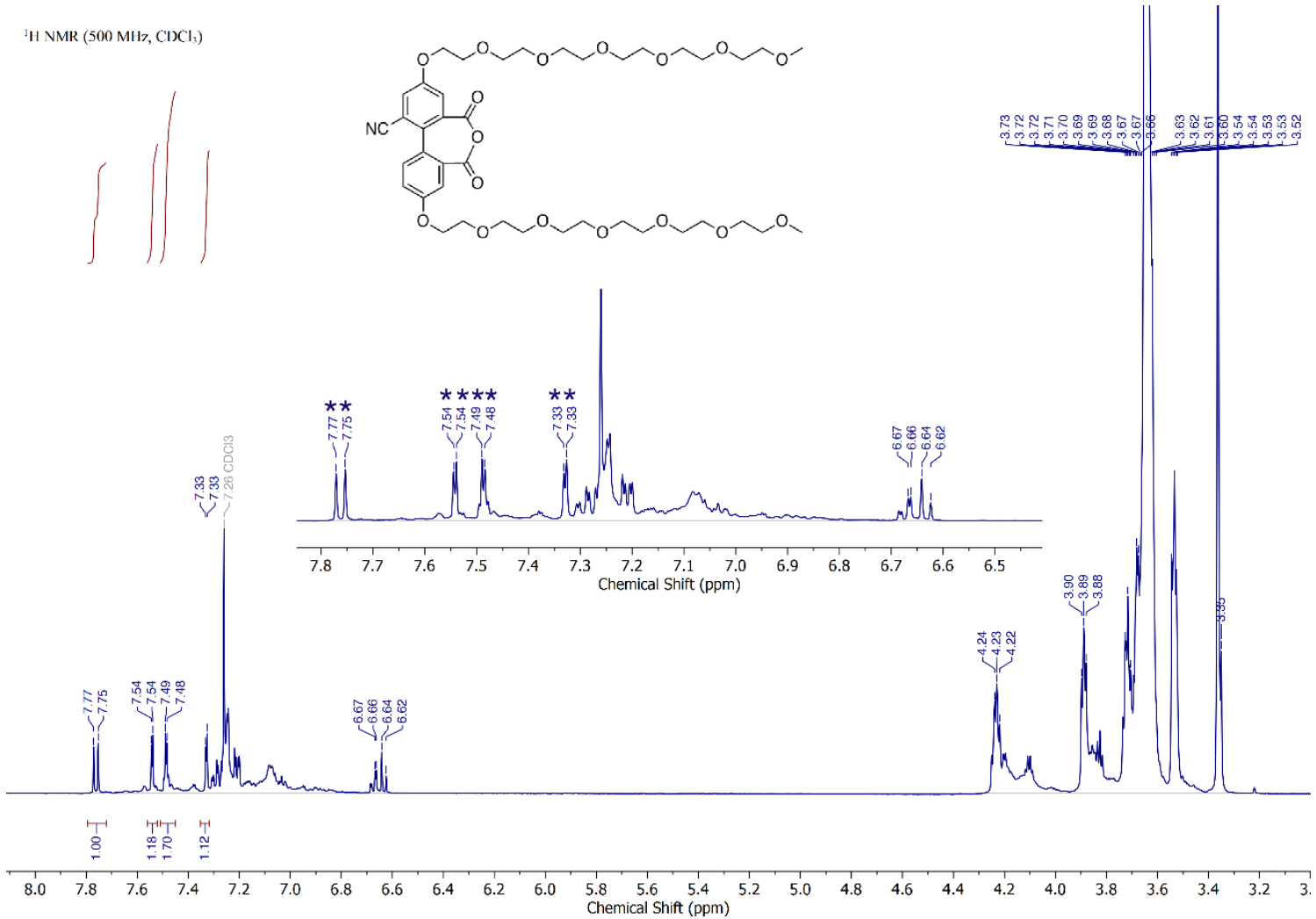

Figure S85. ${ }^{1} \mathrm{H}$ NMR spectrum $\left(500 \mathrm{MHz}, \mathrm{CDCl}_{3}\right)$ of $\mathbf{D P}-\mathbf{A n} 7$ (major product in a mixture, aromatic anhydride peaks are marked with asterisks).

${ }^{13} \mathrm{C} \mathrm{NMR}\left(101 \mathrm{MH} z, \mathrm{CDCl}_{3}\right)$
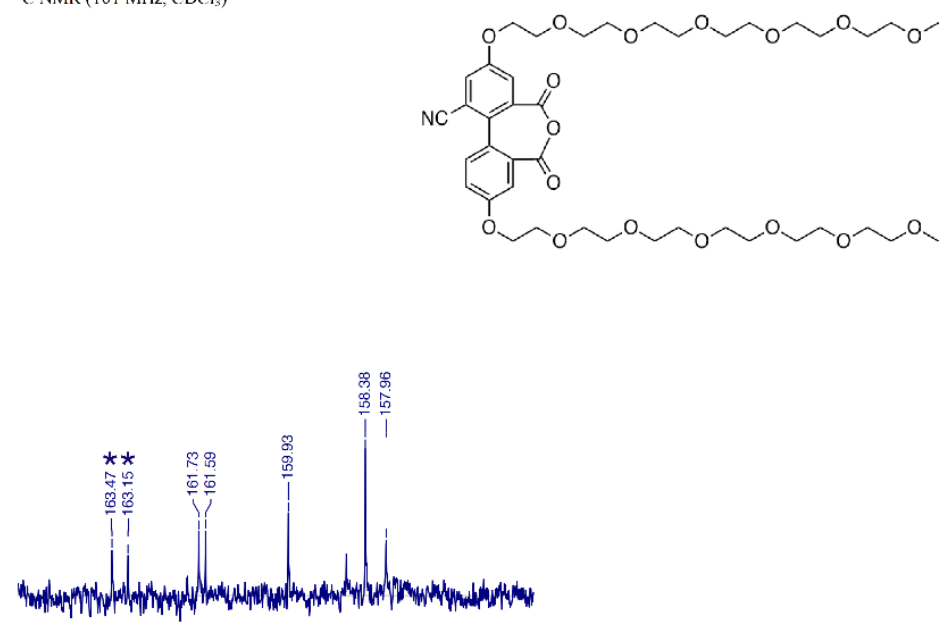

$\begin{array}{lllllllllll}165 & 164 & 163 & 162 & 161 & 160 & 159 & 158 & 157 & 156 & 155\end{array}$ Chemical Shift (ppm)

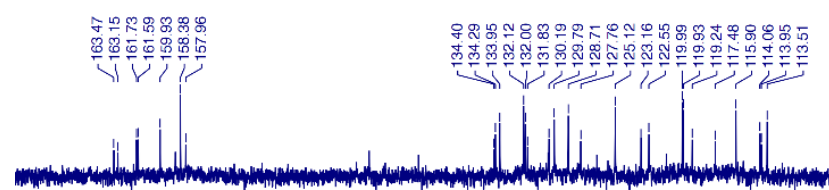

$\begin{array}{llllllllllllllllllllllllllllll}170 & 165 & 160 & 155 & 150 & 145 & 140 & 135 & 130 & 125 & 120 & 115 & 110 & 105 & 100 & 95 & 90 & 85 & 80 & 75 & 70 & 65 & 60 & 55\end{array}$

Figure S86. ${ }^{13} \mathrm{C}\left\{{ }^{1} \mathrm{H}\right\}$ NMR spectrum $\left(101 \mathrm{MHz}, \mathrm{CDCl}_{3}\right)$ of $\mathbf{D P}-\mathbf{A n} 7$ (major product in a mixture, anhydride carbonyl peaks are marked with asterisks). 


\section{References}

1. Jayalath, I. M.; Wang, H.; Mantel, G.; Kariyawasam, L. S.; Hartley, C. S. Chemically fueled transient geometry changes in diphenic acids. Org. Lett. 2020, 22, 7567-7571.

2. Kariyawasam, L. S.; Kron, J. C.; Jiang, R.; Sommer, A. J.; Hartley, C. S. Structure-property effects in the generation of transient aqueous benzoic acid anhydrides by carbodiimide fuels. J. Org. Chem. 2020, 85, 682-690.

3. Fox, J. Bootstrapping regression models. In Applied Regression Analysis and Generalized Linear Models, 3rd Ed.; Sage Publishing: New York, 2016; Chapter 21, pp 587-606.

4. Johnson, K. A.; Simpson, Z. B.; Blom, T. FitSpace Explorer: An algorithm to evaluate multidimensional parameter space in fitting kinetic data. Anal. Biochem. 2009, 387, 30-41. 